Portland State University

PDXScholar

Civil and Environmental Engineering Master's

Project Reports

2016

\title{
A Study on the Current State of Contaminants of Concern Research, with a Focus on Biosolids and Regulations
}

Maren Mariah Fulton

Portland State University

Follow this and additional works at: https://pdxscholar.library.pdx.edu/cengin_gradprojects

Part of the Environmental Engineering Commons, and the Water Resource Management Commons Let us know how access to this document benefits you.

\section{Recommended Citation}

Fulton, Maren Mariah, "A Study on the Current State of Contaminants of Concern Research, with a Focus on Biosolids and Regulations" (2016). Civil and Environmental Engineering Master's Project Reports. 30. https://doi.org/10.15760/CEEMP.7

This Project is brought to you for free and open access. It has been accepted for inclusion in Civil and Environmental Engineering Master's Project Reports by an authorized administrator of PDXScholar. Please contact us if we can make this document more accessible: pdxscholar@pdx.edu. 
A Study on the Current State of Contaminants of Emerging Concern Research, With a Focus on Biosolids and Regulations

\title{
by
}

Maren Mariah Fulton

\begin{abstract}
A research project report submitted in partial fulfillment of the requirement for the degree of

\section{MASTER OF SCIENCE \\ IN \\ CIVIL AND ENVIRONMENTAL ENGINEERING}

\author{
Project Advisor: \\ Dr. Gwynn Johnson
}

Portland State University

(C)2016 


\section{ACKNOWLEDGEMENTS}

I would like to thank my advisor, Dr. Gwynn Johnson of the Department of Civil and Environmental Engineering at Portland State University. Her door was always open, even after my extended sabbatical in my career prior to returning to Portland State University to complete my degree. Her enthusiasm for research and advising helped steer my research and guide my writing when I needed direction, while consistently allowing the freedom for this paper to be my own work.

Additionally, I would like to thank the Columbia River Toxics Reduction Work Group for allowing me to attend several of the meetings. I would also like to thank the following people associated with the Group for their advice regarding the relevant research topic of CECs in biosolids in the Columbia River Basin: Jennifer Morace, Hydrologist at USGS, Northwest Region; Elena Nilsen, Research Chemist at USGS, Northwest Region; and Mary Lou Soscia, Columbia River Coordinator, EPA Region 10.

Thanks is also due to my employers at Ecology and Environment, Inc., for their support and flexibility that allowed me to complete my research while employed full-time.

I would like to thank my sister, Stephanie Fulton, PhD student at the Department of Crop and Soil Sciences, University of Georgia, Athens, for providing valuable feedback and criticism on this paper, as well as her tireless support. I would also like to acknowledge Jack Young, PhD student at the Department of Mechanical and Aerospace Engineering, University of California, Los Angeles, as the second reader of this paper, and I am gratefully indebted to him for his very valuable comments on this paper.

Finally, I would like to express my gratitude to my partner for providing unwavering support and continual encouragement throughout my years of study and researching and writing to complete this project. I also would like to thank my parents, who have always provided endless support and encouragement. This accomplishment would not have been possible without them. Thank you.

Author, Maren Fulton 


\author{
Abstract \\ A Study on the Current State of \\ Contaminants of Emerging Concern Research, \\ With a Focus on Biosolids and Regulations \\ Maren Mariah Fulton \\ Chair of the Supervisory Committee: \\ Maseeh College of Engineering \\ Associate Professor Dr. Gwynn Johnson
}

Wastewater treatment plants are a major source of contaminants of emerging concern, as these facilities are the main receptors of these products via household, commercial, and industrial drains, and transport via stormwater runoff. Biosolids are composed of numerous constituents, with a number of environmentally persistent and potentially toxic contaminants of emerging concern identified as present in large concentrations. Research is needed to understand the transport and fate mechanisms of these compounds in biosolids. Additionally, this research is needed to determine a new priority framework to regulate CECs, both on the national level and regional levels. Wastewater treatment plant influent and effluent treatment regulations and practices may be improved upon as more knowledge accrues regarding contaminants of emerging concern behavior in the environment.

The United States environmental regulatory process is a constant work in progress. Inherited from decades-old public health traditions, environmental regulatory programs arose to address the issues of public health as water and air quality issues surfaced. The Toxic Substances Control Act (TSCA) (15 U.S.C. 2601), enacted in 1976, provided the EPA regulatory authority to protect the environment and consumers' health against risks posed by chemicals in commerce. TSCA only retroactively addressed chemical hazards, after they had been deemed unsafe and previously unrestricted in the public. A bill to overhaul TSCA, the Frank R. Lautenberg Chemical Safety for the $21^{\text {st }}$ Century Act 
(House Amendment to the Senate Amendment to H.R. 2576, TSCA Modernization Act of 2015), was passed by the Senate on June 7, 2016 and sent on for President Obama's signature. The amended law will give the EPA new authority to evaluate the safety of a new chemical before it enters the marketplace. It will also allow EPA to evaluate the safety of chemicals already known to be risks, including chemicals found to persist in the human body and in the environment.

The Columbia River is presented as a case study as an example of a significant waterbody with research and regulatory gaps concerning CECs. The Columbia River waterbody was chosen as it represents an important natural resource for which data gaps exist on CEC sources and pathways into the waterbody, and which also does not receive adequate protective regulations under the national regulatory framework. 


\section{Table of Contents}

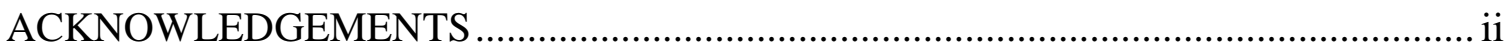

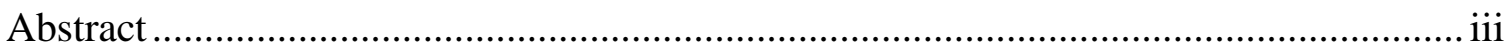

List of Abbreviations ............................................................................................ vi

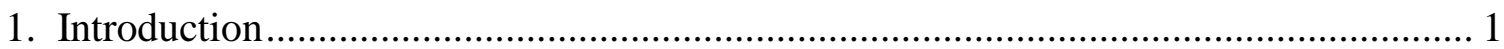

1.1 Objectives and Scope .................................................................. 3

1.2 Problem Statement and Relevance ......................................................... 3

2. Introduction to CECs and Relevant Regulations ................................................... 5

2.1 Introduction to CECs.......................................................................... 5

2.1.1 Wastewater Treatment Plants as Sources of CECs............................ 9

2.2 Relevant Environmental Regulatory Agencies and Environmental Regulations ............................................................................ 10

2.2.1 United States Federal Environmental Agencies ............................ 10

2.2.2 United States Federal Environmental Regulations ......................... 11

2.2.3 International Environmental Regulatory Agencies and Environmental

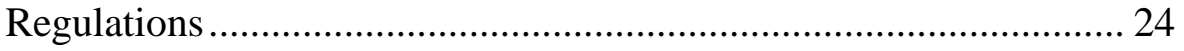

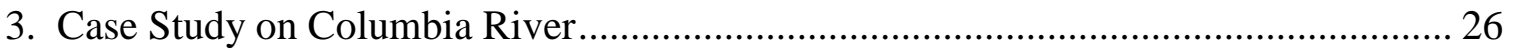

3.1 Introduction/Problem Statement........................................................... 26

3.2 Relevant Agencies and Programs that Affect the Columbia River ......... 27

3.3 Gaps in Columbia River Research and Restoration Funding................. 29

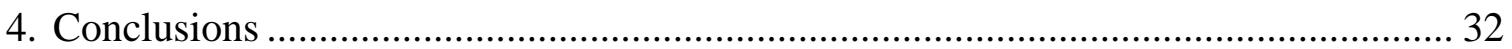

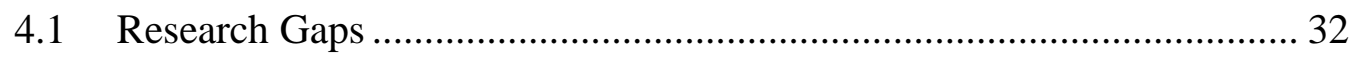

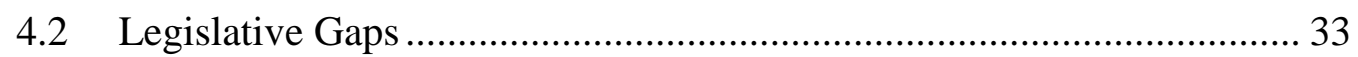

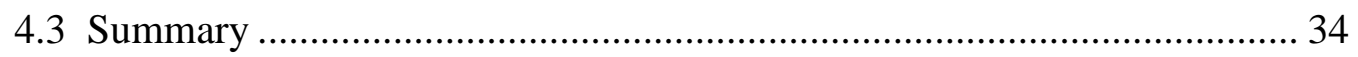

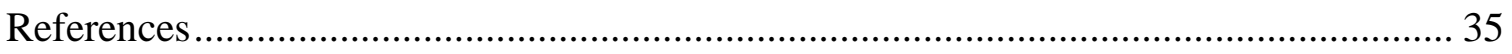

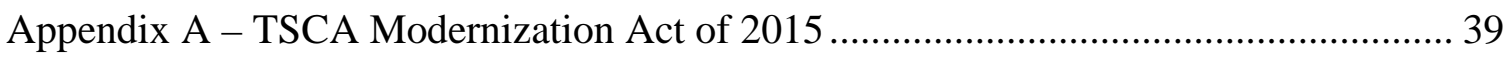




\section{List of Abbreviations}

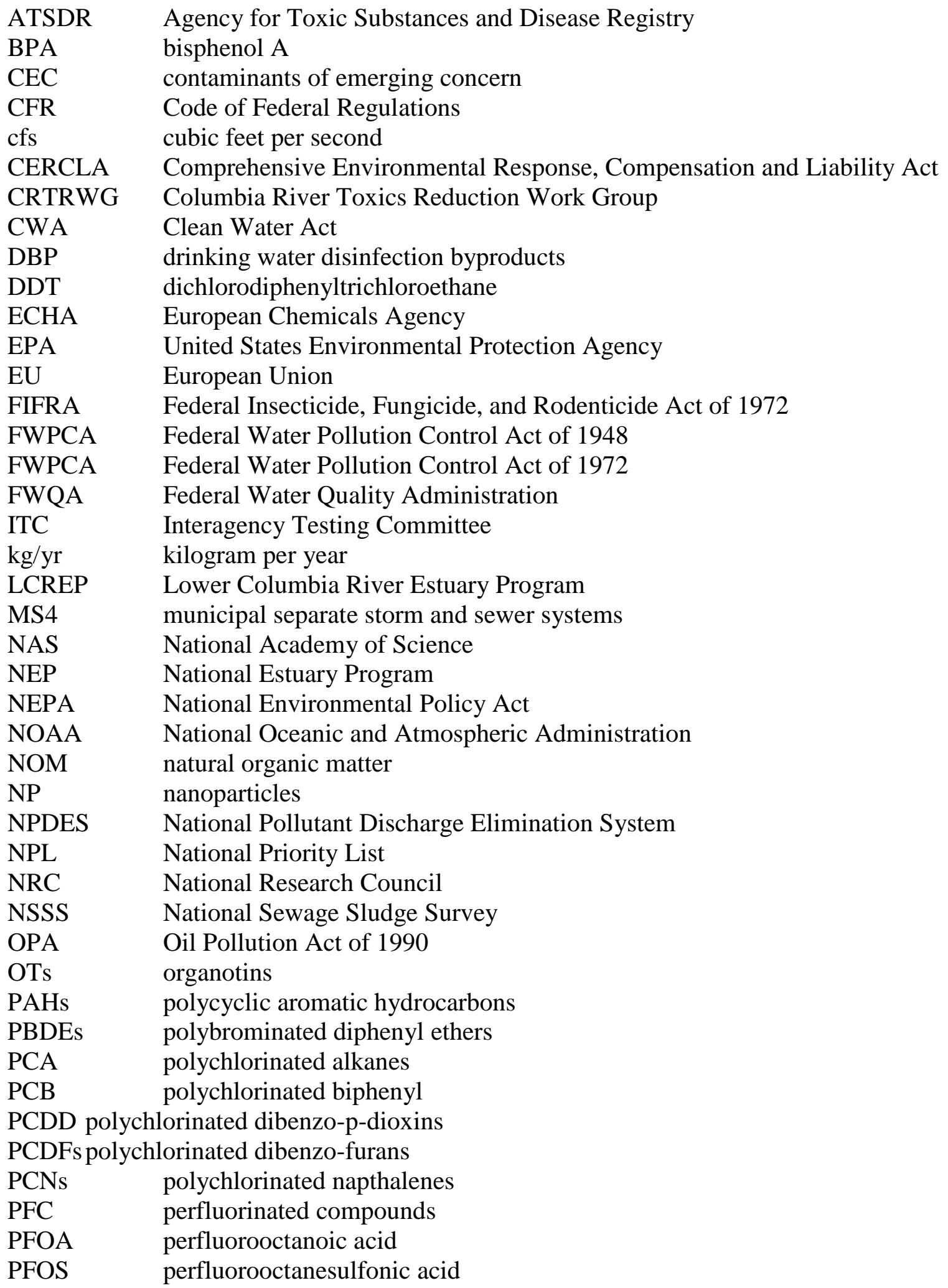




$\begin{array}{ll}\text { PHS } & \text { United States Public Health Service } \\ \text { P.L. } & \text { Public Law } \\ \text { POP } & \text { Persistent Organic Pollutants } \\ \text { POTW publicly owned treatment works } \\ \text { QAC } & \text { quaternary ammonium compounds } \\ \text { RCRA } & \text { Resource Conservation and Recovery Act } \\ \text { REACH } & \text { Registration, Evaluation, Authorisation and Restriction of Chemicals } \\ \text { TCA } & \text { 1,1,1-trichloroethane } \\ \text { TCC } & \text { triclocarban } \\ \text { TCS } & \text { triclosan } \\ \text { TSCA } & \text { Toxic Substances Control Act } \\ \text { TMDL } & \text { Total Maximum Daily Load } \\ \text { USCG } & \text { United States Coast Guard } \\ \text { USDA } & \text { United States Department of Agriculture } \\ \text { USGS } & \text { United States Geological Survey } \\ \text { USACE } & \text { United States Army Corps of Engineers } \\ \text { UV } & \text { ultraviolet } \\ \text { WDOE } & \text { Washington State Department of Ecology } \\ \text { WQA } & \text { Water Quality Act } \\ \text { WRDA } & \text { Water Resources Development Act } \\ \text { WWTP } & \text { wastewater treatment plant }\end{array}$




\section{Chapter 1}

\section{Introduction}

Over the past few decades, research has documented with increasing frequency the effects and occurrence of a class of environmental pollutants now commonly called contaminants of emerging concern (CECs). CECs include all classes of pollutants for which the environmental risks are previously unknown, unrecognized, or unsuspected. A contaminant of 'emerging concern' refers to a compound that is not currently regulated (e.g., not designated as a Priority Pollutant in the United States (U.S.)), is commonly detected at low levels in the environment, and may present a threat to environmental and human health.

The designation, 'emerging concern,' represents a shift in perspective of what is traditionally considered to be an environmental contaminant. Despite being found at low concentrations, due to their ubiquitous nature, CECs are now being more widely detected in far-ranging and diverse locations in the environment, from surface and groundwaters (Vulliet, 2011) to household dust (Ali, 2011), and from plants (Divan Jr., 2009) and animals (Sun, 2012) to arctic ice (De Laender, 2011; Hermanson, 2010). Most of these chemicals have not been adequately examined for toxicological or environmental impacts, and screening methods and regulatory restrictions are still under development (EPA, 2016). Research into the occurrence and risk of exposure to these compounds has been rapidly expanding, and legislation to regulate sources and discharges of CECs to the environment has been evolving to keep up with these scientific findings.

Many CECs are industrially produced, yet are dispersed to the environment often via common domestic, commercial, and industrial uses. CECs include many pharmaceuticals, personal care products (such as shampoos, deodorants, and fragrances), commercial and household chemicals, some pesticides, nanomaterials, and hormones. It has been estimated that over 100,000 chemicals are currently in commerce, with up to 1,000 new compounds added to current-use each year. Of these thousands of chemicals, 
more than 40,000 organic chemicals have been identified as CECs, and that estimate fails to include or consider the associated degradation by-products of those chemicals in environmental systems (Diamond, 2011). Many of these chemicals make their way to wastewater treatment plants (WWTPs), where they may be released to the environment via treated effluent and land application of treated sewage sludge (biosolids).

The land application of biosolids is considered to be a relatively positive reuse option of WWTP sludge, both nationally and internationally. Researchers have shown that biosolids contribute nutrients and beneficial soil amendments such as nitrogen and phosphorus (National Resource Council (NRC) 2002). A significant volume of research has been conducted on the presence of persistent organic pollutants (POPs) in biosolids such as polychlorinated dibenzo-p-dioxins/dibenzo-furans (PCDD/PCDFs), polychlorinated biphenyls (PCBs) and polycyclic aromatic hydrocarbons (PAHs) (e.g.,Wild et al., 1991; Alcock et al., 1996; Stevens et al., 2001), and concentrations of these 'traditional' POPs in biosolids have declined due to effective source control (Wild et al., 1990; Clarke et al., 2008, 2010). However, analytical results have indicated the presence of large concentrations of a number of CECs, identified as environmentally persistent and potentially toxic, as being present in large concentrations in biosolids (NRC 2002; Davis et al., 2012; LaGuardia, 2004).Research on the transport, fate, and potential ecological effects of CECs once biosolids are applied to agricultural fields, garden plots, and landscaped plants and shrubs is still emerging (Clarke, 2011).

Finally, the Columbia River Basin is presented in this paper as a study of a significant waterbody with threatened water quality. The Columbia River discharges an average volume of 265,000 cubic feet per second (cfs), and is the fourth largest river by volume in the U.S. following the Mississippi, the St Lawrence, and the Ohio Rivers, respectively. The Columbia River waterbody was chosen as it represents an important natural resource for which data gaps exist on CEC sources and pathways into the waterbody, and which also does not receive adequate protective regulations under the national regulatory framework. 


\subsection{Objectives and Scope}

Research regarding the transport and fate, and potential ecological effects of CECs sourced from land-applied biosolids is ongoing in both the U.S. and internationally. The purpose of this paper is to present an overview of the current state of CEC research, with a focus on CECs in biosolids. This paper also aims to present a review on the current state of legislation governing regulations of monitoring requirements and acceptable use of land-applied biosolids. The literature review included over 25 articles, spanning from 1990 to 2016, and numerous reports and documents that referenced CEC research, from which a subset was selected based on relevance of studies of CECs and water quality, and biased towards recent and current research. A case study on the Columbia River watershed is also presented to provide a topical perspective on the relevance of regulatory and CEC issues.

\subsection{Problem Statement and Relevance}

Approximately 5.6 million dry tons of biosolids are used or disposed of annually in the United States, of which approximately 60\% are land-applied as soil amendments. EPA estimates that biosolids are applied to approximately $0.1 \%$ of available agricultural land in the United States on an annual basis (NRC, 2002). Biosolids are composed of numerous constituents, with a number of environmentally persistent and potentially toxic CECs identified as present in large concentrations (NRC, 2002; Davis et al., 2012; LaGuardia, 2004), which may be released to the environment via land application.

The presence of priority pollutants such as heavy metals and polychlorinated biphenyls (PCBs) in land-applied biosolids has been extensively studied, including the effects on human health and the environment, and environmental behavior (NRC, 2002). However, data gaps exist in information regarding risks to human and environmental health, occurrence, persistence, transport and fate, and the transformation of emerging contaminants (Chase et al., 2012; Calderon-Preciado, 2011a). Consumption of 
unregulated chemicals is constantly increasing, along with increasing detection rates of significant concentrations of these chemicals in biosolids. Research is needed to understand the transport and fate mechanisms of these unregulated compounds in biosolids. Additionally, this research is needed to determine a new priority framework to regulate CECs, both on the national level and regional levels, including the Columbia River Basin. Advancement in the body of CEC research can also provide guidance on improving regulatory oversight, such as implementing appropriate risk evaluation procedures of new chemicals prior to commercial release, and potentially decrease the frequency of one banned chemical being replaced by a new and unevaluated alternative chemical, such as flame-resistant polybrominated diphenyl ethers (PBDEs) and their replacement congeners (Davis et al., 2012). Understanding the concentrations and environmental behavior of CECs in land-applied biosolids is key to determining the significance and implications of these emerging pollutants on human health and the environment. 


\section{Chapter 2}

\section{Introduction to CECs and Relevant Regulations}

This section provides an introduction to CECs and environmental concerns regarding CECs, as well as a brief history of relevant environmental regulations. The summary of environmental regulations includes a description of Federal regulatory agencies and regulations, as well as international environmental regulations.

\subsection{Introduction to CECs}

CECs include all classes of pollutants for which the environmental risks are previously unknown, unrecognized, or unsuspected. CECs are commonly dispersed to the environment via domestic, commercial, and industrial uses. Sources of CECs include agriculture, landfills, residential household drains and WWTPs, and pesticide use in landscaping applications. CECs include many pharmaceuticals, personal care products, commercial and household chemicals, some pesticides, nanomaterials, and hormones. Classes of CECs identified as problem or priority chemicals include perfluorinated chemicals (e.g., PFOS, PFOA); polychlorinated alkanes (PCAs); polychlorinated naphthalenes (PCNs); organotins (OTs); unregulated congeners of polybrominated diphenyl ethers (PBDEs); triclosan (TCS); triclocarban (TCC); benzothiazoles; antibiotics and pharmaceuticals; synthetic musks; bisphenol A (BPA); quaternary ammonium compounds (QACs), steroids; personal care products; unregulated pesticides; and a wide range of industrial chemicals and nanomaterials.

One of the primary reasons for the increase in awareness of CECs in the environment has been due to recent improvements in the sensitivity of analytical techniques, allowing the detection of previously undetectable low-concentration contaminants. Studies on the risks posed by these pollutants to human and environmental health and safety, and research on the sources, transport, fate, and behavior of CECs are now at the forefront of environmental research. The topic has even gained exposure in media with published 
articles concerning these compounds. One reason that CECs attract popular attention is because the major source of these contaminants is from the general population, via everyday use of products that contain the very compounds that pose environmental risks.

The Athens, Georgia, EPA National Exposure Research Laboratory conducted a 20102011 biennial review to identify particular CECs as major trends in research or as new emerging contaminants (Richardson, 2011a). The EPA acknowledged that many new environmental CECs were identified in this biennial review due to improved analytical techniques that have allowed detection levels at previously undetectable limits in the low $\mathrm{ng} / \mathrm{L}$ concentrations. This is significant, as prior analytical techniques did not allow for such low detection levels, resulting in many chemicals occurring undetected in the environment. The CECs identified in this biennial review are summarized below.

Perflourinated compounds (PFCs) were identified as a major trend of research in the biennial review conducted by the Georgia EPA research laboratory. PFCs have been in production for more than 50 years, and are used in the production of stain repellents, paints, adhesives, waxes, polishes, metals, electronics, fire-fighting foams, caulks, and food packaging such as microwave popcorn bags and French fry boxes. PFCs are persistent and environmentally mobile, due to their unique chemistry of being composed of one of the strongest chemical bonds of carbon-flourine, and their hydrophobic and lipophilic behavior. Between 2000 and 2002, an estimated 5 million kg/yr of PFCs were produced worldwide, with 40\% of this in North America alone (Richardson, 2011a).

Brominated flame retardants have been used for many years, and were updated in manufacturing use by polybrominated diphenyl ethers (PBDEs) since the polybrominated biphenyls were banned about 30 years ago. While penta- and octa-PBDEs were banned in various states, replacement fire retardant chemicals have been produced to keep pace with legislative regulations.

Perchlorate is now recognized as a worldwide environmental issue, and has been found in environmental waters across the United States and in other parts of the world. It has been 
detected in food products in the US, in Europe, and the Far East. Perchlorate is very water-soluble and environmentally stable, and can accumulate in plants which can lead to exposure in humans and animals. Natural sources of perchlorate include naturally sourced nitrate fertilizer. Ammonium perchlorate is used as an oxidizer in solid propellants for rockets, fireworks, and highway flares. Perchlorate can also be a contaminant from the drinking water treatment chemical sodium hypochlorite, and is not removed by conventional water treatment processes, leading to potential for human exposure to occur through drinking water.

Additional CECs include nanomaterials, which are 1 to $100 \mathrm{~nm}$ in size and can have unique properties, including high strength, thermal stability, low permeability, and high conductivity. The chemical structures of nanomaterials are highly varied, including fullerenes, nanotubes, quantum dots, metal oxanes, $\mathrm{TiO}_{2}$ nanoparticles (NPs), nanosilver, nanogold, and zerovalent iron NPs (Richardson, 2011a).

Pharmaceuticals and hormones have been detected in environmental waters. Concerns regarding pharmaceuticals and hormones include potential threats to drinking water, and possible estrogenic and other effects to wildlife and humans. An additional issue of the release of pharmaceuticals to the environment includes the development of bacterial resistance. These CECs are transported to the environment most commonly via effluent from WWTPs due to incomplete removal in wastewater treatment, and also through livestock farm discharges (Richardson, 2011a). An estimated 3200 different substances are used as pharmaceutical ingredients, including painkillers, antibiotics, antidiabetics, betablockers, contraceptives, lipid regulators, antidepressants, chemotherapy drugs, and impotence drugs, and only a very small subset of these compounds has been investigated in environmental studies.

Drinking Water disinfection byproducts (DBPs) were also identified as CECs, and are formed by the reaction of disinfectants (chlorine, chloramines, ozone, chlorine dioxide, etc.) with natural organic matter (NOM) and bromide or iodide in source waters. Nitrosamines, discovered as DBPs in 2002, are probable human carcinogens. Additional 
new CECs include UV filters, used in sunscreens, cosmetics, and other personal care products. UV filters have potential for endocrine disruption and developmental toxicity. Environmental levels of UV filters were detected at levels close to the doses that cause toxic effects in animals (Richardson, 2011a).

1,4-Dioxane has been detected in environmental waters, has also been found in drinking water, and is a probable human carcinogen. Dioxane is a high production chemical used as a solvent stabilizer for the production of textiles including paper and cotton, and also in automotive coolants, cosmetics, and shampoos, as well as a stabilizer in 1,1,1trichloroethane (TCA). In 2002 alone, an excess of 500 tons of dioxane were produced or imported in the United States.

Reports of benzotriazoles as an environmental contaminant have only been detected since approximately 2004, and studies indicate that they are likely ubiquitous environmental contaminants. Benzotriazoles are complexing agents widely used as anticorrosives. The two common forms, benzotriazole (1H-benzotriazole) and tolyltriazole (a mixture of 4and 5-methyl-1H-benzotriazole), are water-soluble, resistant to biodegradation, and only partially removed in wastewater treatment.

Siloxanes have become a relatively new area of research of CECs, with concerns about potential toxicity and transport into the environment due to reportable quantities in wastewater, river water, and landfill biogases (Richardson, 2011b). Siloxanes are used in the production of a number of personal care products and common utensils and household products such as cosmetics, deodorants, soaps, hair conditioners, hair dyes, car waxes, baby pacifiers, cookware, cleaners, furniture polishes, and water-repellent windshield coatings.

Synthetic musk compounds are also a growing area of research of CECs, as they have been widely detected in wildlife and humans. Musks are highly lipophilic, and tend to accumulate in sediments, sludges, and biota. Musks are commonly used as fragrance 
additives in many consumer products, including perfumes, lotions, sunscreens, deodorants, and laundry detergents.

Finally, microorganisms and algal toxins (mostly cyanobacterial toxins produced from blue-green algae) have also been reported as CECs. An unusual CEC identified in this review was sucralose, identified as a persistent (half-life up to several years) contaminant found in surface water, groundwater, and coastal waters (Richardson, 2011b). The research paper by Soh et al. (2011) stated that sucralose is one of very few contaminants that are highly persistent but do not bioaccumulate, and have little or no reported toxicity at environmentally relevant concentrations. Their paper raised an important question:

“Is persistence reason enough for concern or regulation?” (Soh et al., 2011)

\subsubsection{Wastewater Treatment Plants as Sources of CECs}

WWTPs are a major source of CECs, as these facilities are the main receptors of these products via disposal down household, commercial, and industrial drains, and transport via stormwater runoff (e.g., from areas treated with land-applied biosolids). CECs subsequently get introduced to the environment via wastewater effluent that drains to major waterbodies, via leachate after disposal of WWTP sludge in landfills, or transported with treated biosolids and applied to agricultural and other lands as a soil amendment. Approximately 5.6 million dry tons of biosolids are used or disposed of annually in the United States, of which approximately 60\% is used for land application. EPA estimates that biosolids are applied to approximately $0.1 \%$ of available agricultural land in the United States on an annual basis. All biosolids are treated to achieve contaminant concentration limits, as established by the EPA under the 40 CFR Part 503 Standards for the Use or Disposal of Sewage Sludge. Based on the extent of treatment, biosolids may be land-applied under restricted and regulated conditions, as determined by the Part 503 Rule. 


\subsection{Relevant Environmental Regulatory Agencies and Environmental Regulations}

Potential conflict of interests can arise between public health goals and commerce and industry regulations, as is often evident in the evolution of environmental legislation. Regulatory targets are complicated by the myriad factors and stakeholders that hold influence.

This section provides a brief history of relevant environmental regulatory agencies and environmental regulations and an overview of agencies providing regulatory oversight for environmental protection, including the regulation of CECs. Between 2012 and 2016, during which time this literature review was conducted, an effort was made to focus on the most current and relevant papers available at the time on CEC research. At the time of the 2012 research, the Toxic Substances Control Act (TSCA) reform was under consideration, and pending legislation. By the time of the 2016 research period, TSCA reform legislation had been passed by the Senate and signed by President Obama on June 22, 2016. TSCA reform is covered under Section 2.2.2.2. Additionally, a brief summary of international regulations is included for perspective, as well as reference for future direction of regulations.

\subsubsection{United States Federal Environmental Agencies}

This section provides a summary of the evolution and creation of U.S. Federal agencies providing regulatory oversight for environmental protection. The modern climate of the United States environmental regulatory process was inherited from decades-old public health traditions, from which environmental regulatory programs arose to address issues of public health as threatened by water and air quality issues. In addition, maritime navigation protection regulations arose to protect and promote commerce and industry related to harbors, ports, and otherwise navigable waters. 
The U.S. Public Health Service (PHS) originally began in 1798 as the U.S. Marine Hospital Service. Congress changed the name to the "U.S. Public Health and Marine Service” in 1902, expanding its functions to deal with the broad issues of public health, and in 1912 to the PHS. Environmental authorities founded under the PHS included the National Air Pollution Control Administration, originally a research body founded in 1955, and the Federal Water Quality Administration (FWQA), authorized in 1965 by the Water Quality Act (WQA). The FWQA was authorized to issue federal water quality standards for interstate waters, where states failed to do so. The FWQA left the PHS in 1966 to become part of the Department of the Interior, and later was absorbed under the EPA.

The U.S. Environmental Protection Agency (EPA) was established in December 1970, effectively integrating the administration of a variety of federal research, monitoring, standard-setting and enforcement activities, to ensure environmental protection under the umbrella of a single agency. The founding of the EPA was the result of a hybrid of regulations and policy standards originally enacted under agencies such as the PHS and USACE, and many duties were transferred to the EPA from other Federal Agencies. The EPA was assembled from parcels of three federal Departments, three Bureaus, three Administrations, two Councils, one Commission, one Service, and many diverse offices (EPA, 1992).

\subsubsection{United States Federal Environmental Regulations}

This section provides a chronological history of environmental regulations, with a focus on regulations that pertain to water quality, or potential sources of water quality contamination. This background is referenced from the Congressional Research Service Report RL30798, Environmental Laws: Summaries of Major Statutes Administered by the Environmental Protection Agency (Bearden et al., 2013).

The Rivers and Harbors Appropriation Act of 1899 is the oldest environmental law in the United States, and is administered by the U.S. Army Corps of Engineers (USACE). 
Section 9 of the Act, applying to bridges and causeways within navigable waters, was redelegated to the U.S. Coast Guard (USCG) under the provisions of the Department of Transportation Act of 1966, based on the conflict of interest of both ownership and regulation by USACE of many bridges. Actions regulated under section 10 of the Act include excavation, fill, or alteration of any port, harbor or channel, including damming of navigable streams for the purposes of hydroelectric generation or other navigable purposes. Section 13 of the Act controls discharge of refuse of any kind into navigable waters of the United States without a permit, otherwise known as the Refuse Act. Additional environmental enforcement authority under the USCG includes jurisdiction of certain aspects of the Clean Water Act (CWA), such as enforcement of the Oil Pollution Act of 1990 (OPA).

The Federal Water Pollution Control Act (FWPCA) of 1948 was the first comprehensive federal clean water program, passed under Public Law (P.L.) 80-845 (Act of June 30, 1948), and administered under the PHS. At this time, water pollution was viewed as a state and local problem, and there were no federally required goals or guidelines. Federal enforcement and involvement was limited to issues over interstate waters, and only with the consent of the state from which the pollution originated. The FWPCA of 1948 specifically provided state and local government with technical assistance funding to address water pollution problems, including research grants.

In the latter half of the 1950s into the 1960s, water pollution control programs were modified by four laws amending the 1948 FWPCA statute, extending the federal role and federal jurisdiction to include navigable, as well as interstate waters. The four laws were:

- Water Pollution Control Act of 1956 (P.L. $84-660$ (Act of July 9, 1956))

- 1961 Federal Water Pollution Control Act Amendments (P.L. 87-88)

- Water Quality Act of 1965 (P.L. 89-234)

- 1966 Clean Water Restoration Act (P.L 89-753) 
Water quality standards became a feature of the law under the 1965 Water Quality Act, and required states to set standards for interstate waters to be used to determine actual pollution levels.

The Federal Insecticide, Fungicide, and Rodenticide Act (FIFRA) was originally passed in 1947 to address shortcomings of the1910 Federal Insecticide Act, and regulatory authority was assigned to the United States Department of Agriculture (USDA). FIFRA was revised in 1972 by the Federal Environmental Pesticide Control Act (FEPCA), which transferred authority to the EPA. The revised Act emphasized protection of the environment and human health, and shifted the burden of proof of environmental compliance of pesticide products to the chemical manufacturer (EPA, 1996a).

Other notable statutes transferred to the EPA at its inception included certain functions of the National Environmental Policy Act (NEPA) that pertain to ecological systems, and the Federal Water Pollution Control Act (FWPCA) of 1972, better known as the Clean Water Act (CWA).

\subsubsection{Clean Water Act}

The Federal Water Pollution Control Act Amendments of 1972 (P.L. 92-500), referred to as the Clean Water Act (CWA), totally revised the original 1948 FWPCA. The CWA is the primary federal law that governs water pollution, and established the basic structure for regulating the discharge of pollutants into the waters of the United States. This represented a fundamental change in Federal policy, as the CWA shifted the regulatory focus from water quality standards to effluent standards as the foundation for the strategy to control pollution from point sources, primarily industrial dischargers and publicly owned treatment works (POTWs), henceforth referred to as wastewater treatment plants (WWTPs) in this paper. Point sources are defined as discharges from a "discrete conveyance” (or outfall) by industrial facilities (including mining, manufacturing, oil and gas extraction, etc.), municipal governments and other government facilities (such as military bases), and some agricultural facilities (such as animal feed lots). 
The Clean Water Act of 1972 transferred administration of the FWPCA to the EPA, in coordination with state governments. The 1972 law gave the EPA authority to develop pollution control programs such as setting wastewater and industry effluent standards, thereby establishing effluent limitations for the amounts of specific pollutants that may be discharged by municipal sewage plants and industrial facilities. Congress created a major public works financing program for bringing WWTPs up to treatment standards, authorized and funded under Title II.

The CWA also authorized the setting of water quality standards for all contaminants in surface waters. Title IV of the CWA made it unlawful to discharge any pollutant from a point source into navigable waters, unless a permit was obtained under the newly introduced National Pollutant Discharge Elimination System (NPDES), established under section 402. The NPDES program is the primary mechanism under the permit program for regulating point sources of pollution. Initially, the NPDES program focused on WWTPs and industrial wastewater. Nonpoint source pollution was not specifically addressed until the Water Quality Act (WQA) of 1987. A nonpoint source is defined as a diffuse source of pollution that does not have a point of origin. They include stormwater runoff from industrial sources, municipal storm drains, and agricultural stormwater discharges and irrigation return flows.

Additional major changes to the FWPCA have been introduced via additional amendments, including the Clean Water Act of 1977, the Water Quality Act of 1987, and the 1990 Oil Pollution Act. The WQA of 1987 expanded the NPDES program under CWA section 402. The updated program addressed certain nonpoint sources not subject under the 1972 CWA, in particular stormwater runoff, requiring separation of sewer and stormwater systems. Under the Stormwater Phase II Final Rule MS4 Program, operators of regulated small municipal separate storm and sewer systems are required to capture stormwater and provide stormwater treatment at the WWTP, instead of allowing direct discharge of nonpoint stormwater runoff to surface waterbodies. The permit exemption for agricultural discharges continued, but Congress created a grant program at EPA to 
expand research of nonpoint controls and management practices. Additionally, the 1987 WQA created a program for management of biosolids generated by WWTPs.

The CWA was amended again in 1992 to set site-specific allowable pollutant levels for individual water bodies and to create an antidegradation policy to maintain and protect existing uses and high quality waters. Water bodies that do not meet applicable water quality standards are placed on the section 303(d) list, requiring development of a Total Maximum Daily Load (TMDL) of contaminant(s) specific for that water body. A TMDL establishes water quality-based limitations of the maximum amount of a pollutant that a water body can receive and still meet water quality standards. Once a TMDL is issued for a water body, appropriate modification of NPDES permits must be implemented to reflect the TMDL requirements.

\subsubsection{Toxic Substances Control Act}

The Toxic Substances Control Act (TSCA) (15 U.S.C. 2601), enacted in 1976, provided the EPA regulatory authority to protect the environment and consumers' health against risks posed by chemicals in commerce. Chemicals in current-use are subject under TSCA, with the exception of chemicals regulated under other federal laws, such as those laws concerning food, drugs, cosmetics, firearms, ammunition, pesticides, tobacco, or mixtures. EPA is required by Section 8 of TSCA to develop and maintain an inventory of all chemicals, or categories of chemicals, manufactured or processed in the United States. EPA reviews approximately 700 new chemical manufacturing notices annually.

The TSCA inventory in 1979 identified approximately 55,000 chemicals in commerce. While this Act authorized EPA to passively screen new and existing chemicals used in U.S. manufacturing and commerce to identify potentially dangerous products or uses that should be subject to federal regulation, to require chemical manufacturers to conduct reporting and record-keeping, and require testing for chemical products, TSCA did not give EPA authority to independently evaluate the safety of a chemical before it went to marketplace. Based on these evaluations of new and existing chemicals and their 
environmental risks, the EPA could only place restrictions relating to chemical substances and/or mixtures.

TSCA only retroactively addressed chemical hazards, after they had been deemed unsafe and previously unrestricted in the public. Title I, enacted in 1976, addressed two chemical substances, PCBs and elemental mercury. Specifically, Section 6(e) originally regulated PCBs and banned most uses, and with 2008 amendments restricting sales of elemental mercury (P.L. 110-414). In addition, five titles have been added to address the following specific chemical concerns:

- asbestos in 1986 (Title II, P.L. 99-519)

- radon in 1988 (Title III, P.L. 100- 551)

- lead in 1992 (Title IV, P.L. 102-550)

- environmental issues in schools in 2007 (Title V, P.L. 110-140)

- formaldehyde in 2010 (Title VI, P.L. 111-199)

TSCA was formed with the intention to conduct and report test data by producers (i.e., manufacturers, importers, and processors) of chemicals in commerce, however the law did not give the EPA the ability to control substances on the market. A bill to overhaul TSCA, the Frank R. Lautenberg Chemical Safety for the $21^{\text {st }}$ Century Act (House Amendment to the Senate Amendment to H.R. 2576, TSCA Modernization Act of 2015), was passed by the Senate on June 7, 2016, and sent on for President Obama's signature. President Obama signed the Act into Law on June 22, 2016.

\section{TSCA Limitations and TSCA Reform}

Many chemicals, even some in widespread use, are not well characterized in terms of their potential health and environmental effects, and many of these are potential or existing CECs. TSCA is one of the first lines of defense in regulating new and existing CECs, but has been considered ineffective and out of date (Schierow, 2009), and incapable of assessing the safety of all chemicals in use today. 
The Frank R. Lautenberg Chemical Safety for the $21^{\text {st }}$ Century Act will amend TSCA to give the EPA new authority to evaluate the safety of a new chemical before it enters the marketplace. It will also allow EPA to evaluate the safety of chemicals already known to be risks, including chemicals found to persist in the human body and in the environment. The bill also limits companies’ ability to claim product information as confidential, allowing regulators, health professionals and the general public access to previously restricted information about the chemical components in chemical products. The TSCA Modernization Act of 2015 is presented in full in Appendix A.

The first version of the TSCA inventory in 1979 identified approximately 55,000 chemicals in commerce. Due to the overwhelming number of chemicals, Section 4(e) of TSCA established the Interagency Testing Committee (ITC) as an independent advisory committee to the Administrator of the EPA. The ITC was created to make recommendations on prioritizing and selecting chemicals for testing or information reporting to meet the data needs among government agencies. These chemicals are then added to the "Priority Testing List".

Chemicals were assigned a higher priority if known or suspected to cause or contribute to cancer, gene mutations, or birth defects. Section 4(a) of TSCA directed the EPA to require test data to be reported on existing chemicals when certain conditions prevail, including:

- $\quad$ the manufacture, processing, distribution, use, or disposal of the chemical "may present an unreasonable risk;” (Sec. 4(a)(1)(A)(i)

- $\quad$ the chemical is produced in very large volume and there is a potential for a substantial quantity to be released into the environment or for substantial or significant human exposure. (Sec. 4(a)(1)(B)(i)

If either condition existed, EPA shall by rule require that testing be conducted if:

(ii) existing data are insufficient to resolve the question of safety, and

(iii) testing is necessary to develop the data 
Section 5 and Section 6 of TSCA Title I directed EPA to require manufacturers and processors to conduct testing for existing chemicals in order to:

- prevent future risks through pre-manufacture screening and regulatory tracking of new chemical products (Section 5);

- control unreasonable risks already known, or as they are discovered for existing chemicals (Section 6).

TSCA also required EPA to be given a short notice of 90 days when there were plans to produce, process, or use an existing chemical in a way that differs from previously permitted uses, if the Administrator determined by rule that new uses of the chemical may produce significant changes in human and environmental exposures and therefore require notification. Although the legislative history of TSCA included a presumption that testing of new products would take place before they were widely used, either as the chemical was developed, or as its markets grew, TSCA forbade promulgation of blanket testing requirements for all new chemicals. This reflected a concern that uniform testing requirements could stifle innovation in the chemical industry. The purpose of the screening procedure was to identify potential hazards, and control them before use of a chemical becomes widespread; however, the ability of EPA to direct regulation of new chemical products was limited by the original TSCA language. Thus, EPA was restricted to determining only which chemicals, or which categories of chemicals, warrant the costs of premarket testing, and was required by TSCA to regulate only "to the extent necessary to protect adequately" against a risk, and to use the "least burdensome” regulatory approach, even in controlling unreasonable risks.

The TSCA Modernization Act of 2015 updates TSCA Section 6 - Prioritization , Risk Evaluation, and Regulation of Chemical Substance and Mixtures, subsection (a), by striking the language "to protect adequately against such risk using the least burdensome requirements," and inserts, "so that the chemical substance or mixture no longer presents such risk.” Additionally, the TSCA Modernization Act of 2015 requires the Administrator to establish a risk-based screening process, including criteria for 
designating substances as high-priority or low-priority for risk evaluations. The Act further clarifies that:

The process to designate the priority of chemical substances shall include a consideration of the hazard and exposure potential of a chemical substance or a category of chemical substances (including consideration of persistence and bioaccumulation, potentially exposed or susceptible subpopulations and storage near significant sources of drinking water), the conditions of use or significant changes in the conditions of use of the chemical substance, and the volume or significant changes in the volume of the chemical substance manufactured or processed.

The TSCA Modernization Act of 2015 also gives the EPA greater time periods for evaluating new chemicals, expands the authority of EPA to determine the risk-based screening process required by a manufacturer, and grants the authority to EPA to independently designate a chemical as high-risk. Chemical manufacturers will be required to make a safety finding to get a product on market, which gets away from the passive system as TSCA originally existed. Instead of requiring that EPA had to document that a chemical posed a risk before it could ask the manufacturer to conduct toxicity or exposure tests, EPA will be able to determine that chemicals in furniture, clothing, cleaning products and other common household items are safe before such products are allowed into commerce.

However, the Act still allows for some regulatory leeway in interpretation, as language in the legislation states EPA must consider the "cost-effectiveness" of any proposed rule, which may be considered restating the previously mentioned "least-burdensome requirements” on industry. 


\subsubsection{Additional Environmental Protection Acts}

The Safe Drinking Water Act (1974), Title XIV of the Public Health Service Act, protects the public water supplies from harmful contaminants. The law focuses on all waters actually or potentially designed for drinking use, whether from above-ground or underground sources.

The Resource Conservation and Recovery Act (RCRA), passed in 1976, created authority for the EPA to control hazardous waste from “cradle to grave.” This includes the generation, transportation, treatment, storage and disposal of hazardous waste. This law also set a framework for the management of non-hazardous waste.

The Comprehensive Environmental Response, Compensation and Liability Act (CERCLA), enacted in 1980, provides for a federally funded "Superfund” to clean up uncontrolled or abandoned hazardous waste sites as well as accidents, spills and other releases of pollutants into the environment. To prioritize cleanup action, CERCLA directed EPA to create a National Priorities List (NPL) of the most contaminated sites which present the greatest risks to human health and the environment. The NPL includes both non-federal sites and federal facilities deemed to present a sufficient level of risk to warrant listing. The law gives the U.S. EPA the authority to locate the parties responsible for any release and assure their cooperation in the cleanup. Additionally, Section 104(i) of CERCLA established the Agency for Toxic Substances and Disease Registry (ATSDR) mainly to assess potential health risks at NPL sites. The ATSDR assesses individual sites based on the likelihood of human exposure to contamination through the air, soil, surface water, groundwater, and other pathways such as consumption of contaminated food sources. These assessments serve two purposes: to inform the public of potential health hazards at a contaminated site and to aid decision-makers in evaluating what cleanup actions may be warranted to prevent potentially harmful exposure.

The Pollution Prevention Act (1990) focuses industry, government and public attention on reducing pollution through cost-effective changes in production, operation and raw 
material use. Pollution prevention also includes other practices such as source reduction, recycling and sustainable agriculture that increase efficiency in the use of energy, water and other natural resources.

\subsubsection{Wastewater Treatment Plant and Land-Applied Biosolids Regulatory Requirements}

Wastewater treatment produces two end products: effluent and sewage sludge. Biosolids are the treated component of sewage sludge. Approximately 75\% of the United States population contributes to wastewater directly through a sewerage system to over 16,000 wastewater treatment plants (DHS, 2016).

Wastewater pretreatment regulations were established through 40 CFR Part 403 (as of June 26, 1978). These regulations addressed industrial facilities contributing to the influent stream, and aimed to prevent introduction of pollutants into the WWTPs that would interfere with the operation of a plant, including interference with disposal of municipal biosolids due to contamination. These regulations under Part 403 dramatically reduced concentrations of selected pollutants (e.g., pollutants which create a fire hazard, oil and grease, and corrosive pollutants, among other hazardous wastes) discharged to WWTPs and therefore reduced the concentrations of pollutants in treated biosolids.

Section 402 of the CWA (the NPDES permit program), and 40 CFR Part 503 (Standards for Use or Disposal of Sewage Sludge), allows regulation of land-applied biosolids from the consideration of a point-source discharge to groundwater. The 1993 Code of Federal Regulations, 40 CFR Part 503, under Section 405 of the 1987 WQA, created a program for general requirements, pollutant limits, management practices, and operational standards, for the final use or disposal of sewage sludge produced during treatment of domestic sewage in WWTPs. Contaminants considered under this rule were selected based in part on analytical results from the 1988 National Sewage Sludge Survey (NSSS), which analyzed sewage sludge for 411 possible contaminants from 176 WWTPs within the U.S. 
The Part 503 rule established management practices for usage and disposal of biosolids, including land-application of biosolids, concentration limits, and loading rates for chemicals occurring in biosolids, and treatment and use requirements designed to control and reduce pathogens (EPA, 1993). The chemical land-application standards in the Part 503 rule were determined by EPA through risk assessments aimed at identifying the chemical constituents in biosolids judged likely to pose the greatest hazard. Likely exposure scenarios and calculated concentration limits and loading rates were also identified. The regulations to guide the management practices and operational standards are as follows:

(1) Identify uses for sewage sludge, including disposal;

(2) Specify factors to be taken into account in determining the measures and practices applicable to each such use or disposal (including publication of information on costs); and

(3) Identify concentrations of pollutants which interfere with each such use or disposal.

Under Part 503, the first primary regulated contaminants in biosolids were ten inorganic chemicals: arsenic, cadmium, chromium (limits later deleted under 60 FR 54764), copper, lead, mercury, molybdenum, nickel, selenium, and zinc.

Different land application rules apply to different classes of biosolids, and the following quality control regulations were established under the Part 503 regulation:

Two levels of sewage sludge quality with respect to heavy metal concentrations:

- Pollutant ceiling concentrations

- Pollutant concentrations ("high quality" sewage sludge)

Two levels of quality with respect to pathogen densities:

- Class A

- Class B 
Two types of approaches for meeting vector attraction reduction:

- Sewage sludge processing

- The use of physical barriers.

Class A biosolids contain no detectible levels of pathogens, must meet strict vector attraction reduction requirements and low levels metals contents, and are permitted to ensure that these standards have been met. Class B biosolids are treated but still contain detectible levels of pathogens, and have buffer requirements to protect water quality, restricted public access, and crop harvesting restrictions for virtually all forms of Class B biosolids.

Under the Part 503 regulation, fewer restrictions are imposed on the use of higher quality sewage sludge. Class A biosolids may be applied in small quantities without restriction by the general public on public-contact sites, including parks, golf courses, lawns, and home gardens. When used in bulk, Class A biosolids are subject to buffers for water quality protection, but not to crop harvesting restrictions. Based on the extent of treatment, Class B biosolids may be applied where little exposure of the general public is expected to occur on the sites, such as on agricultural land, forests, and reclamation sites.

In 1995 EPA revisited the pollutants considered in Rule 503 under the so-called "Round Two" evaluation. However, a second comprehensive analytical survey of contaminants in biosolids was not conducted, and EPA instead focused largely on compounds previously considered during the original NSSS, with an emphasis on chlorinated dioxins, furans and co-planar PCBs (EPA, 1996b). In 2003, EPA concluded that these compounds did not present a significant risk to human health or the environment, and made the decision to not regulate levels of these compounds in biosolids (EPA Headquarters Press Release October 17, 2003).

As public health concerns regarding the use of biosolids increased, EPA in 1999 asked the National Academy of Science (NAS) to conduct an independent evaluation 
reassessing the scientific basis of the Part 503 Rule. NAS produced the resulting report Biosolids Applied to Lands: Advancing Practices and Standards in 2002. The NAS committee stated in the 2002 report that the Part 503 Rule relied on an outdated biosolid contaminant characterization (NRC, 2002), and that the original NSSS did not address possible adverse changes in biosolids composition due to changes in treatment processes and chemical uses over the last decade. Suggested actions recommended by the committee included that a new national sewage sludge survey be conducted, to ensure that Part 503 Rule risk assessment assumptions are based on sound science (NRC 2002). At the 2003 Biosolids Research Summit, a research agenda was created to address research gaps identified by the NRC report. The top identified research gaps were to create a targeted characterization of pathogens, and to conduct a new national survey of CECs in biosolids. Both were ranked as the second and third highest research priorities, following only the development of a rapid incident response study aimed at examining whether a linkage existed between biosolids land application and reports of human health impacts (WERF, 2004).

\subsubsection{International Environmental Regulatory Agencies and Environmental Regulations}

Europe has passed tough chemical regulations, including one of the world's most extensive chemical safety regulations, known as REACH (Registration, Evaluation, Authorization and Restriction of Chemicals), passed on June 1, 2007. The European Chemicals Agency (ECHA) is the prime regulatory authority for REACH, and helps companies comply with the legislation, advances the safe use of chemicals, and provides information on chemicals and addresses chemicals of concern (ECHA REACH, 2016). The law requires companies that produce or sell chemicals in the European Union (EU) to register toxicity data on the compounds and to outline any new tests needed to clarify their biological effects and places the burden of proof on companies. To comply with the regulation, companies must identify and manage the risks linked to the substances they manufacture and market in the EU. 
The European Union Council Directive 86/278/EEC was adopted over 20 years ago to promote land application of biosolids in agriculture and to regulate its use, to prevent harmful effects on soil, vegetation, animals, and humans. The Directive was initiated June 12, 1986, with the intent of the protection of the environment, and in particular of the soil, when sewage sludge is used in agriculture. The Directive currently sets limit values for seven heavy metals that may be toxic to plants and humans: cadmium, chromium, copper, nickel, lead, zinc, and mercury. Since its adoption, several Member States have enacted and implemented stricter limit values for heavy metals and set requirements for other contaminants. Currently, the European Commission is assessing whether the current Directive should be reviewed, and to what extent (EC, 2016). 


\section{Chapter 3}

\section{Case Study on Columbia River}

The Columbia River is presented as a case study as an example of a significant waterbody with research and regulatory gaps concerning CECs.

\subsection{Introduction/Problem Statement}

The Columbia River is important to the entire Pacific Northwest region as a food and water source, for transportation and shipping, for recreation, and also as a cultural resource for the many tribes within the Columbia River watershed. The Columbia spans three states and two nations, which makes for complex oversight authority.

The Columbia River is a receptor of numerous point-sources of pollution throughout its length, including urban stormwater runoff, wastewater treatment plant and industrial manufacturing effluent, as well as non-point source pollution such as overland flow from agricultural and industrial fields and air deposition of contaminants. Currently, the Columbia River is extensively monitored for known contaminants (mercury, PCBs, DDT, PBDEs) while limited resources are dedicated to identifying and monitoring emerging contaminants in the Columbia River. Additionally, the Columbia River Basin is a prime candidate for targeted studies on the effects land-applied biosolids within the watershed.

The purpose of this case study is to present an in-depth compilation of current research on emerging contaminants and to identify potential new monitoring methods and programs. This case study also provides an overview of the current Columbia River Monitoring Plan and describes current actions being undertaken by monitoring agencies and resource management agencies to monitor and control emerging contaminants. 


\subsection{Relevant Agencies and Programs that Affect the Columbia River}

This section provides a summary of regional agencies and watershed protection groups providing regulatory oversight for environmental protection of the Columbia River basin.

\section{National Estuary Program and LCREP}

Between 1989 and 1995, a six-year study was conducted by the Bi-State Water Quality Program on the lower Columbia River between the Bonneville Dam and the Pacific Ocean. Research studies collected water quality data and toxic contaminant data within the lower Columbia River and estuary, generating a large dataset on the threats to the health of the river and river organisms.

The findings of the six-year study highlighted four problems in the lower Columbia River estuary:

- Toxics in sediment and fish tissue that can affect the health of humans, fish, and wildlife

- Habitat loss/modification that can affect fish and wildlife resources

- Water quality problems that affect beneficial uses in portions of the estuary

- Overall decline in anadromous fish runs that has resulted in threatened and endangered species listings (WDOE, 1997)

Based on the results of this research, the lower Columbia River was nominated by the governors of Washington and Oregon states for the EPA National Estuary Program (NEP) in July 1995. The NEP is a non-regulatory program established by Congress via amendments to the Clean Water Act in 1987, and is a place-based program established to protect and restore "water quality and ecological integrity of estuaries of national significance” (EPA NEP Overview 2016). The NEP provides support for the development of management plans for the Nation's most significant estuaries that are threatened by degradation caused by human activity. Currently, 28 estuaries are 
designated as significant, and the program provides resources to help manage these estuaries of national, regional, and local significance.

The EPA accepted the lower Columbia River into the NEP, and established the Lower Columbia Estuary Partnership (LCREP). LCREP is supported by the US Environmental Protection Agency, the states of Oregon and Washington, and numerous other public and private entities. LCREP advocates for long-term monitoring, to address issues about the sources, distribution, and persistence of toxics in the lower river.

\section{Columbia River Toxics Reduction Work Group}

As part of the NEP, a long-term monitoring plan was developed for the lower Columbia River and estuary to address many of the issues that face the lower Columbia River Basin. The Columbia River Toxics Reduction Work Group (CRTRWG) was formed in 2005 as a collaborative workgroup among EPA and federal, state, tribal, local, industry, and nonprofit partners to focus on toxics in the Columbia River, with the goal to reduce toxics in the Columbia River Basin and prevent further contamination. This group was modeled on EPA collaborative efforts underway throughout the U.S. including the Chesapeake Bay and the National Estuary Program (EPA and CRTRWG, 2010). In 2009, the EPA produced The Columbia River Basin State of the River Report for Toxics with the support and guidance of CRTRWG.

The State of the River Report for Toxics determined that four contaminants were above risk action levels: mercury, dichlorodiphenyltrichloroethane (DDT) and associated breakdown products, polychlorinated biphenyls (PCBs), and polybrominated diphenyl ether (PBDE) flame retardants. Additional contaminants are found in the Basin, including arsenic, dioxins, radionuclides, lead, pesticides, industrial chemicals, and CECs including pharmaceuticals found in wastewater.

EPA and the CRTRWG released the Columbia River Toxics Reduction Action Plan (Action Plan) in September 2010. The Action Plan included five general initiatives and 
actions to be accomplished through 2015, to better understand and reduce toxic contamination in the Columbia River Basin:

- Increase public understanding and political commitment to toxics reduction in the Basin

- Increase toxic reduction actions

- Conduct monitoring to identify sources and then work to reduce toxic contamination

- Develop a regional, multi-agency research program

- Develop a data management system that will allow sharing of information on toxics in the Basin

The work with the CRTRWG is currently conducted via coordination and partnerships without any designated funding sources, with the exception of work done in the estuary through LCREP. The CRTRWG states that:

"To a great extent, success in reducing toxics in the Basin will depend on a commitment by all levels of government, in both the United States and Canada, tribal governments, nongovernmental organizations, industry groups, and the public to work together. The problems are too large, widespread, and complex to be solved by only one organization or country.”

\subsection{Gaps in Columbia River Research and Restoration Funding}

The CRTRWG identified a number of priorities for state and local governments to address to reduce toxics in the Columbia Basin. The workgroup believes that a focus on enhancing programs in these areas will help advance the prevention and reduction of toxics in the Columbia River Basin. The Priority Initiatives of the Columbia River Toxics Reduction Working Group, January 2013, are summarized below: 
- Sustainable Purchasing: Develop a list of sustainable products and a list of chemicals of concern that could be used by all entities in the Basin for greening their operations

- Green Chemistry: Initiate a Regional Green Chemistry Center to advance the discussion on how to develop chemical processes that provide less toxic materials

- Chemicals of Emerging Concern: Develop monitoring programs and toxicity information to inform actions to address chemicals of emerging concern that are currently unregulated

- Pesticide Stewardship Partnerships: Enhance and expand the successful Pesticide Stewardship Partnership model used by the State of Oregon to encourage voluntary changes in pesticide use and practices that lead to measurable environmental improvements

- Stormwater: Expand stormwater technical assistance programs to small and medium businesses, providing much-needed pollution prevention expertise at the local level

Contaminants such as DDTs have been determined to persist in the Columbia River despite being banned decades ago, while CECs, including flame retardants (PBDEs) and personal care products, pose new threats to human health and fish and wildlife. However, the Columbia River Basin is the only major EPA-designated 'large aquatic ecosystem' to receive zero funding pursuant to the NEP designation. Additionally, the Columbia River Monitoring Plan does not address CECs in biosolids.

In May 2015, U.S Senator Jeff Merkley (D-OR) and Congressman Earl Blumenauer (DOR), reintroduced the Columbia River Basin Restoration Act. On September 15, 2016, the U.S. Senate passed the Act as part of the Water Resources Development Act (WRDA) of 2016 (LCREP September 16, 2016). This bill addresses critical fish and wildlife habitat, water quality, and infrastructure needs in a total of 18 states and would authorize Congress to appropriate funds for a voluntary grant program to expand and add to monitoring efforts and provide the resources for sustained action to reduce 
contaminants and evaluate them throughout the Columbia River system. If the Act becomes law, which has not yet been passed as of the time of this report, the status of the Columbia River would be elevated to that of other Large Aquatic Ecosystems, and it would authorize Congress to appropriate funds through the EPA to implement its Columbia Basin Toxics Reduction Plan and the Estuary Partnership Management Plan. 


\section{Chapter 4}

\section{Conclusions}

With over 100,000 chemicals in current use and new chemicals added each year, the environmental risks and behavior of these chemicals need to be properly evaluated and regulated. Ideally, problematic chemicals should be identified prior to their release into the environment and controlled accordingly. TSCA is one of the first lines of defense in regulating new and existing CECs, and is an important regulatory tool to assess the safety of chemicals in use today. Additionally, WWTPs are a destination for environmental contaminants sourced from residential and industrial sewer and storm drains, and many of these contaminants end up partitioning onto the treated sewage sludge. This sewage sludge that turns into treated biosolids then becomes a vector for environmental contamination as it is dispersed as land-applied biosolids.

\subsection{Research Gaps}

Data gaps exist for CECs in understanding their occurrence, persistence, transport and fate, their transformation products, the characterization of CECs in biosolids, their risks to human and environmental health, and research on prioritizing CECs for regulatory purposes. Data gaps exist on national and regional scales for impacts from CECs released from biosolids to environments such as the Columbia River Basin. Additional concerns regarding CECs in environment include unknown exposure duration and mixture effects, or unknown synergistic and cumulative effects of CECs in the environment.

Questions raised by this research include:

- How do you decide which pollutants to permit? Toxicologists defer to EPA, and human-health revisions are based on EPA reference doses, etc.

- Toxicity data is needed to reach conclusions on regulating compounds

- Standards are needed for methods to perform monitoring requirements 
This literature review also concluded that many new CECs were identified due to improved analytical techniques that have allowed detection levels at previously undetectable limits in the low ng/L concentrations. This is significant, as prior analytical techniques did not allow for such low detection levels, and many chemicals went undetected in the environment, their presence unknown previous to the new lowdetection analytical techniques.

\subsection{Legislative Gaps}

The reformed TSCA law still allows for some regulatory leeway in interpretation and regulatory enforcement. The regulatory language states EPA must consider the "costeffectiveness" of any proposed rule, which may be considered restating the previously mentioned "least-burdensome requirements" on industry. Strong legislation is needed to predict and prevent chemicals from being unnecessarily released to the environment. Additionally, wastewater pretreatment regulations and wastewater treatment methods can be improved to reduce CECs from both WWTP influent streams and effluent products.

The extent of environmental protection afforded by the current evaluation approaches for risk-based assesssment does not consider the cumulative risk of the mixture of all CECs present. A multifaceted approach is needed to address these challenges, including a set of tools to characterize CEC exposure at the suborganism, organism, and population levels, to identify potential or actual effects of CECs on aquatic communities. Possible approaches include incorporating existing approaches used by the various water agencies to assess the risk of individual chemicals. However, addressing the extent of the potential effects of mixtures of the chemicals in combination with more common pollutants and other environmental stressors is complex.

There is a need to characterize and better understand the environmental and biological fate, transport, and transformation of CECs. This knowledge gap becomes more important as water supplies become more limited and water re-use practices change. 
More than 40,000 organic chemicals have been identified as CECs, which does not include the associated breakdown products in the environment. However, agencies responsible for monitoring efforts, such as the National Oceanic and Atmospheric Administration (NOAA), the U.S. Geological Survey (USGS), and the U.S. Environmental Protection Agency (U.S. EPA), have widely different definitions as to what a CEC actually is (Diamond, 2011). For example, some researchers consider an already regulated chemical to be a CEC if there are additional, unregulated effects, such as endocrine disruption. Others broadly define a CEC as a chemical that is currently unregulated. With no consensus on the definition of a CEC, each agency monitors its own subjective list of chemicals.

\subsection{Summary}

Biosolids are composed of numerous constituents, with a number of environmentally persistent and potentially toxic CECs identified as present in large concentrations. The presence of priority pollutants such as heavy metals and polychlorinated biphenyls (PCBs) in land-applied biosolids has been extensively studied, including the effects on human health and the environment, and environmental behavior. However, with the constantly increasing consumption of unregulated chemicals and the detection of significant concentrations of these chemicals in biosolids, research is needed to understand the transport and fate mechanisms of these compounds in biosolids. Additionally, this research is needed to determine a new priority framework to regulate CECs, both on the national level and regional levels. WWTP influent and effluent treatment regulations and practices may be improved upon as more knowledge accrues regarding CEC behavior in the environment. Understanding the concentrations and environmental behavior of CECs in land-applied biosolids is key to determining the significance and implications of these emerging pollutants on human health and the environment. 


\section{References}

Alcock RE, Bacon J, Bardget RD, Beck AJ, Haygarth PM, Lee RGM, et al., 1996. Persistence and fate of polychlorinated biphenyls (PCBs) in sewage sludge-amended agricultural soils. Environ Pollut; 93:83.

Ali N, Harrad S, et al., 2011. “Novel”' brominated flame retardants in Belgian and UK indoor dust: Implications for human exposure. Chemosphere, 83, 1360-1365.

Bearden DM, Copeland C, Luther L, McCarthy J E, Tiemann M, Esworthy R, Yen J, December 20, 2013. Environmental Laws: Summaries of Major Statutes Administered by the Environmental Protection Agency. Congressional Research Service Report RL30798.

Calderon-Preciado D et al., 2011a. Occurrence and potential crop uptake of emerging contaminants and related compounds in an agricultural irrigation network. Science of the Total Environment; 412-413:14-19.

Calderón-Preciado D, Jiménez-Cartagena C, Matamoros V, Bayona JM, 2011b. Screening of 47 organic microcontaminants in agricultural irrigation waters and their soil loading. Water Res; 45:221-31.

Chase DA et al., 2012. Occurrence of synthetic musk fragrances in effluent and noneffluent impacted environments. Science of the Total Environment; 416:253-60.

Clarke B, Porter N, Symons R, Blackbeard J, Ades P, Marriott P, 2008. Dioxin-like compounds in Australian sewage sludge - review and national survey. Chemosphere; 72: 1215-28.

Clarke BO, Porter NA, Marriott PJ, Blackbeard JR, 2010. Investigating the levels and trends of organochlorine pesticides and polychlorinated biphenyl in sewage sludge. Environ Int; 36:323-9.

Clarke BO, 2011. Review of 'emerging' organic contaminants in biosolids an assessment of international research priorities for the agricultural use of biosolids. Environmental International; 37:226-247.

Davis EF et al., 2012. Measurement of flame retardants and triclosan in municipal sewage sludge and biosolids. Environment International; 40:1-7.

De Laender F, Hammer J, et al., 2011. Combining Monitoring Data and Modeling Identifies PAHs as Emerging Contaminants in the Arctic. Environ. Sci. Technol., 45, 9024-9029. 
Diamond, JM et al., 2011. Prioritizing Contaminants of Emerging Concern for

Ecological Screening Assessments. Environmental Toxicology and Chemistry, 30 (No. 11): p. 2385-94.

Divan Junior A, de Oliviera P, et al., 2009. Using wild plant species as indicators for the accumulation of emissions from a thermal power plant, Candiota, South Brazil. Ecological Indicators, 9, 1156-1162.

U.S. Department of Homeland Security (DHS). Critical Infrastructure Sectors, Water and Wastewater Systems Sector. https://www.dhs.gov/water-and-wastewater-systemssector. Retrieved 3 July 2016.

U.S Environmental Protection Agency (EPA), 1992. The Guardian: Origins of the EPA. http://www.epa.gov/aboutepa/guardian-origins-epa. Retrieved 2 February 2016.

EPA (U.S. Environmental Protection Agency), 1993. Federal Register: February 19, 1993. 40 CFR Parts 257, 403, and 503. The Standards for the Use or Disposal of Sewage Sludge. Final Rules. EPA 822/Z-93/001. U.S. Environmental Protection Agency.

EPA, 1996a. Federal Insecticide, Fungicide, and Rodenticide Act (FIFRA). http://www.epa.gov/laws-regulations/summary-federal-insecticide-fungicide-androdenticide-act. Retrieved 2 February 2016.

EPA, 1996b. Technical Support Document for Round Two Sewage Sludge Pollutants; EPA/822/R-96/003; Office of Water: Washington, DC.

EPA, 1999. Biosolids generation, use, and disposal in the United States. EPA530-R99-009, Environmental Protection Agency, Office of Solid Waste Washington, DC.

EPA, 2009. Retrieved from www.epa.gov/columbiariver/columbia-river-basin-stateriver-report-toxics-january-2009. Retrieved 26 January, 2016.

EPA, 2016, September 27. Water Quality Criteria - Contaminants of Concern including Pharmaceuticals and Personal Care Products. Retrieved from https://www.epa.gov/wqc/contaminants-emerging-concern-including-pharmaceuticalsand-personal-care-products. Retrieved November 27, 2016.

EPA NEP Overview 2016. https://www.epa.gov/nep/overview-national-estuary-program, last updated on August 25, 2016. Retrieved September 26, 2016.

EPA \& the Columbia River Toxics Reduction Working Group (CRTRWG), September, 2010. Columbia River Basin Toxics Reduction Action Plan.

https://www.epa.gov/sites/production/files/documents/columbia_river_toxics_action plan_sept2010.pdf 
European Commission (EC), 2016. Retrieved from

http://ec.europa.eu/environment/waste/sludge/. Retrieved November 28. 2016.

European Chemicals Agency (ECHA), REACH 2016.

https://echa.europa.eu/regulations/reach/. Retrieved September 26, 2016.

Hermanson M, Isaksson E, et al., 2010. Deposition History of Brominated Flame Retardant Compounds in an Ice Core from Holtedahlfonna, Svalbard, Norway. Environ. Sci. Technol., 44, 7405-7410.

Kosjek T et al., 2012. Environmental occurrence, fate and transformation of benzodiazepines in water treatment. Water Research; 46:355-368.

La Guardia MJ, 2004. Organic Contaminants of Emerging Concern in Land-Applied Sewage Sludge (Biosolids). Journal of Residuals Science \& Technology; 01/02:111112.

Lower Columbia River Estuary Program (LCREP) September 16, 2016. http://www.estuarypartnership.org/news/columbia-river-basin-restoration-act-passes-ussenate. Retrieved September 26, 2016.

National Research Council (NRC), Committee on Toxicants and Pathogens in Biosolids Applied to Land, 2002. Biosolids Applied to Land: Advancing Standards and Practices. The National Academies Press, 2002.

Richardson SD, 2011a. Environmental Mass Spectrometry: Emerging Contaminants and Current Issues. Analytical Chemistry 2012; 84: 747-778.

Richardson SD, Ternes TA, 2011b. Water Analysis: Emerging Contaminants and Current Issues. Anal. Chem., 83, 4614-4648.

Schierow L, 2009. The Toxic Substances Control Act (TSCA): Implementation and New Challenges. Congressional Research Service, Report for Congress; July 28, 2009.

Soh L, Connors KA, Brooks BW, Zimmerman J, 2011. Fate of Sucralose through Environmental and Water Treatment Processes and Impact on Plant Indicator Species. Environ. Sci. Technol., 45, 1363-1369.

Stevens J, Green NJL, Jones KC., 2001. Survey of PCDD/Fs and non-ortho PCBs in UK sewage sludges. Chemosphere;44:1455.

Sun Y, Luo X, et al., 2012. Brominated flame retardants in three terrestrial passerine birds from South China: Geographical pattern and implication for potential sources. Environmental Pollution 162, 381-388. 
Vulliet E, Cren-Olive C, 2011. Screening of pharmaceuticals and hormones at the regional scale, in surface and groundwaters intended to human consumption.

Environ. Pol., 159, 2929-2934.

Washington Department of Ecology (WDOE), January 1997. Briefsheet, National Estuary Program for the Lower Columbia River: Publication No. 97-2004-

WQ\&FA. https://fortress.wa.gov/ecy/publications/documents/972004wqfa.pdf. Accessed August 1, 2016.

Water Environment Research Foundation (WERF), 2004. Proceedings From the Biosolids Research Summit; Final Report, 2004. July 28-30, 2003, in Alexandria, Virginia; Water Environment Research Foundation.

Wild SR, Waterhouse KS, McGrath SP, Jones KC, 1990. Organic contaminants in an agricultural soil with a known history of sewage sludge amendments: polynuclear aromatic hydrocarbons. Environ Sci Technol; 24:1706-11.

Wild SR, Berrow ML, Jones KC, 1991. The persistence of polynuclear aromatic hydrocarbons (PAHs) in sewage sludge amended agricultural soils. Environ Pollut; 72:141-57. 
Appendix A - TSCA Modernization Act of 2015 
MaY 20, 2016

\section{Rules Committee Print 114-54}

Text of House amendment to THE Senate AMENDMENT TO H.R. 2576, TSCA MoDERNIZATION ACT OF 2015

\section{[Showing the text of the Frank R. Lautenberg Chemical Safety for the 21st Century Act.]}

\section{SECTION 1. SHORT TITLE; TABLE OF CONTENTS.}

6 this Act is as follows:

Sec. 1. Short title; table of contents.

\section{TITLE I—CHEMICAL SAFETY}

Sec. 2. Findings, policy, and intent.

Sec. 3. Definitions.

Sec. 4. Testing of chemical substances and mixtures.

Sec. 5. Manufacturing and processing notices.

Sec. 6. Prioritization, risk evaluation, and regulation of chemical substances and mixtures.

Sec. 7. Imminent hazards.

Sec. 8. Reporting and retention of information.

Sec. 9. Relationship to other Federal laws.

Sec. 10. Exports of elemental mercury.

Sec. 11. Confidential information.

Sec. 12. Penalties.

Sec. 13. State-Federal relationship.

Sec. 14. Judicial review.

Sec. 15. Citizens' civil actions.

Sec. 16. Studies.

Sec. 17. Administration of the Act.

Sec. 18. State programs.

Sec. 19. Conforming amendments.

Sec. 20. No retroactivity. 
Sec. 21. Trevor's Law.

TITLE II-RURAL HEALTHCARE CONNECTIVITY

Sec. 201. Short title.

Sec. 202. Telecommunications services for skilled nursing facilities.

\section{TITLE I-CHEMICAL SAFETY}

2 SEC. 2. FINDINGS, POLICY, AND INTENT.

3 Section 2(c) of the Toxic Substances Control Act (15

4 U.S.C. 2601(c)) is amended by striking "proposes to

5 take" and inserting "proposes as provided".

6 SEC. 3. DEFINITIONS.

7 Section 3 of the Toxic Substances Control Act (15

8 U.S.C. 2602) is amended-

9 (1) by redesignating paragraphs (4) through

10 (14) as paragraphs (5), (6), (8), (9), (10), (11),

11 (13), (14), (15), (16), and (17), respectively;

12 (2) by inserting after paragraph (3) the fol-

13 lowing:

14 “(4) The term 'conditions of use' means the cir-

15 cumstances, as determined by the Administrator, under

16 which a chemical substance is intended, known, or reason-

17 ably foreseen to be manufactured, processed, distributed

18 in commerce, used, or disposed of.";

(3) by inserting after paragraph (6), as so re-

20 designated, the following:

21 “(7) The term 'guidance' means any significant writ-

22 ten guidance of general applicability prepared by the Ad-

23 ministrator."; and 
1 (4) by inserting after paragraph (11), as so re-

2 designated, the following:

3 “(12) The term 'potentially exposed or susceptible

4 subpopulation' means a group of individuals within the

5 general population identified by the Administrator who,

6 due to either greater susceptibility or greater exposure,

7 may be at greater risk than the general population of ad-

8 verse health effects from exposure to a chemical substance

9 or mixture, such as infants, children, pregnant women,

10 workers, or the elderly.".

11 SEC. 4. TESTING OF CHEMICAL SUBSTANCES AND MIXTURES.

13 Section 4 of the Toxic Substances Control Act (15

14 U.S.C. 2603) is amended-

15 (1) by striking "standards" each place it ap16 pears and inserting "protocols and methodologies";

17 (2) in subsection (a) -

18 (A) by striking "If the Administrator 19 finds" and inserting "(1) If the Administrator 20 finds";

(B) in paragraph (1), as so designated-

(i) by striking "(1)(A)(i)" and inserting "(A)(i)(I)";

(ii) by striking “(ii)” each place it appears and inserting "(II)"; 
1

2

3

4

5

6

7

8

9

10

11

12

13

14

15

16

17

18

19

20

21

22

23 (iii) by striking "are insufficient data" and inserting "is insufficient information" each place it appears;

(iv) by striking "(iii)" each place it appears and inserting "(III)";

(v) by striking "such data" and inserting "such information" each place it appears;

(vi) by striking “(B)(i)” and inserting "(ii)(I)";

(vii) by striking “(I)" and inserting "(aа)";

(viii) by striking "(II)" and inserting "(bb)";

(ix) by striking "(2)" and inserting "(B)"; and

(x) in the matter following subparagraph (B), as so redesignated-

(I) by inserting ", or, in the case of a chemical substance or mixture described in subparagraph (A)(i), by rule, order, or consent agreement," after "rule"; 
1

2
(II) by striking "data" each place it appears and inserting "information"; and

(III) by striking "and which are relevant" and inserting "and which is relevant"; and

(C) by adding at the end the following:

“(2) Additional Testing AUthority.-In addition to the authority provided under paragraph (1), the Administrator may, by rule, order, or consent agreement-

"(A) require the development of new information relating to a chemical substance or mixture if the Administrator determines that the information is necessary-

"(i) to review a notice under section 5 or to perform a risk evaluation under section 6(b);

"(ii) to implement a requirement imposed in a rule, order, or consent agreement under subsection (e) or (f) of section 5 or in a rule promulgated under section $6(\mathrm{a})$;

"(iii) at the request of a Federal implementing authority under another Fed- 
1

2 eral law, to meet the regulatory testing needs of that authority with regard to toxicity and exposure; or "(iv) pursuant to section $12(\mathrm{a})(2)$;

and

"(B) require the development of new information for the purposes of prioritizing a chemical substance under section $6(\mathrm{~b})$ only if the Administrator determines that such information is necessary to establish the priority of the substance, subject to the limitations that-

"(i) not later than 90 days after the date of receipt of information regarding a chemical substance complying with a rule, order, or consent agreement under this subparagraph, the Administrator shall designate the chemical substance as a highpriority substance or a low-priority substance; and

"(ii) information required by the Administrator under this subparagraph shall not be required for the purposes of establishing or implementing a minimum information requirement of broader applicability. 
"(3) Statement OF NeED.-When requiring

2 the development of new information relating to a

3 chemical substance or mixture under paragraph (2),

4 the Administrator shall identify the need for the new

5 information, describe how information reasonably

6 available to the Administrator was used to inform

7 the decision to require new information, explain the

8 basis for any decision that requires the use of

9 vertebrate animals, and, as applicable, explain why

10 issuance of an order is warranted instead of promul-

11 gating a rule or entering into a consent agreement.

12 "(4) Tiered Testing.-When requiring the

13 development of new information under this sub-

14 section, the Administrator shall employ a tiered

15 screening and testing process, under which the re-

16 sults of screening-level tests or assessments of avail-

17 able information inform the decision as to whether

181 or more additional tests are necessary, unless in-

19 formation available to the Administrator justifies

20 more advanced testing of potential health or environ-

21 mental effects or potential exposure without first

22 conducting screening-level testing.";

$23 \quad$ (3) in subsection (b)-

24 (A) in paragraph (1) - 
1

2

3

4

5

6

7

8

9

10

11

12

13

14

15

16

17

18

19

20

21

22

23

24 (i) in subparagraph (B), by striking "test data" and inserting "information";

(ii) in subparagraph (C), by striking "data" and inserting "information"; and

(iii) in the matter following subparagraph (C), by striking "data" and inserting "information";

(B) in paragraph (2) -

(i) in subparagraph (A)-

(I) by striking "test data" and inserting "information";

(II) by inserting "Protocols and methodologies for the development of information may also be prescribed for the assessment of exposure or exposure potential to humans or the environment." after the first sentence; and

(III) by striking "hierarchical tests" and inserting "tiered testing"; and

(ii) in subparagraph (B), by striking "data" and inserting "information";

(C) in paragraph (3)- 


\section{1}

2

3

4

5

6

7

8

9

10

11

12

13

14

15

16 subsection (a) may require the development of information

17 by any person who manufactures or processes, or intends

18 to manufacture or process, a chemical substance or mix-

19 ture subject to the rule or order.";

20

21

22

23

(i) by striking "data" each place it appears and inserting "information";

(ii) in subparagraph (A), by inserting “or (C), as applicable," after "subparagraph (B)";

(iii) by striking " $(\mathrm{a})(1)(\mathrm{A})(\mathrm{ii})$ or (a)(1)(B)(ii)" each place it appears in subparagraph (B) and inserting "(a)(1)(A)(i)(II) or (a)(1)(A)(ii)(II)";

(iv) in subparagraph (B), in the matter before clause (i), by striking "subsection (a)" and inserting "subsection (a)(1)"; and

(v) by adding at the end the following: “(C) A rule or order under paragraph (1) or (2) of (D) in paragraph (4) -

(i) by striking "of data" each place it appears and inserting "of information"; and 
1 (ii) by striking "test data" each place it appears and inserting "information"; and

(E) by striking paragraph (5);

(4) in subsection (c)-

(A) in paragraph (1), by striking "data" and inserting "information";

(B) in paragraph (2), by striking "data" each place it appears and inserting "information";

(C) in paragraph (3)-

(i) by striking "test data" each place it appears and inserting "information"; and

(ii) by striking "such data" each place it appears and inserting "such information"; and

(D) in paragraph (4) by striking "test data" each place it appears and inserting "information";

(5) in subsection (d)-

(A) by striking "test data" each place it appears and inserting "information";

(B) by striking "such data" each place it appears and inserting "such information"; and 
1
(C) by striking "for which data have" and inserting "for which information has";

(6) in subsection (e)-

(A) in paragraph (1)-

(i) in subparagraph $(\mathrm{A})-$

(I) by striking "promulgation of a rule" and inserting "development of information"; and

(II) by striking "data" each place it appears and inserting "information"; and

(ii) in subparagraph (B), by striking "either initiate a rulemaking proceeding under subsection (a) or if such a proceeding is not initiated within such period, publish in the Federal Register the Administrator's reason for not initiating such a proceeding" and insert "issue an order, enter into a consent agreement, or initiate a rulemaking proceeding under subsection (a), or, if such an order or consent agreement is not issued or such a proceeding is not initiated within such period, publish in the Federal Register the Administrator's reason for not issuing such an order, en- 
1 tering into such a consent agreement, or initiating such a proceeding"'; and (B) in paragraph $(2)(\mathrm{A})-$

(i) by striking "eight members" and inserting "ten members"; and

(ii) by adding at the end the following:

"(ix) One member appointed by the Chairman of the Consumer Product Safety Commission from Commissioners or employees of the Commission.

"(x) One member appointed by the Commissioner of Food and Drugs from employees of the Food and Drug Administration.";

(7) in subsection (f)-

(A) in paragraph (1), by striking "test data" and inserting "information"; and

(B) in the matter following paragraph $(2)-$

(i) by striking "from cancer, gene mutations, or birth defects";

(ii) by striking "data or";

(iii) by striking "appropriate" and inserting "applicable"; and

(iv) by inserting ", made without consideration of costs or other nonrisk fac- 

17 this title, the use of vertebrate animals in the testing 18 of chemical substances or mixtures under this title

19 by-

tors," after "publish in the Federal Register a finding";

(8) in subsection $(\mathrm{g})$ -

(A) by amending the subsection heading to read as follows:"Petition FOR Protocols and Methodologies for the Development OF INFORMATION";

(B) by striking "test data" each place it appears and inserting "information"; and

(C) by striking "submit data" and inserting "submit information"; and (9) by adding at the end the following: “(h) Reduction of Testing on Vertebrates.“(1) IN GENERAL.- The Administrator shall reduce and replace, to the extent practicable, scientifically justified, and consistent with the policies of "(A) prior to making a request or adopting. a requirement for testing using vertebrate animals, and in accordance with subsection (a)(3), taking into consideration, as appropriate and to the extent practicable and scientifically justi- 
1

2 fied, reasonably available existing information, including-

"(i) toxicity information;

"(ii) computational toxicology and bioinformatics; and

"(iii) high-throughput screening methods and the prediction models of those methods; and

"(B) encouraging and facilitating-

"(i) the use of scientifically valid test methods and strategies that reduce or replace the use of vertebrate animals while providing information of equivalent or better scientific quality and relevance that will support regulatory decisions under this title;

"(ii) the grouping of 2 or more chemical substances into scientifically appropriate categories in cases in which testing of a chemical substance would provide scientifically valid and useful information on other chemical substances in the category; and

"(iii) the formation of industry consortia to jointly conduct testing to avoid 
1 unnecessary duplication of tests, provided that such consortia make all information from such testing available to the Administrator.

“(2) Implementation of aLternative testING METHODS.- To promote the development and timely incorporation of new scientifically valid test methods and strategies that are not based on vertebrate animals, the Administrator shall-

"(A) not later than 2 years after the date of enactment of the Frank R. Lautenberg Chemical Safety for the 21st Century Act, develop a strategic plan to promote the development and implementation of alternative test methods and strategies to reduce, refine, or replace vertebrate animal testing and provide information of equivalent or better scientific quality and relevance for assessing risks of injury to health or the environment of chemical substances or mixtures through, for example-

"(i) computational toxicology and bioinformatics;

“(ii) high-throughput screening methods; 
1 "(iii) testing of categories of chemical substances;

"(iv) tiered testing methods;

"(v) in vitro studies;

"(vi) systems biology;

"(vii) new or revised methods identified by validation bodies such as the Interagency Coordinating Committee on the Validation of Alternative Methods or the Organization for Economic Co-operation and Development; or "(viii) industry consortia that develop information submitted under this title; "(B) as practicable, ensure that the strategic plan developed under subparagraph (A) is reflected in the development of requirements for testing under this section;

"(C) include in the strategic plan developed under subparagraph (A) a list, which the Administrator shall update on a regular basis, of particular alternative test methods or strategies the Administrator has identified that do not require new vertebrate animal testing and are scientifically reliable, relevant, and capable of providing information of equivalent or better 
scientific reliability and quality to that which would be obtained from vertebrate animal testing;

“(D) provide an opportunity for public notice and comment on the contents of the plan developed under subparagraph (A), including the criteria for considering scientific reliability and relevance of the test methods and strategies that may be identified pursuant to subparagraph $(\mathrm{C})$;

"(E) beginning on the date that is 5 years after the date of enactment of the Frank R. Lautenberg Chemical Safety for the 21st Century Act, and every 5 years thereafter, submit to Congress a report that describes the progress made in implementing the plan developed under subparagraph (A) and goals for future alternative test methods and strategies implementation; and

"(F) prioritize and, to the extent consistent with available resources and the Administrator's other responsibilities under this title, carry out performance assessment, validation, and translational studies to accelerate the development of scientifically valid test methods and 
strategies that reduce, refine, or replace the use of vertebrate animals, including minimizing duplication, in any testing under this title.

“(3) Voluntary Testing.-

"(A) In GENERAL. - Any person developing information for submission under this title on a voluntary basis and not pursuant to any request or requirement by the Administrator shall first attempt to develop the information by means of an alternative test method or strategy identified by the Administrator pursuant to paragraph (2)(C), if the Administrator has identified such a test method or strategy for the development of such information, before conducting new vertebrate animal testing.

"(B) EFFECT OF PARAGRAPH.-Nothing in this paragraph shall, under any circumstance, limit or restrict the submission of any existing information to the Administrator. "(C) Relationship TO OTHER LAW.-A violation of this paragraph shall not be a prohibited act under section 15 .

“(D) REVIEW OF MEANS._-This paragraph authorizes, but does not require, the Administrator to review the means by which a person 


$$
\text { (A).". }
$$

\section{SEC. 5. MANUFACTURING AND PROCESSING NOTICES.}

4 Section 5 of the Toxic Substances Control Act (15

5 U.S.C. 2604) is amended-

(1) in subsection (a)-

$$
\text { (A) in paragraph (1) - }
$$

(i) by striking "Except as provided in" and inserting "(A) Except as provided in subparagraph (B) of this paragraph and";

(ii) by redesignating subparagraphs (A) and (B) as clauses (i) and (ii), respectively;

(iii) by striking all that follows "significant new use" and inserting a period; and

(iv) by adding at the end the following:

"(B) A person may take the actions described in subparagraph (A) if-

"(i) such person submits to the Administrator, at least 90 days before such manufacture or processing, a notice, in accordance with subsection (d), of such person's intention to 
17 the applicable review period, subject to section 18 , 18 the Administrator shall review such notice and de19 termine-

manufacture or process such substance and such person complies with any applicable requirement of, or imposed pursuant to, subsection (b), (e), or (f); and

"(ii) the Administrator"(I) conducts a review of the notice; and

"(II) makes a determination under subparagraph (A), (B), (C), or (D) of paragraph (3) and takes the actions required in association with that determination under such subparagraph within the applicable review period.'”; and

(B) by adding at the end the following new paragraphs:

\section{“(3) RevieW AND DETERMINATION.-Within}

"(A) that the relevant chemical substance or significant new use presents or will present an unreasonable risk of injury to health or the environment, without consideration of costs or other nonrisk factors, including an unreasonable risk to a potentially exposed or susceptible 
subpopulation identified as relevant by the Administrator under the conditions of use, in which case the Administrator shall take the actions required under subsection (f);

"(B) that-

"(i) the information available to the Administrator is insufficient to permit a reasoned evaluation of the health and environmental effects of the relevant chemical substance or significant new use; or "(ii)(I) in the absence of sufficient information to permit the Administrator to make such an evaluation, the manufacture, processing, distribution in commerce, use, or disposal of such substance, or any combination of such activities, may present an unreasonable risk of injury to health or the environment, without consideration of costs or other nonrisk factors, including an unreasonable risk to a potentially exposed or susceptible subpopulation identified as relevant by the Administrator; or "(II) such substance is or will be produced in substantial quantities, and such substance either enters or may reasonably 
1

2 be anticipated to enter the environment in substantial quantities or there is or may be significant or substantial human exposure to the substance, in which case the Administrator shall take the actions required under subsection (e);

"(C) that the relevant chemical substance or significant new use is likely not to present an unreasonable risk of injury to health or the environment, without consideration of costs or other nonrisk factors, including an unreasonable risk to a potentially exposed or susceptible subpopulation identified as relevant by the Administrator under the conditions of use, in which case the submitter of the notice may commence manufacture of the chemical substance or manufacture or processing for a significant new use; or

"(D) that the relevant chemical substance is a low-hazard substance, in which case the submitter of the notice may commence manufacture of the chemical substance or manufacture or processing of the chemical substance for a significant new use.

“(4) Failure to Render determination.- 
1
"(A) FAilure TO RENDER DETERMinaTION.-If the Administrator fails to make a determination on a notice under paragraph (3) by the end of the applicable review period and the notice has not been withdrawn by the submitter, the Administrator shall refund to the submitter all applicable fees charged to the submitter for review of the notice pursuant to section 26(b), and the Administrator shall not be relieved of any requirement to make such determination.

"(B) Limitations.-(i) A refund of applicable fees under subparagraph (A) shall not be made if the Administrator certifies that the submitter has not provided information required under subsection (b) or has otherwise unduly delayed the process such that the Administrator is unable to render a determination within the applicable review period.

"(ii) A failure of the Administrator to render a decision shall not be deemed to constitute a withdrawal of the notice.

"(iii) Nothing in this paragraph shall be construed as relieving the Administrator or the 
1 submitter of the notice from any requirement of

2 this section.

3 “(5) Article consideration.-The Adminis-

4 trator may require notification under this section for

5 the import or processing of a chemical substance as

6 part of an article or category of articles under para-

7 graph (1)(A)(ii) if the Administrator makes an af-

8 firmative finding in a rule under paragraph (2) that

9 the reasonable potential for exposure to the chemical

10 substance through the article or category of articles

11 subject to the rule justifies notification.";

$12 \quad(2)$ in subsection (b)-

13 (A) in the subsection heading, by striking

14 "TeSt DATA" and inserting "InFORMaTion";

15 (B) in paragraph (1)-

16 (i) in subparagraph (A)-

17 (I) by striking "test data" and

18 inserting "information"; and

19 (II) by striking "such data" and

20 inserting "such information"; and

(ii) in subparagraph (B)-

(I) by striking "test data" and inserting "information"; 
(II) by striking "subsection (a)(1)(A)" and inserting "subsection (a)(1)(A)(i)"; and

(III) by striking "subsection (a)(1)(B)" and inserting "subsection (a)(1)(A)(ii)";

(C) in paragraph (2) -

(i) in subparagraph (A)-

(I) by striking "test data" in clause (ii) and inserting "information";

(II) by striking "shall" and inserting "may"; and

(III) by striking "data prescribed" and inserting "information prescribed"; and

(ii) in subparagraph (B)-

(I) by striking "Data" and inserting "Information";

(II) by striking "data" both places it appears and inserting "information";

(III) by striking "show" and inserting "shows"; 
1

2
(IV) by striking "subsection (a)(1)(A)" in clause (i) and inserting "subsection (a)(1)(A)(i)"; and

(V) by striking "subsection (a)(1)(B)" in clause (ii) and inserting "subsection (a)(1)(A)(ii)";

(D) in paragraph (3)-

(i) by striking "Data" and inserting "Information"; and

(ii) by striking "paragraph (1) or (2)" and inserting "paragraph (1) or (2) of this subsection or under subsection (e)"; and (E) in paragraph (4)-

(i) in subparagraph (A)(i), by inserting ", without consideration of costs or other nonrisk factors" after "health or the environment"; and

(ii) in subparagraph (C), by striking ", except that" and all that follows through "subparagraph (A)";

(3) in subsection (c)-

(A) in the subsection heading, by striking "Notice" and inserting "Review"; and (B) by striking "before which" and all that follows through "subsection may begin"; 
1

2
(4) in subsection (d)-

(A) by striking "test data" in paragraph (1)(B) and inserting "information";

(B) by striking "data" each place it appears in paragraph (1)(C) and paragraph (2) and inserting "information";

(C) in paragraph (2)(B), by striking "uses or intended uses of such substance" and inserting "uses of such substance identified in the notice"; and

(D) in paragraph (3)-

(i) by striking "for which the notification period prescribed by subsection (a), (b), or (c)" and inserting "for which the applicable review period"; and

(ii) by striking "such notification period" and inserting "such period";

(5) in subsection (e)-

(A) in paragraph $(1)(\mathrm{A})-$

(i) in clause (i), by striking "; and" and inserting "; or";

(ii) in clause (ii)(I), by inserting "without consideration of costs or other nonrisk factors, including an unreasonable risk to a potentially exposed subpopulation 
identified as relevant by the Administrator under the conditions of use;" after "health or the environment,"; and

(iii) in the matter after clause (ii)(II)-

(I) by striking "may issue a proposed order" and inserting "shall issue an order";

(II) by striking "notification period applicable to the manufacturing or processing of such substance under subsection (a), (b), (c)" and inserting "applicable review period"; and (III) by inserting "to the extent necessary to protect against an unreasonable risk of injury to health or the environment, without consideration of costs or other nonrisk factors, including an unreasonable risk to a potentially exposed or susceptible subpopulation identified as relevant by the Administrator under the conditions of use, and the submitter of the notice may commence manufacture of the chemical substance, or manufac- 
1

2 ture or processing of the chemical substance for a significant new use, including while any required information is being developed, only in compliance with the order' before the period at the end;

(B) in paragraph (1)(B)-

(i) by striking "A proposed order" and inserting "An order";

(ii) by striking "notification period applicable to the manufacture or processing of such substance under subsection (a), (b), (c)" and inserting "applicable review period'; and

(iii) by striking "of the proposed order" and inserting "of the order";

(C) by striking paragraph (1)(C); and

(D) by striking paragraph (2);

(6) in subsection (f)-

\section{(A) in paragraph (1)-}

(i) by striking "finds that there is a reasonable basis to conclude that the manufacture, processing, distribution in commerce, use, or disposal of a chemical substance with" and inserting "determines 
1 that a chemical substance or significant new use with";

(ii) by striking ", or that any combination of such activities,";

(iii) by striking "before a rule promulgated under section 6 can protect against such risk," and inserting ", without consideration of costs or other nonrisk factors, including an unreasonable risk to a potentially exposed subpopulation identified as relevant by the Administrator under the conditions of use,"; and

(iv) by striking "notification period applicable under subsection (a), (b), or (c) to the manufacturing or processing of such substance" and inserting "applicable review period";

(B) in paragraph (2), the matter following subparagraph (C), by striking "Section $6(\mathrm{~d})(2)(\mathrm{B})$ " and inserting "Section $6(\mathrm{~d})(3)(\mathrm{B}) "$

(C) in paragraph (3)-

(i) in subparagraph $(\mathrm{A})$ -

(I) by striking "Administrator may" and all that follows through 
1

2

3

4

5

6

7

8

9

10

11

12

13

14

15

16

17

18

19

20

21

22

23

24 "issue a proposed order to prohibit the" and inserting "Administrator may issue an order to prohibit or limit the"; and

(II) by striking "under paragraph (1)" and all that follows through "processing of such substance." and inserting "under paragraph (1). Such order shall take effect on the expiration of the applicable review period.";

(ii) by striking subparagraph (B) and redesignating subparagraph (C) as subparagraph $(\mathrm{B})$;

(iii) in subparagraph (B), as so redesignated-

(I) by striking "subparagraphs (B) and (C)" and inserting "subparagraph (B)";

(II) by striking "clause (i) of"; and

(III) by striking "; and the provisions of subparagraph (C) of subsection (e)(2) shall apply with respect 
to an injunction issued under subparagraph (B)',; and

(iv) by striking subparagraph (D); and

(D) by adding at the end the following:

“(4) TreatMent OF NONCONFORMING USES.Not later than 90 days after taking an action under paragraph (2) or (3) or issuing an order under subsection (e) relating to a chemical substance with respect to which the Administrator has made a determination under subsection $(\mathrm{a})(3)(\mathrm{A})$ or $(\mathrm{B})$, the Administrator shall consider whether to promulgate a rule pursuant to subsection (a)(2) that identifies as a significant new use any manufacturing, processing, use, distribution in commerce, or disposal of the chemical substance that does not conform to the restrictions imposed by the action or order, and, as applicable, initiate such a rulemaking or publish a statement describing the reasons of the Administrator for not initiating such a rulemaking.

“(5) WorkPlace ExPOSURES.-To the extent practicable, the Administrator shall consult with the Assistant Secretary of Labor for Occupational Safety and Health prior to adopting any prohibition or other restriction relating to a chemical substance 
1 with respect to which the Administrator has made a

2 determination under subsection $(\mathrm{a})(3)(\mathrm{A})$ or $(\mathrm{B})$ to

3 address workplace exposures.";

$4 \quad$ (7) by amending subsection $(\mathrm{g})$ to read as fol5 lows:

6 " 6 (g) Statement on Administrator Finding.- If

7 the Administrator finds in accordance with subsection

8 (a)(3)(C) that a chemical substance or significant new use

9 is likely not to present an unreasonable risk of injury to

10 health or the environment, or in accordance with sub-

11 section $(\mathrm{a})(3)(\mathrm{D})$ that the chemical substance is a low-haz-

12 ard substance, then notwithstanding any remaining por-

13 tion of the applicable review period, the submitter of the

14 notice may commence manufacture of the chemical sub-

15 stance or manufacture or processing for the significant

16 new use, and the Administrator shall make public a state-

17 ment of the Administrator's finding. Such a statement

18 shall be submitted for publication in the Federal Register

19 as soon as is practicable before the expiration of such pe-

20 riod. Publication of such statement in accordance with the

21 preceding sentence is not a prerequisite to the manufac-

22 turing or processing of the substance with respect to which

23 the statement is to be published.";

$24 \quad(8)$ in subsection $(\mathrm{h})-$ 
17 lows:

22 as used in this section shall not displace any statutory or 23 common law.

24 "(3) For purposes of this section, the term 'applicable 25 review period' means the period starting on the date the 
1 Administrator receives a notice under subsection (a)(1)

2 and ending 90 days after that date, or on such date as

3 is provided for in subsection (b)(1) or (c).".

4 SEC. 6. PRIORITIZATION, RISK EVALUATION, AND REGULATION OF CHEMICAL SUBSTANCES AND MIXTURES.

7 Section 6 of the Toxic Substances Control Act (15

8 U.S.C. 2605) is amended-

9 (1) by striking the section heading and insert-

10 ing "PRIORITIZATION, RISK EVALUATION, AND

11 REGULATION OF CHEMICAL SUBSTANCES AND

12 MIXTURES";

13 (2) in subsection (a) -

14 (A) by striking "finds that there is a rea15 sonable basis to conclude" and inserting "deter16 mines in accordance with subsection $(\mathrm{b})(4)(\mathrm{A})$ ";

17 (B) by inserting "and subject to section 18 18, and in accordance with subsection (c)(2)," 19 after "shall by rule";

20 (C) by striking "to protect adequately 21 against such risk using the least burdensome 22 requirements" and inserting "so that the chem23 ical substance or mixture no longer presents 24 such risk"; 
1

16 lows:
(D) by inserting "or otherwise restricting", after "prohibiting" in paragraphs (1)(A) and (2) $(\mathrm{A})$;

(E) by inserting "minimum" before "warnings" both places it appears in paragraph (3); (F) by striking "and monitor or conduct tests" and inserting "or monitor or conduct tests" in paragraph (4); and

(G) in paragraph $(7)-$

(i) by striking "such unreasonable risk of injury" and inserting "such determination'; and

(ii) by striking "such risk of injury" and inserting "such determination";

(3) by amending subsection (b) to read as fol- 
substances as high-priority substances for risk evaluations or low-priority substances for which risk evaluations are not warranted at the time. The process to designate the priority of chemical substances shall include a consideration of the hazard and exposure potential of a chemical substance or a category of chemical substances (including consideration of persistence and bioaccumulation, potentially exposed or susceptible subpopulations and storage near significant sources of drinking water), the conditions of use or significant changes in the conditions of use of the chemical substance, and the volume or significant changes in the volume of the chemical substance manufactured or processed.

"(B) IDENTIFICATION OF PRIORITIES FOR RISK EVALUATION.-

"(i) High-PRIORITY SUBStanCES.The Administrator shall designate as a high-priority substance a chemical substance that the Administrator concludes, without consideration of costs or other nonrisk factors, may present an unreasonable risk of injury to health or the environment because of a potential hazard and a 
potential route of exposure under the conditions of use, including an unreasonable risk to a potentially exposed or susceptible subpopulation identified as relevant by the Administrator.

\section{“(ii) LOW-PRIORITY SUBSTANCES.-} Except as provided in clause (iii), the Administrator shall designate a chemical substance as a low-priority substance if the Administrator concludes, based on information sufficient to establish, without consideration of costs or other nonrisk factors, that such substance does not meet the standard identified in clause (i) for designating a chemical substance a high-priority substance.

"(iii) LOW-HAZARD SUBSTANCES.The Administrator may designate a lowpriority substance as a low-hazard substance if the Administrator concludes, based on information sufficient to establish, without consideration of costs or other nonrisk factors or exposure, that the chemical substance poses no or low hazard to health or the environment, including any 
hazard to a potentially exposed or susceptible subpopulation identified as relevant by the Administrator.

"(C) INFORMATION REQUEST AND REVIEW AND PROPOSED AND FINAL PRIORITIZATION DESIGNATION.-The rulemaking required in subparagraph (A) shall ensure that the time required to make a priority designation of a chemical substance be no shorter than nine months and no longer than 1 year, and that the process for such designations includes-

"(i) a requirement that the Administrator request interested persons to submit relevant information on a chemical substance that the Administrator has initiated the prioritization process on, before proposing a priority designation for the chemical substance, and provide 90 days for such information to be provided; "(ii) a requirement that the Administrator publish each proposed designation of a chemical substance as a high- or low-priority substance, along with an identification of the information, analysis, and basis used to make the proposed designations, 
1 and provide 90 days for public comment on each such proposed designation; and "(iii) a process by which the Administrator may extend the deadline in clause (i) for up to three months in order to receive or evaluate information required to be submitted in accordance with section $4(\mathrm{a})(2)(\mathrm{B})$, subject to the limitation that if the information available to the Administrator at the end of such an extension remains insufficient to enable the designation of the chemical substance as a low-priority substance, the Administrator shall designate the chemical substance as a high-priority substance.

“(2) Initial Risk EVALUATIONS AND SUBSEQUENT DESIGNATIONS OF HIGH- AND LOW-PRIORITY SUBSTANCES.-

"(A) INITIAL RISK EVALUATIONS.-Not later than 180 days after the date of enactment of the Frank R. Lautenberg Chemical Safety for the 21st Century Act, the Administrator shall ensure that risk evaluations are being conducted on at least 10 chemical substances drawn from the 2014 update of the TSCA 
Work Plan for Chemical Assessments and shall publish the list of such chemical substances during the 180 day period.

“(B) AdDitional Risk evaluations.Not later than three and one half years after the date of enactment of the Frank R. Lautenberg Chemical Safety for the 21st Century Act, the Administrator shall ensure that risk evaluations are being conducted on at least 20 highpriority substances and that at least 20 chemical substances have been designated as low-priority or low-hazard substances, subject to the limitation that at least 50 percent of all chemical substances on which risk evaluations are being conducted by the Administrator are drawn from the 2014 update of the TSCA Work Plan for Chemical Assessments.

\section{“(C) Continuing Designations And} RISK EVALUATIONS.-The Administrator shall continue to designate priority substances and conduct risk evaluations in accordance with this subsection at a pace consistent with the ability of the Administrator to complete risk evaluations in accordance with the deadlines under paragraph $(4)(G)$. 
"(D) Preference.-In designating highpriority substances, the Administrator shall give preference to-

"(i) chemical substances that are listed in the 2014 update of the TSCA Work Plan for Chemical Assessments as having a Persistence and Bioaccumulation Score of 3 ; and

"(ii) chemical substances that are listed in the 2014 update of the TSCA Work Plan for Chemical Assessments that are known human carcinogens and have high acute and chronic toxicity.

"(E) Metals and metal Compounds.In identifying priorities for risk evaluation and conducting risk evaluations of metals and metal compounds, the Administrator shall use the Framework for Metals Risk Assessment of the Office of the Science Advisor, Risk Assessment Forum, and dated March 2007, or a successor document that addresses metals risk assessment and is peer reviewed by the Science Advisory Board.

“(3) Initiation of Risk Evaluations; DES- 
1
"(A) Risk EVALUATION INITLATION.Upon designating a chemical substance as a high-priority substance, the Administrator shall initiate a risk evaluation on the substance.

"(B) Revision.-The Administrator may revise the designation of a low-priority substance or a low-hazard substance based on information made available to the Administrator. "(C) Ongoing Designations. - The Administrator shall designate at least one highpriority substance upon the completion of each risk evaluation (other than risk evaluations for chemical substances designated under paragraph $(4)(\mathrm{C})(\mathrm{ii}))$.

“(4) Risk EVAluation PROCESS AND DEADLINES.- -

"(A) IN GENERAL.-The Administrator shall conduct risk evaluations pursuant to this paragraph to determine whether a chemical substance presents an unreasonable risk of injury to health or the environment, without consideration of costs or other nonrisk factors, including an unreasonable risk to a potentially exposed or susceptible subpopulation identified as 
relevant to the risk evaluation by the Administrator, under the conditions of use.

"(B) Establishment of PRocess.-Not later than 1 year after the date of enactment of the Frank R. Lautenberg Chemical Safety for the 21st Century Act, the Administrator shall establish, by rule, a process to conduct risk evaluations in accordance with subparagraph (A).

"(C) Requirement.-The Administrator shall conduct and publish risk evaluations, in accordance with the rule promulgated under subparagraph (B), for a chemical substance-

"(i) that has been identified under paragraph (2)(A) or designated under paragraph (1)(B)(i); and

“(ii) subject to subparagraph (E), that a manufacturer of the chemical substance has requested, in a form and manner and using the criteria prescribed by the Administrator in the rule promulgated under subparagraph (B), be subjected to a risk evaluation.

"(D) SCOPE.-The Administrator shall, not later than 6 months after the initiation of 
a risk evaluation, publish the scope of the risk evaluation to be conducted, including the hazards, exposures, conditions of use, and the potentially exposed or susceptible subpopulations the Administrator expects to consider, and, for each designation of a high-priority substance, ensure not less than 12 months between the initiation of the prioritization process for the chemical substance and the publication of the scope of the risk evaluation for the chemical substance, and for risk evaluations conducted on chemical substances that have been identified under paragraph (2)(A) or selected under subparagraph (E)(iv)(II) of this paragraph, ensure not less than 3 months before the Administrator publishes the scope of the risk evaluation.

\section{“(E) LIMITATION AND CRITERIA.-}

“(i) Percentage Requirements.The Administrator shall ensure that, of the number of chemical substances that undergo a risk evaluation under clause (i) of subparagraph $(\mathrm{C})$, the number of chemical substances undergoing a risk evaluation under clause (ii) of subparagraph (C) is- 
1

2
"(I) not less than 25 percent, if sufficient requests are made under clause (ii) of subparagraph (C); and

"(II) not more than 50 percent. “(ii) Requested Risk evaluaTIONS.-Requests for risk evaluations under subparagraph (C)(ii) shall be subject to the payment of fees pursuant to section 26(b), and the Administrator shall not expedite or otherwise provide special treatment to such risk evaluations.

“(iii) Preference.-In deciding whether to grant requests under subparagraph (C)(ii), the Administrator shall give preference to requests for risk evaluations on chemical substances for which the Administrator determines that restrictions imposed by 1 or more States have the potential to have a significant impact on interstate commerce or health or the environment.

$$
\text { "(iv) Exceptions.-(I) Chemical }
$$
substances for which requests have been granted under subparagraph (C)(ii) and that are not drawn from the 2014 update 
1 of the TSCA Work Plan for Chemical Assessments shall not be subject to section 18(b).

"(II) Requests for risk evaluations on chemical substances which are made under subparagraph (C)(ii) and that are drawn from the 2014 update of the TSCA Work Plan for Chemical Assessments shall be granted at the discretion of the Administrator and not be subject to clause (i)(II). "(F) Requirements.-In conducting a risk evaluation under this subsection, the Administrator shall-

"(i) integrate and assess available information on hazards and exposures for the conditions of use of the chemical substance, including information that is relevant to specific risks of injury to health or the environment and information on potentially exposed or susceptible subpopulations identified as relevant by the Administrator; "(ii) describe whether aggregate or sentinel exposures to a chemical substance under the conditions of use were considered, and the basis for that consideration; 
"(iii) not consider costs or other nonrisk factors;

"(iv) take into account, where relevant, the likely duration, intensity, frequency, and number of exposures under the conditions of use of the chemical substance; and

"(v) describe the weight of the scientific evidence for the identified hazard and exposure.

"(G) Deadlines. - The Administrator-

"(i) shall complete a risk evaluation for a chemical substance as soon as practicable, but not later than 3 years after the date on which the Administrator initiates the risk evaluation under subparagraph (C); and

"(ii) may extend the deadline for a risk evaluation for not more than 6 months.

"(H) Notice AND COMment.-The Administrator shall provide no less than 30 days public notice and an opportunity for comment on a draft risk evaluation prior to publishing a final risk evaluation."; 
(4) by amending subsection (c) to read as fol-

2 lows:

3 “(c) Promulgation of Subsection (a) Rules.-

4 “(1) DEADLINES.-If the Administrator deter-

5 mines that a chemical substance presents an unrea-

6 sonable risk of injury to health or the environment

7 in accordance with subsection (b)(4)(A), the Admin-

8 istrator-

9 "(A) shall propose in the Federal Register

10 a rule under subsection (a) for the chemical

11 substance not later than 1 year after the date

12 on which the final risk evaluation regarding the

13 chemical substance is published;

14 "(B) shall publish in the Federal Register

15 a final rule not later than 2 years after the date

16 on which the final risk evaluation regarding the

17 chemical substance is published; and

18 "(C) may extend the deadlines under this

19 paragraph for not more than two years, subject

20 to the condition that the aggregate length of ex-

21 tensions under this subparagraph and sub-

22 section $(b)(4)(G)(i i)$ does not exceed two years,

23 and subject to the limitation that the Adminis-

24 trator may not extend a deadline for the publi-

25 cation of a proposed or final rule regarding a 
1 chemical substance drawn from the 2014 up-

2 date of the TSCA Work Plan for Chemical As-

3 sessments or a chemical substance that, with

4 respect to persistence and bioaccumulation,

5 scores high for 1 and either high or moderate

6 for the other, pursuant to the TSCA Work Plan

7 Chemicals Methods Document published by the

8 Administrator in February 2012 (or a successor

9 scoring system), without adequate public jus-

10 tification that demonstrates, following a review

11 of the information reasonably available to the

12 Administrator, that the Administrator cannot

13 complete the proposed or final rule without ad-

14 ditional information regarding the chemical

15 substance.

“(2) Requirements FOR RULe.-

“(A) Statement of efFects.-In pro-

posing and promulgating a rule under sub-

19 section (a) with respect to a chemical substance

20 or mixture, the Administrator shall consider

and publish a statement based on reasonably

available information with respect to-

"(i) the effects of the chemical sub- 
1 nitude of the exposure of human beings to the chemical substance or mixture;

"(ii) the effects of the chemical substance or mixture on the environment and the magnitude of the exposure of the environment to such substance or mixture; "(iii) the benefits of the chemical substance or mixture for various uses; and "(iv) the reasonably ascertainable economic consequences of the rule, including consideration of-

"(I) the likely effect of the rule on the national economy, small business, technological innovation, the environment, and public health;

"(II) the costs and benefits of the proposed and final regulatory action and of the 1 or more primary alternative regulatory actions considered by the Administrator; and

"(III) the cost effectiveness of the proposed regulatory action and of the 1 or more primary alternative regulatory actions considered by the Administrator. 
"(B) Selecting Requirements.-In selecting among prohibitions and other restrictions, the Administrator shall factor in, to the extent practicable, the considerations under subparagraph (A) in accordance with subsection (a).

"(C) Consideration OF ALterNATIVES.-Based on the information published under subparagraph (A), in deciding whether to prohibit or restrict in a manner that substantially prevents a specific condition of use of a chemical substance or mixture, and in setting an appropriate transition period for such action, the Administrator shall consider, to the extent practicable, whether technically and economically feasible alternatives that benefit health or the environment, compared to the use so proposed to be prohibited or restricted, will be reasonably available as a substitute when the proposed prohibition or other restriction takes effect.

“(D) Replacement PaRTs.-

"(i) IN GENERAL.—The Administrator shall exempt replacement parts for complex durable goods and complex consumer goods 
that are designed prior to the date of publication in the Federal Register of the rule under subsection (a), unless the Administrator finds that such replacement parts contribute significantly to the risk, identified in a risk evaluation conducted under subsection $(b)(4)(A)$, to the general population or to an identified potentially exposed or susceptible subpopulation.

"(ii) Definitions.-In this subparagraph-

"(I) the term 'complex consumer goods' means electronic or mechanical devices composed of multiple manufactured components, with an intended useful life of 3 or more years, where the product is typically not consumed, destroyed, or discarded after a single use, and the components of which would be impracticable to redesign or replace; and

"(II) the term 'complex durable goods' means manufactured goods composed of 100 or more manufactured components, with an intended 
1

2 useful life of 5 or more years, where the product is typically not consumed, destroyed, or discarded after a single use.

"(E) ARTICLES.-In selecting among prohibitions and other restrictions, the Administrator shall apply such prohibitions or other restrictions to an article or category of articles containing the chemical substance or mixture only to the extent necessary to address the identified risks from exposure to the chemical substance or mixture from the article or category of articles so that the substance or mixture does not present an unreasonable risk of injury to health or the environment identified in the risk evaluation conducted in accordance with subsection $(\mathrm{b})(4)(\mathrm{A})$.

“(3) Procedures.-When prescribing a rule under subsection (a) the Administrator shall proceed in accordance with section 553 of title 5, United States Code (without regard to any reference in such section to sections 556 and 557 of such title), and shall also- 
"(A) publish a notice of proposed rulemaking stating with particularity the reason for the proposed rule;

"(B) allow interested persons to submit written data, views, and arguments, and make all such submissions publicly available;

"(C) promulgate a final rule based on the matter in the rulemaking record; and

"(D) make and publish with the rule the determination described in subsection (a).';

(5) in subsection (d)-

(A) by redesignating paragraph (2) as paragraph $(3)$;

(B) by striking paragraph (1) and inserting the following:

“(1) IN GENERAL.-In any rule under subsection (a), the Administrator shall-

"(A) specify the date on which it shall take effect, which date shall be as soon as practicable;

"(B) except as provided in subparagraphs (C) and (D), specify mandatory compliance dates for all of the requirements under a rule under subsection (a), which shall be as soon as practicable, but not later than 5 years after the 
1

17 ministrator, the compliance dates established under

18 paragraph (1) may vary for different affected per-

19 sons.'; and

date of promulgation of the rule, except in a case of a use exempted under subsection (g);

"(C) specify mandatory compliance dates for the start of ban or phase-out requirements under a rule under subsection (a), which shall be as soon as practicable, but not later than 5 years after the date of promulgation of the rule, except in the case of a use exempted under subsection $\left(g^{)}\right)$

"(D) specify mandatory compliance dates for full implementation of ban or phase-out requirements under a rule under subsection (a), which shall be as soon as practicable; and

"(E) provide for a reasonable transition period.

“(2) VARIABILITY. - As determined by the Ad(C) in paragraph (3), as so redesignated by subparagraph (A) of this paragraph-

(i) in subparagraph $(\mathrm{A})$ -

(I) by striking "upon its publication" and all that follows through "respecting such rule if" and inserting ", 
1

and compliance with the proposed requirements to be mandatory, upon publication in the Federal Register of the proposed rule and until the compliance dates applicable to such requirements in a final rule promulgated under section 6(a) or until the Administrator revokes such proposed rule, in accordance with subparagraph (B), if''; and

(II) in clause (i)(I), by inserting "without consideration of costs or other non-risk factors" after "effective date"; and

(ii) in subparagraph (B), by striking “, provide reasonable opportunity" and all that follows through the period at the end and inserting "in accordance with subsection (c), and either promulgate such rule (as proposed or with modifications) or revoke it.";

(6) in subsection (e)(4), by striking "paragraphs (2), (3), and (4)" and inserting "paragraph (3)" ; and 
(7) by adding at the end the following new sub-

2 sections:

3 " $3(\mathrm{~g})$ EXEMPTIONS.-

4 “(1) Criteria FOR Exemption.-The Admin-

5 istrator may, as part of a rule promulgated under

6 subsection (a), or in a separate rule, grant an ex-

7 emption from a requirement of a subsection (a) rule

8 for a specific condition of use of a chemical sub-

9 stance or mixture, if the Administrator finds that-

10 "(A) the specific condition of use is a crit-

11 ical or essential use for which no technically

12 and economically feasible safer alternative is

13 available, taking into consideration hazard and

14 exposure;

15 "(B) compliance with the requirement, as

16 applied with respect to the specific condition of

17 use, would significantly disrupt the national

18 economy, national security, or critical infra-

19 structure; or

20 "(C) the specific condition of use of the

21 chemical substance or mixture, as compared to

22 reasonably available alternatives, provides a

23 substantial benefit to health, the environment,

24 or public safety. 
1
“(2) EXEMPTION ANALYSIS AND STATEMENT.In proposing an exemption under this subsection, the Administrator shall analyze the need for the exemption, and shall make public the analysis and a statement describing how the analysis was taken into account.

“(3) Period OF EXEMPtion.-The Administrator shall establish, as part of a rule under this subsection, a time limit on any exemption for a time to be determined by the Administrator as reasonable on a case-by-case basis, and, by rule, may extend, modify, or eliminate an exemption if the Administrator determines, on the basis of reasonably available information and after adequate public justification, the exemption warrants extension or modification or is no longer necessary.

“(4) Conditions.-As part of a rule promulgated under this subsection, the Administrator shall include conditions, including reasonable recordkeeping, monitoring, and reporting requirements, to the extent that the Administrator determines the conditions are necessary to protect health and the environment while achieving the purposes of the exemption. 
1 “(h) Chemicals That Are Persistent, Bio2 accumulative, and Toxic.-

4 years after the date of enactment of the Frank R.

5 Lautenberg Chemical Safety for the 21st Century

6 Act, the Administrator shall propose rules under

$7 \quad$ subsection (a) with respect to chemical substances

8 identified in the 2014 update of the TSCA Work

$9 \quad$ Plan for Chemical Assessments-

10 "(A) that the Administrator has a reason11 able basis to conclude are toxic and that with 12 respect to persistence and bioaccumulation 13 score high for one and either high or moderate 14 for the other, pursuant to the TSCA Work Plan 15 Chemicals Methods Document published by the 16 Administrator in February 2012 (or a successor 17 scoring system), and are not a metal or a metal 18 compound, and for which the Administrator has not completed a Work Plan Problem Formulation, initiated a review under section 5, or entered into a consent agreement under section 4, prior to the date of enactment of the Frank R. Lautenberg Chemical Safety for the 21st Century Act; and 
"(B) exposure to which under the conditions of use is likely to the general population or to a potentially exposed or susceptible subpopulation identified by the Administrator, or the environment, on the basis of an exposure and use assessment conducted by the Administrator.

“(2) No Risk EVALUATiOn REQUired.-The Administrator shall not be required to conduct risk evaluations on chemical substances that are subject to paragraph (1).

“(3) Final RULE.-Not later than 18 months after proposing a rule pursuant to paragraph (1), the Administrator shall promulgate a final rule under subsection (a).

“(4) SELECTING RESTRICTIONS.-In selecting among prohibitions and other restrictions promulgated in a rule under subsection (a) pursuant to paragraph (1), the Administrator shall address the risks of injury to health or the environment that the Administrator determines are presented by the chemical substance and shall reduce exposure to the substance to the extent practicable.

“(5) Relationship TO subsection (b).- - If, at any time prior to the date that is 90 days after 
1 the date of enactment of the Frank R. Lautenberg

2 Chemical Safety for the 21st Century Act, the Ad-

3 ministrator makes a designation under subsection

$4 \quad(\mathrm{~b})(1)(\mathrm{B})(\mathrm{i})$, or receives a request under subsection

$5 \quad(b)(4)(C)($ ii) that meets the criteria prescribed by

6 the Administrator in the rule promulgated under

7 subsection $(\mathrm{b})(4)(\mathrm{B})$, such chemical substance shall

8 not be subject to this subsection, except that in se-

9 lecting among prohibitions and other restrictions

10 promulgated in a rule pursuant to subsection (a),

11 the Administrator shall both ensure that the chem-

12 ical substance meets the rulemaking standard under

13 subsection (a) and reduce exposure to the substance

14 to the extent practicable.

15 "(i) Final AgEnCy ACTiOn.-Under this section

16 and subject to section 18

17 "(1) a determination by the Administrator 18 under subsection $(\mathrm{b})(4)(\mathrm{A})$ that a chemical sub19 stance does not present an unreasonable risk of in20 jury to health or the environment shall be issued by 21 order and considered to be a final agency action, ef22 fective beginning on the date of issuance of the 23 order; and

24 "(2) a final rule promulgated under subsection 25 (a), including the associated determination by the 
63

1 Administrator under subsection (b)(4)(A) that a

2 chemical substance presents an unreasonable risk of

3 injury to health or the environment, shall be consid-

4 ered to be a final agency action, effective beginning

5 on the date of promulgation of the final rule.

6 "(j) Definition.-For the purposes of this Act, the

7 term 'requirement' as used in this section shall not dis-

8 place statutory or common law.".

9 SEC. 7. IMMINENT HAZARDS.

10 Section 7 of the Toxic Substances Control Act (15

11 U.S.C. 2606) is amended-

12 (1) in subsection (b)(1), by inserting "(as iden-

13 tified by the Administrator without consideration of

14 costs or other nonrisk factors)" after "from the un-

15 reasonable risk"; and

16 (2) in subsection (f), by inserting ", without

17 consideration of costs or other nonrisk factors" after

18 "widespread injury to health or the environment".

19 SEC. 8. REPORTING AND RETENTION OF INFORMATION.

20 (a) In General.-Section 8 of the Toxic Substances

21 Control Act (15 U.S.C. 2607) is amended-

22

(1) in subsection (a)-

23

(A) in paragraph (2), by striking the matter that follows subparagraph $(\mathrm{G})$; 
(B) in paragraph (3), by adding at the end the following:

3 "(C) Not later than 180 days after the date of enact4 ment of the Frank R. Lautenberg Chemical Safety for the 5 21st Century Act, and not less frequently than once every 610 years thereafter, the Administrator, after consultation 7 with the Administrator of the Small Business Administra8 tion, shall-

9 "(i) review the adequacy of the standards pre10 scribed under subparagraph (B); and

11 “(ii) after providing public notice and an oppor12 tunity for comment, make a determination as to 13 whether revision of the standards is warranted."; 14 and

(C) by adding at the end the following: “(4) Contents.-The rules promulgated pur17 suant to paragraph (1)-

"(A) may impose differing reporting and recordkeeping requirements on manufacturers and processors; and

"(B) shall include the level of detail necessary to be reported, including the manner by which use and exposure information may be reported. 
“(5) Administration.-In carrying out this

2 section, the Administrator shall, to the extent fea-

3 sible-

"(A) not require reporting which is unnecessary or duplicative;

"(B) minimize the cost of compliance with this section and the rules issued thereunder on small manufacturers and processors; and those persons likely to have information relevant to the effective implementation of this title.

“(6) Negotiated Rulemaking.-(A) The Ad-

14 ministrator shall enter into a negotiated rulemaking 15 pursuant to subchapter III of chapter 5 of title 5 , 16 United States Code, to develop and publish, not 17 later than 3 years after the date of enactment of the 18 Frank R. Lautenberg Chemical Safety for the 21st 19 Century Act, a proposed rule providing for limiting 20 the reporting requirements, under this subsection, 21 for manufacturers of any inorganic byproducts, 22 when such byproducts, whether by the byproduct 23 manufacturer or by any other person, are subse24 quently recycled, reused, or reprocessed. 
"(B) Not later than 3 and one-half years after

2 such date of enactment, the Administrator shall pub-

3 lish a final rule resulting from such negotiated rule-

4 making."; and

5 (2) in subsection (b), by adding at the end the

6 following:

7

8

9

10

11

12

13

14

15

16

17

18

19
“(3) Nomenclature.-

"(A) In GENERAL.—In carrying out paragraph (1), the Administrator shall-

"(i) maintain the use of Class 2 nomenclature in use on the date of enactment of the Frank R. Lautenberg Chemical Safety for the 21st Century Act; "(ii) maintain the use of the Soap and Detergent Association Nomenclature System, published in March 1978 by the Administrator in section 1 of addendum III of the document entitled 'Candidate List of Chemical Substances', and further described in the appendix A of volume I of the 1985 edition of the Toxic Substances Control Act Substances Inventory (EPA Document No. EPA-560/7-85-002a); and "(iii) treat the individual members of the categories of chemical substances iden- 
1 tified by the Administrator as statutory mixtures, as defined in Inventory descriptions established by the Administrator, as being included on the list established under paragraph (1).

“(B) Multiple NOMEnClature ListINGS.-If a manufacturer or processor demonstrates to the Administrator that a chemical substance appears multiple times on the list published under paragraph (1) under different CAS numbers, the Administrator may recognize the multiple listings as a single chemical substance.

"(C) Relationship TO SECTiOn 5.Nothing in subparagraph (B), nor any action of the Administrator pursuant to subparagraph (B), shall be construed as a basis to conclude that any chemical substance is not a new chemical substance.

"(4) Chemical substances IN COMmerce."(A) Rules.-

"(i) IN GENERAL.-Not later than 1 year after the date of enactment of the Frank R. Lautenberg Chemical Safety for the 21st Century Act, the Administrator, 
68

1

2

3

4

5

6

7

8

9

10

11

12

13

14

15

16

17

18

19

20

21

22

23

24 by rule, shall require manufacturers, and may require processors, subject to the limitations under subsection (a)(5)(A), to notify the Administrator, by not later than 180 days after the date on which the final rule is published in the Federal Register, of each chemical substance on the list published under paragraph (1) that the manufacturer or processor, as applicable, has manufactured or processed for a nonexempt commercial purpose during the 10year period ending on the day before the date of enactment of the Frank R. Lautenberg Chemical Safety for the 21st Century Act.

"(ii) Active substances.-The Administrator shall designate chemical substances for which notices are received under clause (i) to be active substances on the list published under paragraph (1).

“(iii) Inactive substances.-The Administrator shall designate chemical substances for which no notices are received under clause (i) to be inactive sub- 
1 stances on the list published under paragraph (1).

"(iv) Limitation.-No chemical substance on the list published under paragraph (1) shall be removed from such list by reason of the implementation of this subparagraph, or be subject to section $5(\mathrm{a})(1)(\mathrm{A})(\mathrm{i})$ by reason of a change to active status under paragraph (5)(B).

"(B) Confidential Chemical SubSTANCES.-In promulgating a rule under subparagraph (A), the Administrator shall-

"(i) maintain the list under paragraph (1), which shall include a confidential portion and a nonconfidential portion consistent with this section and section 14; "(ii) require any manufacturer or processor of a chemical substance on the confidential portion of the list published under paragraph (1) that seeks to maintain an existing claim for protection against disclosure of the specific chemical identity of the chemical substance as confidential pursuant to section 14 to submit 
a notice under subparagraph (A) that includes such request;

"(iii) require the substantiation of those claims pursuant to section 14 and in accordance with the review plan described in subparagraph $(\mathrm{C})$; and "(iv) move any active chemical substance for which no request was received to maintain an existing claim for protection against disclosure of the specific chemical identity of the chemical substance as confidential from the confidential portion of the list published under paragraph (1) to the nonconfidential portion of that list. "(C) Review Plan.-Not later than 1 year after the date on which the Administrator compiles the initial list of active substances pursuant to subparagraph (A), the Administrator shall promulgate a rule that establishes a plan to review all claims to protect the specific chemical identities of chemical substances on the confidential portion of the list published under paragraph (1) that are asserted pursuant to subparagraph (B). 
1
“(D) REQUIREMENTS OF REVIEW PLAN.In establishing the review plan under subparagraph (C), the Administrator shall-

"(i) require, at a time specified by the Administrator, all manufacturers or processors asserting claims under subparagraph (B) to substantiate the claim, in accordance with section 14 , unless the manufacturer or processor has substantiated the claim in a submission made to the Administrator during the 5-year period ending on the last day of the of the time period specified by the Administrator; and "(ii) in accordance with section 14“(I) review each substantiation"(aa) submitted pursuant to clause (i) to determine if the claim qualifies for protection from disclosure; and

“(bb) submitted previously by a manufacturer or processor and relied on in lieu of the substantiation required pursuant to clause (i), if the substantiation has not been previously reviewed 
1

2

3

4

5

6

7

8

9

10

11

12

13

14

15

16

17

18

19

20

21

22

23

24

25 by the Administrator, to determine if the claim warrants protection from disclosure;

“(II) approve, approve in part and deny in part, or deny each claim; and

"(III) except as provided in this section and section 14, protect from disclosure information for which the Administrator approves such a claim for a period of 10 years, unless, prior to the expiration of the period-

"(aa) the person notifies the Administrator that the person is withdrawing the claim, in which case the Administrator shall not protect the information from disclosure; or

"(bb) the Administrator otherwise becomes aware that the information does not qualify for protection from disclosure, in which case the Administrator shall take the actions described in section $14(\mathrm{~g})(2)$. 
1
“(E) Timeline for COMpletion OF REVIEWS.-

“(i) IN GENERAL.—The Administrator shall implement the review plan so as to complete reviews of all claims specified in subparagraph (C) not later than 5 years after the date on which the Administrator compiles the initial list of active substances pursuant to subparagraph (A). "(ii) Considerations."(I) IN GENERAL.-The Administrator may extend the deadline for completion of the reviews for not more than 2 additional years, after an adequate public justification, if the Administrator determines that the extension is necessary based on the number of claims needing review and the available resources.

“(II) Annual Review gOAL AND RESULTS.-At the beginning of each year, the Administrator shall publish an annual goal for reviews and the number of reviews completed in the prior year. 


\section{“(5) ACtive and inactive substances.-}

"(A) IN GENERAL.-The Administrator shall keep designations of active substances and inactive substances on the list published under paragraph (1) current.

“(B) Change to active status.-

"(i) IN GENERAL.-Any person that intends to manufacture or process for a nonexempt commercial purpose a chemical substance that is designated as an inactive substance shall notify the Administrator before the date on which the inactive substance is manufactured or processed.

“(ii) Confidential Chemical IDENTITY.-If a person submitting a notice under clause (i) for an inactive substance on the confidential portion of the list published under paragraph (1) seeks to maintain an existing claim for protection against disclosure of the specific chemical identity of the inactive substance as confidential, the person shall, consistent with the requirements of section $14-$

"(I) in the notice submitted under clause (i), assert the claim; and 
1
"(II) by not later than 30 days after providing the notice under clause (i), substantiate the claim.

“(iii) ACTIVE Status.-On receiving a notification under clause (i), the Administrator shall-

"(I) designate the applicable chemical substance as an active substance;

"(II) pursuant to section 14, promptly review any claim and associated substantiation submitted pursuant to clause (ii) for protection against disclosure of the specific chemical identity of the chemical substance and approve, approve in part and deny in part, or deny the claim; "(III) except as provided in this section and section 14, protect from disclosure the specific chemical identity of the chemical substance for which the Administrator approves a claim under subclause (II) for a period of 10 years, unless, prior to the expiration of the period- 
1

2

3

4

5

6

7

8

9

10

11

12

13

14

15

16

17

18

19

20

21

22

23

24 "(aa) the person notifies the Administrator that the person is withdrawing the claim, in which case the Administrator shall not protect the information from disclosure; or

"(bb) the Administrator otherwise becomes aware that the information does not qualify for protection from disclosure, in which case the Administrator shall take the actions described in section $14(\mathrm{~g})(2)$; and "(IV) pursuant to section 6(b), review the priority of the chemical substance as the Administrator determines to be necessary.

"(C) Category status.-The list of inactive substances shall not be considered to be a category for purposes of section 26(c).

“(6) INTERIM List OF ACTIVE substanCES.Prior to the promulgation of the rule required under paragraph (4)(A), the Administrator shall designate the chemical substances reported under part 711 of title 40, Code of Federal Regulations (as in effect on 
1 the date of enactment of the Frank R. Lautenberg

2 Chemical Safety for the 21st Century Act), during

3 the reporting period that most closely preceded the

4 date of enactment of the Frank R. Lautenberg

$5 \quad$ Chemical Safety for the 21st Century Act, as the in-

6 terim list of active substances for the purposes of

7 section $6(b)$.

8 “(7) Public Information.-Subject to this

9 subsection and section 14, the Administrator shall

10 make available to the public-

11 "(A) each specific chemical identity on the 12 nonconfidential portion of the list published 13 under paragraph (1) along with the Administra14 tor's designation of the chemical substance as 15 an active or inactive substance;

16 "(B) the unique identifier assigned under 17 section 14 , accession number, generic name, 18 and, if applicable, premanufacture notice case 19 number for each chemical substance on the con20 fidential portion of the list published under 21 paragraph (1) for which a claim of confiden22 tiality was received; and

23 "(C) the specific chemical identity of any 24 active substance for which- 
1 "(i) a claim for protection against disclosure of the specific chemical identity of the active substance was not asserted, as required under this subsection or section 14

“(ii) all claims for protection against disclosure of the specific chemical identity of the active substance have been denied by the Administrator; or

"(iii) the time period for protection against disclosure of the specific chemical identity of the active substance has expired.

“(8) Limitation.-No person may assert a new claim under this subsection or section 14 for protection from disclosure of a specific chemical identity of any active or inactive substance for which a notice is received under paragraph $(4)(\mathrm{A})(\mathrm{i})$ or $(5)(\mathrm{B})(\mathrm{i})$ that is not on the confidential portion of the list published under paragraph (1).

“(9) Certification.-Under the rules promulgated under this subsection, manufacturers and processors, as applicable, shall be required-

"(A) to certify that each notice or substantiation the manufacturer or processor submits 
1

2

9 Toxic Substances Control Act (15 U.S.C. 2607(b)) (as

10 amended by subsection (a)) is further amended by adding

11 at the end the following:

complies with the requirements of the rule, and that any confidentiality claims are true and correct; and

"(B) to retain a record documenting compliance with the rule and supporting confidentiality claims for a period of 5 years beginning on the last day of the submission period.'.

(b) Mercury Inventory.-Section 8(b) of the “(10) MerCuRY.-

"(A) DEFINITION OF MERCURY.-In this paragraph, notwithstanding section $3(2)(\mathrm{B})$, the term 'mercury' means-

“(i) elemental mercury; and

"(ii) a mercury compound.

"(B) Publication.-Not later than April 1, 2017, and every 3 years thereafter, the Administrator shall carry out and publish in the Federal Register an inventory of mercury supply, use, and trade in the United States.

"(C) Process.-In carrying out the inventory under subparagraph (B), the Administrator shall- 
1 "(i) identify any manufacturing processes or products that intentionally add mercury; and

“(ii) recommend actions, including proposed revisions of Federal law or regulations, to achieve further reductions in mercury use.

“(D) Reporting.-

"(i) In GENERAL.-To assist in the preparation of the inventory under subparagraph (B), any person who manufactures mercury or mercury-added products or otherwise intentionally uses mercury in a manufacturing process shall make periodic reports to the Administrator, at such time and including such information as the Administrator shall determine by rule promulgated not later than 2 years after the date of enactment of this paragraph.

“(ii) Coordination.-To avoid duplication, the Administrator shall coordinate the reporting under this subparagraph with the Interstate Mercury Education and Reduction Clearinghouse. 


\section{1}

1

2

3

4

5

6

7 SEC. 9. RELATIONSHIP TO OTHER FEDERAL LAWS.

8 Section 9 of the Toxic Substances Control Act (15

9 U.S.C. 2608) is amended-

10

11

12

13

14

15

16

17

18

19

20

21

22

23

24
(1) in subsection (a)-

(A) in paragraph (1)-

(i) by striking "has reasonable basis to conclude" and inserting "determines";

and

(ii) by inserting ", without consideration of costs or other nonrisk factors, including an unreasonable risk to a potentially exposed or susceptible subpopulation identified as relevant by the Administrator, under the conditions of use," after "or the environment";

(B) in paragraph (2)-

(i) in subparagraph (A), by inserting ", within the time period specified by the 
1

2

11 "(3) The Administrator shall take the actions de-

13 port under paragraph (1) with respect to a chemical sub-

14 stance or mixture and the agency to which the report was 15 made does not-

"(A) issue the order described in paragraph

17 (2)(A) within the time period specified by the Ad18 ministrator in the report; or

19 “(B)(i) respond under paragraph (1) within the

20 timeframe specified by the Administrator in the re21 port; and

“(ii) initiate action within 90 days of publica-

23 tion in the Federal Register of the response de24 scribed in clause (i). 
1 "(4) If an agency to which a report is submitted 2 under paragraph (1) does not take the actions described 3 in subparagraph (A) or (B) of paragraph (3), the Admin4 istrator shall-

5 "(A) initiate or complete appropriate action 6 under section 6 ; or "(B) take any action authorized or required 8 under section 7, as applicable.

9 “(5) This subsection shall not relieve the Adminis10 trator of any obligation to take any appropriate action 11 under section 6(a) or 7 to address risks from the manufac12 ture, processing, distribution in commerce, use, or disposal 13 of a chemical substance or mixture, or any combination 14 of those activities, that are not identified in a report issued 15 by the Administrator under paragraph (1).";

16

17

22 that it is in the public interest for the Administrator to 23 take an action under this title with respect to a chemical 24 substance or mixture rather than under another law ad25 ministered in whole or in part by the Administrator, the 
1 Administrator shall consider, based on information rea-

2 sonably available to the Administrator, all relevant aspects

3 of the risk described in paragraph (1) and a comparison

4 of the estimated costs and efficiencies of the action to be

5 taken under this title and an action to be taken under

6 such other law to protect against such risk."; and

7 (3) by adding at the end the following:

8 “(e) Exposure Information.-In addition to the

9 requirements of subsection (a), if the Administrator ob-

10 tains information related to exposures or releases of a

11 chemical substance or mixture that may be prevented or

12 reduced under another Federal law, including a law not

13 administered by the Administrator, the Administrator

14 shall make such information available to the relevant Fed-

15 eral agency or office of the Environmental Protection

16 Agency.".

\section{SEC. 10. EXPORTS OF ELEMENTAL MERCURY.}

18 (a) Prohibition on Export of Certain Mercury

19 Compounds.-Section 12(c) of the Toxic Substances

20 Control Act (15 U.S.C. 2611(c)) is amended-

21 (1) in the subsection heading, by inserting

22 "and Mercury Compounds" after "Mercury";

23 and

24 (2) by adding at the end the following: 
“(7) Prohibition ON EXPORT OF CERTAIN

"(A) IN GENERAL.-Effective January 1, 2020 , the export of the following mercury compounds is prohibited:

“(i) Mercury (I) chloride or calomel.

“(ii) Mercury (II) oxide.

“(iii) Mercury (II) sulfate.

“(iv) Mercury (II) nitrate.

“(v) Cinnabar or mercury sulphide.

"(vi) Any mercury compound that the Administrator adds to the list published under subparagraph (B) by rule, on determining that exporting that mercury compound for the purpose of regenerating elemental mercury is technically feasible.

"(B) Publication.-Not later than 90 days after the date of enactment of the Frank R. Lautenberg Chemical Safety for the 21st Century Act, and as appropriate thereafter, the Administrator shall publish in the Federal Register a list of the mercury compounds that are prohibited from export under this paragraph. 
1
“(C) Petition.-Any person may petition the Administrator to add a mercury compound to the list published under subparagraph (B).

“(D) Environmentally SOUND DISPOSAL.-This paragraph does not prohibit the export of mercury compounds on the list published under subparagraph (B) to member countries of the Organization for Economic Cooperation and Development for environmentally sound disposal, on the condition that no mercury or mercury compounds so exported are to be recovered, recycled, or reclaimed for use, or directly reused, after such export.

"(E) REPORT.-Not later than 5 years after the date of enactment of the Frank $R$. Lautenberg Chemical Safety for the 21st Century Act, the Administrator shall evaluate any exports of mercury compounds on the list published under subparagraph (B) for disposal that occurred after such date of enactment and shall submit to Congress a report that-

"(i) describes volumes and sources of mercury compounds on the list published under subparagraph (B) exported for disposal; 


\section{7}

1

2 "(ii) identifies receiving countries of such exports;

"(iii) describes methods of disposal used after such export;

"(iv) identifies issues, if any, presented by the export of mercury compounds on the list published under subparagraph (B);

"(v) includes an evaluation of management options in the United States for mercury compounds on the list published under subparagraph (B), if any, that are commercially available and comparable in cost and efficacy to methods being utilized in such receiving countries; and

"(vi) makes a recommendation regarding whether Congress should further limit or prohibit the export of mercury compounds on the list published under subparagraph (B) for disposal.

"(F) EFFECT ON OTHER LAW.-Nothing in this paragraph shall be construed to affect the authority of the Administrator under the Solid Waste Disposal Act (42 U.S.C. 6901 et seq.).'”. 
1 (b) Temporary Generator Accumulation.-Sec-

2 tion 5 of the Mercury Export Ban Act of 2008 (42 U.S.C.

3 6939f) is amended-

$4 \quad$ (1) in subsection (a)(2), by striking "2013" and

$5 \quad$ inserting " 2019 ”;

$6 \quad(2)$ in subsection (b)-

7

8

9

10

11

12

13

14

15

16

17

18

19
(A) in paragraph (1) -

(i) by redesignating subparagraphs (A), (B), and (C), as clauses (i), (ii), and (iii), respectively and indenting appropriately;

(ii) in the first sentence, by striking "After consultation" and inserting the following:

"(A) Assessment AND COLlection.After consultation";

(iii) in the second sentence, by striking "The amount of such fees" and inserting the following:

"(B) Amount.-The amount of the fees described in subparagraph (A)";

(iv) in subparagraph (B) (as so designated)-

(I) in clause (i) (as so redesignated), by striking "publically avail- 
89

1

2

3

4

5

6

7

8

9

10

11

12

13

14

15

16

17

18

19

20

21

22

23

24 able not later than October 1, 2012"

and inserting "publicly available not later than October 1, 2018";

(II) in clause (ii) (as so redesignated), by striking “and”;

(III) in clause (iii) (as so redesignated), by striking the period at the end and inserting “, subject to clause (iv); and"; and

(IV) by adding at the end the following:

"(iv) for generators temporarily accumulating elemental mercury in a facility subject to subparagraphs (B) and (D)(iv) of subsection $(\mathrm{g})(2)$ if the facility designated in subsection (a) is not operational by January 1, 2019, shall be adjusted to subtract the cost of the temporary accumulation during the period in which the facility designated under subsection (a) is not operational."; and

(v) by adding at the end the following: “(C) Conveyance of title and PermitTING.- If the facility designated in subsection 
1

2

3 (a) is not operational by January 1, 2020, the Secretary-

"(i) shall immediately accept the conveyance of title to all elemental mercury that has accumulated in facilities in accordance with subsection $(\mathrm{g})(2)(\mathrm{D})$, before January 1, 2020, and deliver the accumulated mercury to the facility designated under subsection (a) on the date on which the facility becomes operational;

“(ii) shall pay any applicable Federal permitting costs, including the costs for permits issued under section 3005(c) of the Solid Waste Disposal Act (42 U.S.C. 6925(c)); and

"(iii) shall store, or pay the cost of storage of, until the time at which a facility designated in subsection (a) is operational, accumulated mercury to which the Secretary has title under this subparagraph in a facility that has been issued a permit under section 3005(c) of the Solid Waste Disposal Act (42 U.S.C. 6925(c))."; and 
(B) in paragraph (2), in the first sentence, by striking "paragraph (1)(C)" and inserting "paragraph (1)(B)(iii)"; and (3) in subsection $(\mathrm{g})(2)-$

(A) in the undesignated material at the end, by striking "This subparagraph" and inserting the following:

"(C) Subparagraph (B)";

(B) in subparagraph (C) (as designated by subparagraph (A)), by inserting "of that subparagraph" before the period at the end; and (C) by adding at the end the following:

“(D) A generator producing elemental mercury incidentally from the beneficiation or processing of ore or related pollution control activities may accumulate the mercury produced onsite that is destined for a facility designated by the Secretary under subsection (a) for more than 90 days without a permit issued under section 3005(c) of the Solid Waste Disposal Act (42 U.S.C. 6925(c)), and shall not be subject to the storage prohibition of section $3004(\mathrm{j})$ of that Act (42 U.S.C. $6924(\mathrm{j}))$, if-

"(i) the Secretary is unable to accept the mercury at a facility designated by the 
Secretary under subsection (a) for reasons beyond the control of the generator;

"(ii) the generator certifies in writing. to the Secretary that the generator will ship the mercury to a designated facility when the Secretary is able to accept the mercury;

"(iii) the generator certifies in writing to the Secretary that the generator is storing only mercury the generator has produced or recovered onsite and will not sell, or otherwise place into commerce, the mercury; and

"(iv) the generator has obtained an identification number under section 262.12 of title 40, Code of Federal Regulations, and complies with the requirements described in paragraphs (1) through (4) of section 262.34(a) of title 40, Code of Federal Regulations (as in effect on the date of enactment of this subparagraph).

"(E) Management standards for temPORARY STORAGE.-Not later than January 1, 2017, the Secretary, after consultation with the Administrator of the Environmental Protection 
93

1 Agency and State agencies in affected States, 2 shall develop and make available guidance that 3 establishes procedures and standards for the 4 management and short-term storage of ele5 mental mercury at a generator covered under 6 subparagraph (D), including requirements to 7 ensure appropriate use of flasks or other suit8 able containers. Such procedures and standards 9 shall be protective of health and the environ10 ment and shall ensure that the elemental mer11 cury is stored in a safe, secure, and effective 12 manner. A generator may accumulate mercury 13 in accordance with subparagraph (D) imme14 diately upon enactment of this subparagraph, 15 and notwithstanding that guidance called for by 16 this paragraph has not been developed or made 17 available.".

18 (c) Interim Status.-Section 5(d)(1) of the Mer19 cury Export Ban Act of 2008 (42 U.S.C. $6939 \mathrm{f}(\mathrm{d})(1)$ ) is 20 amended-

21 (1) in the fourth sentence, by striking "in exist22 ence on or before January 1, 2013,"; and

23 (2) in the last sentence, by striking "January 24 1, 2015" and inserting "January 1, 2020". 
1 SEC. 11. CONFIDENTIAL INFORMATION.

2 Section 14 of the Toxic Substances Control Act (15

3 U.S.C. 2613) is amended to read as follows:

4 “SEC. 14. CONFIDENTIAL INFORMATION.

5 "(a) In General.-Except as provided in this sec-

6 tion, the Administrator shall not disclose information that

7 is exempt from disclosure pursuant to subsection (a) of

8 section 552 of title 5, United States Code, by reason of

9 subsection (b)(4) of that section-

10 "(1) that is reported to, or otherwise obtained

11 by, the Administrator under this Act; and

12 "(2) for which the requirements of subsection

$13 \quad(\mathrm{c})$ are met.

14 In any proceeding under section 552(a) of title 5, United

15 States Code, to obtain information the disclosure of which

16 has been denied because of the provisions of this sub17 section, the Administrator may not rely on section $18552(\mathrm{~b})(3)$ of such title to sustain the Administrator's ac19 tion.

20 “(b) Information Not Protected From Disclo21 SURE.-

22 “(1) Mixed CONFIDENTIAL AND NONCON23 FIDENTIAL INFORMATION.-Information that is pro24 tected from disclosure under this section, and which 25 is mixed with information that is not protected from 26 disclosure under this section, does not lose its pro- 
1 tection from disclosure notwithstanding that it is

2 mixed with information that is not protected from 3 disclosure.

5 STUDiEs.- Subsection (a) does not prohibit the dis6 closure ofsubmitted under this Act with respect to-

"(i) any chemical substance or mixture which, on the date on which such study is to be disclosed has been offered for commercial distribution; or "(ii) any chemical substance or mixture for which testing is required under section 4 or for which notification is required under section 5; and

"(B) any information reported to, or otherwise obtained by, the Administrator from a health and safety study which relates to a chemical substance or mixture described in clause (i) or (ii) of subparagraph (A).

22 This paragraph does not authorize the disclosure of 23 any information, including formulas (including mo24 lecular structures) of a chemical substance or mix25 ture, that discloses processes used in the manufac- 
1 turing or processing of a chemical substance or mix-

2 ture or, in the case of a mixture, the portion of the

3 mixture comprised by any of the chemical substances

4 in the mixture.

5 “(3) OTHER INFORMATION NOT PROTECTED

6 FROM DISCLOSURE.-Subsection (a) does not pro-

7 hibit the disclosure of-

8 "(A) any general information describing

9 the manufacturing volumes, expressed as spe-

10 cific aggregated volumes or, if the Adminis-

11 trator determines that disclosure of specific ag-

12 gregated volumes would reveal confidential in-

13 formation, expressed in ranges; or

14 "(B) a general description of a process

15 used in the manufacture or processing and in-

16 dustrial, commercial, or consumer functions and

17 uses of a chemical substance, mixture, or article

18 containing a chemical substance or mixture, in-

19 cluding information specific to an industry or

20 industry sector that customarily would be

21 shared with the general public or within an in-

22 dustry or industry sector.

23 “(4) BANS AND PHASE-OUTS.-

24 "(A) In GENERAL.-If the Administrator

25 promulgates a rule pursuant to section 6(a) 
that establishes a ban or phase-out of a chemical substance or mixture, the protection from disclosure of any information under this section with respect to the chemical substance or mixture shall be presumed to no longer apply, subject to subsection $(\mathrm{g})(1)(\mathrm{E})$ and subparagraphs (B) and (C) of this paragraph.

"(B) Limitations.-

"(i) Critical UsE.-In the case of a chemical substance or mixture for which a specific condition of use is subject to an exemption pursuant to section $6(\mathrm{~g})$, if the Administrator establishes a ban or phaseout described in subparagraph (A) with respect to the chemical substance or mixture, the presumption against protection under such subparagraph shall only apply to information that relates solely to any conditions of use of the chemical substance or mixture to which the exemption does not apply.

"(ii) ExporT.-In the case of a chemical substance or mixture for which there is manufacture, processing, or distribution in commerce that meets the conditions of sec- 
tion 12(a)(1), if the Administrator establishes a ban or phase-out described in subparagraph (A) with respect to the chemical substance or mixture, the presumption against protection under such subparagraph shall only apply to information that relates solely to any other manufacture, processing, or distribution in commerce of the chemical substance or mixture for the conditions of use subject to the ban or phase-out, unless the Administrator makes the determination in section 12(a)(2).

“(iii) SPECIFIC CONDITIONS OF USE.-In the case of a chemical substance or mixture for which the Administrator establishes a ban or phase-out described in subparagraph (A) with respect to a specific condition of use of the chemical substance or mixture, the presumption against protection under such subparagraph shall only apply to information that relates solely to the condition of use of the chemical substance or mixture for which the ban or phase-out is established.

“(C) Request For NONDisclosure.- 
1 "(i) In GENERAL.-A manufacturer or processor of a chemical substance or mixture subject to a ban or phase-out described in this paragraph may submit to the Administrator, within 30 days of receiving a notification under subsection $(\mathrm{g})(2)(\mathrm{A})$, a request, including documentation supporting such request, that some or all of the information to which the notice applies should not be disclosed or that its disclosure should be delayed, and the Administrator shall review the request under subsection $(\mathrm{g})(1)(\mathrm{E})$.

“(ii) EfFeCt OF NO REQUest OR DENIAL.- If no request for nondisclosure or delay is submitted to the Administrator under this subparagraph, or the Administrator denies such a request under subsection $(\mathrm{g})(1)(\mathrm{A})$, the information shall not be protected from disclosure under this section.

“(5) Certain Requests.-If a request is made to the Administrator under section 552(a) of title 5, United States Code, for information reported to or otherwise obtained by the Administrator under this 
1 Act that is not protected from disclosure under this

2 subsection, the Administrator may not deny the re-

3 quest on the basis of section $552(\mathrm{~b})(4)$ of title 5 ,

$4 \quad$ United States Code.

5 “(c) REQUIREMENTS FOR CONFIDENTIALITY 6 Clatims.-

7

8

9

10

11

12

13

14

15

16

17

18

19

20

21

22

23

24

\section{“(1) Assertion of Clatms.-}

"(A) In GENERAL.-A person seeking to protect from disclosure any information that person submits under this Act (including information described in paragraph (2)) shall assert to the Administrator a claim for protection from disclosure concurrent with submission of the information, in accordance with such rules regarding a claim for protection from disclosure as the Administrator has promulgated or may promulgate pursuant to this title.

"(B) InCLusion.-An assertion of a claim under subparagraph (A) shall include a statement that the person has-

"(i) taken reasonable measures to protect the confidentiality of the information; "(ii) determined that the information is not required to be disclosed or otherwise 
made available to the public under any other Federal law;

"(iii) a reasonable basis to conclude that disclosure of the information is likely to cause substantial harm to the competitive position of the person; and "(iv) a reasonable basis to believe that the information is not readily discoverable through reverse engineering.

“(C) ADDitional REQUIREMENTS FOR CLAIMS REGARDING CHEMICAL IDENTITY INFORMATION.- In the case of a claim under subparagraph (A) for protection from disclosure of a specific chemical identity, the claim shall include a structurally descriptive generic name for the chemical substance that the Administrator may disclose to the public, subject to the condition that such generic name shall-

"(i) be consistent with guidance developed by the Administrator under paragraph $(4)(\mathrm{A})$; and

"(ii) describe the chemical structure of the chemical substance as specifically as practicable while protecting those features of the chemical structure- 
"(I) that are claimed as confidential; and

"(II) the disclosure of which would be likely to cause substantial harm to the competitive position of the person.

“(2) INFORMATION GENERALLY NOT SUBJECT TO SUBSTANTIATION REQUIREMENTS.-Subject to subsection (f), the following information shall not be subject to substantiation requirements under paragraph (3):

"(A) Specific information describing the processes used in manufacture or processing of a chemical substance, mixture, or article.

"(B) Marketing and sales information.

"(C) Information identifying a supplier or customer.

"(D) In the case of a mixture, details of the full composition of the mixture and the respective percentages of constituents.

"(E) Specific information regarding the use, function, or application of a chemical substance or mixture in a process, mixture, or article. 
"(F) Specific production or import volumes of the manufacturer or processor.

"(G) Prior to the date on which a chemical substance is first offered for commercial distribution, the specific chemical identity of the chemical substance, including the chemical name, molecular formula, Chemical Abstracts Service number, and other information that would identify the specific chemical substance, if the specific chemical identity was claimed as confidential at the time it was submitted in a notice under section 5 .

“(3) Substantiation Requirements.-Except as provided in paragraph (2), a person asserting a claim to protect information from disclosure under this section shall substantiate the claim, in accordance with such rules as the Administrator has promulgated or may promulgate pursuant to this section.

“(4) Guidance.-The Administrator shall develop guidance regarding-

"(A) the determination of structurally descriptive generic names, in the case of claims for the protection from disclosure of specific chemical identity; and 
1

11 SURE.-Information described in subsection (a)-

"(B) the content and form of the statements of need and agreements required under paragraphs (4), (5), and (6) of subsection (d). “(5) Certification.-An authorized official of a person described in paragraph (1)(A) shall certify that the statement required to assert a claim submitted pursuant to paragraph (1)(B), and any information required to substantiate a claim submitted pursuant to paragraph (3), are true and correct.

“(d) Exceptions to Protection From Disclo"(1) shall be disclosed to an officer or employee of the United States-

"(A) in connection with the official duties of that person under any Federal law for the protection of health or the environment; or

“(B) for a specific Federal law enforcement purpose;

"(2) shall be disclosed to a contractor of the United States and employees of that contractor-

"(A) if, in the opinion of the Administrator, the disclosure is necessary for the satisfactory performance by the contractor of a contract with the United States for the performance of work in connection with this Act; and 
"(B) subject to such conditions as the Administrator may specify;

"(3) shall be disclosed if the Administrator de-

4 termines that disclosure is necessary to protect

5 health or the environment against an unreasonable

6 risk of injury to health or the environment, without

7 consideration of costs or other nonrisk factors, in-

8 cluding an unreasonable risk to a potentially exposed

9 or susceptible subpopulation identified as relevant by

10 the Administrator under the conditions of use;

11 "(4) shall be disclosed to a State, political sub-

12 division of a State, or tribal government, on written

13 request, for the purpose of administration or en-

14 forcement of a law, if such entity has 1 or more ap-

15 plicable agreements with the Administrator that are

16 consistent with the guidance developed under sub-

17 section $(\mathrm{c})(4)(\mathrm{B})$ and ensure that the entity will take

18 appropriate measures, and has adequate authority,

19 to maintain the confidentiality of the information in

20 accordance with procedures comparable to the proce-

21 dures used by the Administrator to safeguard the in22 formation;

23 "(5) shall be disclosed to a health or environ24 mental professional employed by a Federal or State 25 agency or tribal government or a treating physician 
1 or nurse in a nonemergency situation if such person

2 provides a written statement of need and agrees to

3 sign a written confidentiality agreement with the Ad-

4 ministrator, subject to the conditions that-

5 "(A) the statement of need and confiden6 tiality agreement are consistent with the guidance developed under subsection (c)(4)(B); or will assist in-

"(B) the statement of need shall be a statement that the person has a reasonable basis to suspect that-

"(i) the information is necessary for, crist assist in

"(I) the diagnosis or treatment of 1 or more individuals; or

"(II) responding to an environmental release or exposure; and "(ii) 1 or more individuals being diagnosed or treated have been exposed to the chemical substance or mixture concerned, or an environmental release of or exposure to the chemical substance or mixture concerned has occurred; and

"(C) the person will not use the information for any purpose other than the health or 
of need, except as otherwise may be authorized by the terms of the agreement or by the person who has a claim under this section with respect to the information, except that nothing in this title prohibits the disclosure of any such information through discovery, subpoena, other court order, or any other judicial process otherwise allowed under applicable Federal or State law;

"(6) shall be disclosed in the event of an emergency to a treating or responding physician, nurse, agent of a poison control center, public health or environmental official of a State, political subdivision of a State, or tribal government, or first responder (including any individual duly authorized by a Federal agency, State, political subdivision of a State, or tribal government who is trained in urgent medical care or other emergency procedures, including a police officer, firefighter, or emergency medical technician) if such person requests the information, subject to the conditions that such person shall-

"(A) have a reasonable basis to suspect that-

"(i) a medical, public health, or environmental emergency exists; 
"(ii) the information is necessary for, or will assist in, emergency or first-aid diagnosis or treatment; or

"(iii) 1 or more individuals being diagnosed or treated have likely been exposed to the chemical substance or mixture concerned, or a serious environmental release of or exposure to the chemical substance or mixture concerned has occurred; and

"(B) if requested by a person who has a claim with respect to the information under this section-

"(i) provide a written statement of need and agree to sign a confidentiality agreement, as described in paragraph (5); and

"(ii) submit to the Administrator such statement of need and confidentiality agreement as soon as practicable, but not necessarily before the information is disclosed;

"(7) may be disclosed if the Administrator determines that disclosure is relevant in a proceeding under this Act, subject to the condition that the dis- 
1 closure is made in such a manner as to preserve con-

2 fidentiality to the extent practicable without impair-

$3 \quad$ ing the proceeding; and

4 "(8) shall be disclosed if the information is re-

5 quired to be made public under any other provision

6 of Federal law.

7 “(e) Duration of Protection From Disclo-

8 SURE.-

9 “(1) IN GENERAL.—Subject to paragraph (2), 10 subsection (f)(3), and section 8(b), the Adminis-

11 trator shall protect from disclosure information de12 scribed in subsection (a) -

13 "(A) in the case of information described 14 in subsection (c)(2), until such time as-

15 "(i) the person that asserted the claim 16 notifies the Administrator that the person 17 is withdrawing the claim, in which case the 18 information shall not be protected from 19 disclosure under this section; or

20 "(ii) the Administrator becomes aware 21 that the information does not qualify for 22 protection from disclosure under this sec23 tion, in which case the Administrator shall 24 take any actions required under sub25 sections (f) and (g); and 
"(B) in the case of information other than information described in subsection (c)(2)—

"(i) for a period of 10 years from the date on which the person asserts the claim with respect to the information submitted to the Administrator; or "(ii) if applicable before the expiration of such 10-year period, until such time as-

"(I) the person that asserted the claim notifies the Administrator that the person is withdrawing the claim, in which case the information shall not be protected from disclosure under this section; or

"(II) the Administrator becomes aware that the information does not qualify for protection from disclosure under this section, in which case the Administrator shall take any actions required under subsections (f) and $(\mathrm{g})$.

"(2) Extensions.-

"(A) In GENERAL.-In the case of information other than information described in sub- 
section $(\mathrm{c})(2)$, not later than the date that is 60 days before the expiration of the period described in paragraph (1)(B)(i), the Administrator shall provide to the person that asserted the claim a notice of the impending expiration of the period.

"(B) Request.-

"(i) IN GENERAL.-Not later than the date that is 30 days before the expiration of the period described in paragraph (1)(B)(i), a person reasserting the relevant claim shall submit to the Administrator a request for extension substantiating, in accordance with subsection (c)(3), the need to extend the period.

“(ii) ACTION BY ADMINISTRATOR.Not later than the date of expiration of the period described in paragraph (1)(B)(i), the Administrator shall, in accordance with subsection $(\mathrm{g})(1)$ -

"(I) review the request submitted under clause (i);

"(II) make a determination regarding whether the claim for which the request was submitted continues 
1

2 to meet the relevant requirements of this section; and

"(III)(aa) grant an extension of

10 years; or

"(bb) deny the request.

"(C) No Limit ON NUMBER OF EXTENSIONS._-There shall be no limit on the number of extensions granted under this paragraph, if the Administrator determines that the relevant request under subparagraph $(\mathrm{B})(\mathrm{i})-$

"(i) establishes the need to extend the period; and

"(ii) meets the requirements established by the Administrator.

“(f) Review and Resubstantiation.-

“(1) Discretion OF ADMINISTRATOR.-The Administrator may require any person that has claimed protection for information from disclosure under this section, whether before, on, or after the date of enactment of the Frank R. Lautenberg Chemical Safety for the 21st Century Act, to reassert and substantiate or resubstantiate the claim in accordance with this section- 
17 tion, whether before, on, or after the date of enact-

18 ment of the Frank R. Lautenberg Chemical Safety

19 for the 21st Century Act, to reassert and substan-

20 tiate or resubstantiate the claim in accordance with 21 this section-

"(A) after the chemical substance is designated as a high-priority substance under section $6(b)$;

"(B) for any chemical substance designated as an active substance under section $8(\mathrm{~b})(5)(\mathrm{B})(\mathrm{iii})$; or

"(C) if the Administrator determines that disclosure of certain information currently protected from disclosure would be important to assist the Administrator in conducting risk evaluations or promulgating rules under section 6.

“(2) REVIEW REQUIRED.-The Administrator shall review a claim for protection of information from disclosure under this section and require any person that has claimed protection for that informa-

"(A) as necessary to determine whether the information qualifies for an exemption from disclosure in connection with a request for in- 
1 formation received by the Administrator under

17 from disclosure for a period of 10 years from the 18 date of such determination, subject to any subse19 quent requirement by the Administrator under this 20 subsection. section 552 of title 5, United States Code;

"(B) if the Administrator has a reasonable basis to believe that the information does not qualify for protection from disclosure under this section; or

"(C) for any chemical substance the Administrator determines under section $6(\mathrm{~b})(4)(\mathrm{A})$ presents an unreasonable risk of injury to health or the environment.

“(3) Period of Protection.-If the Administrator requires a person to reassert and substantiate or resubstantiate a claim under this subsection, and determines that the claim continues to meet the relevant requirements of this section, the Administrator shall protect the information subject to the claim “(g) Duties of Administrator.“(1) Determination."(A) In GENERAL.-Except for claims regarding information described in subsection (c)(2), the Administrator shall, subject to sub- 
paragraph $(\mathrm{C})$, not later than 90 days after the receipt of a claim under subsection (c), and not later than 30 days after the receipt of a request for extension of a claim under subsection (e) or a request under subsection $(\mathrm{b})(4)(\mathrm{C})$, review and approve, approve in part and deny in part, or deny the claim or request.

"(B) REAsOns FOR DENIAL.-If the Administrator denies or denies in part a claim or request under subparagraph (A) the Administrator shall provide to the person that asserted the claim or submitted the request a written statement of the reasons for the denial or denial in part of the claim or request.

"(C) Subsets.-The Administrator shall-

"(i) except with respect to information described in subsection $(c)(2)(G)$, review all claims or requests under this section for the protection from disclosure of the specific chemical identity of a chemical substance; and

"(ii) review a representative subset, comprising at least 25 percent, of all other 
claims or requests for protection from disclosure under this section.

"(D) EfFect of FAILURe TO ACT.-The failure of the Administrator to make a decision regarding a claim or request for protection from disclosure or extension under this section shall not have the effect of denying or eliminating a claim or request for protection from disclosure. “(E) Determination OF REQUests UNDER SUBSECTION $(\mathrm{b})(4)(\mathrm{C})$. - With respect to a request submitted under subsection $(b)(4)(C)$, the Administrator shall, with the objective of ensuring that information relevant to the protection of health and the environment is disclosed to the extent practicable, determine whether the documentation provided by the person rebuts what shall be the presumption of the Administrator that the public interest in the disclosure of the information outweighs the public or proprietary interest in maintaining the protection for all or a portion of the information that the person has requested not be disclosed or for which disclosure be delayed.

“(2) Notification.- 
"(A) In GENERAL.-Except as provided in subparagraph (B) and subsections (b), (d), and (e), if the Administrator denies or denies in part a claim or request under paragraph (1), concludes, in accordance with this section, that the information does not qualify for protection from disclosure, intends to disclose information pursuant to subsection (d), or promulgates a rule under section 6(a) establishing a ban or phase-out with respect to a chemical substance or mixture, the Administrator shall notify, in writing, the person that asserted the claim or submitted the request of the intent of the Administrator to disclose the information or not protect the information from disclosure under this section. The notice shall be furnished by certified mail (return receipt requested), by personal delivery, or by other means that allows verification of the fact and date of receipt.

"(B) Disclosure of information.-Except as provided in subparagraph (C), the Administrator shall not disclose information under this subsection until the date that is 30 days after the date on which the person that asserted 
1 the claim or submitted the request receives notification under subparagraph (A).

"(C) ExceptTions.-

“(i) Fifteen DAY NOtification.For information the Administrator intends to disclose under subsections $(d)(3),(d)(4)$, (d)(5), and (j), the Administrator shall not disclose the information until the date that is 15 days after the date on which the person that asserted the claim or submitted the request receives notification under subparagraph (A), except that, with respect to information to be disclosed under subsection (d)(3), if the Administrator determines that disclosure of the information is necessary to protect against an imminent and substantial harm to health or the environment, no prior notification shall be necessary.

“(ii) Notification as sOON As PRACTICABLE.-For information the Administrator intends to disclose under paragraph (6) of subsection (d), the Administrator shall notify the person that submitted the information that the information has been 
1

2 disclosed as soon as practicable after disclosure of the information.

"(iii) No NOTIFICATION REQUIRED.Notification shall not be required-

"(I) for the disclosure of information under paragraphs (1), (2), (7), or (8) of subsection (d); or

"(II) for the disclosure of information for which-

"(aa) the Administrator has provided to the person that asserted the claim a notice under subsection $(\mathrm{e})(2)(\mathrm{A})$; and

"(bb) such person does not submit to the Administrator a request under subsection (e)(2)(B) on or before the deadline established in subsection (e)(2)(B)(i).

“(D) APPEALs.-

"(i) ACtion TO REstrain DIscloSURE.-If a person receives a notification under this paragraph and believes the information is protected from disclosure under this section, before the date on which the information is to be disclosed 
23 The Administrator, in consultation with the Director 24 of the Centers for Disease Control and Prevention, 25 shall develop a request and notification system that, 
1 in a format and language that is readily accessible

2 and understandable, allows for expedient and swift

3 access to information disclosed pursuant to para-

4 graphs (5) and (6) of subsection (d).

5 “(4) UNIQUE IDENTIFIER.-The Administrator

6 shall-

7

8

9

10

11

12

13

14

15

16

17

18

19

20

21

22

23

24

25
"(A)(i) develop a system to assign a unique identifier to each specific chemical identity for which the Administrator approves a request for protection from disclosure, which shall not be either the specific chemical identity or a structurally descriptive generic term; and “(ii) apply that identifier consistently to all information relevant to the applicable chemical substance;

"(B) annually publish and update a list of chemical substances, referred to by their unique identifiers, for which claims to protect the specific chemical identity from disclosure have been approved, including the expiration date for each such claim;

"(C) ensure that any nonconfidential information received by the Administrator with respect to a chemical substance included on the list published under subparagraph (B) while the 
specific chemical identity of the chemical substance is protected from disclosure under this section identifies the chemical substance using the unique identifier; and

"(D) for each claim for protection of a specific chemical identity that has been denied by the Administrator or expired, or that has been withdrawn by the person who asserted the claim, and for which the Administrator has used a unique identifier assigned under this paragraph to protect the specific chemical identity in information that the Administrator has made public, clearly link the specific chemical identity to the unique identifier in such information to the extent practicable.

“(h) Criminal Penalty for Wrongful Disclo“(1) INDIVIDUALS SUBJECT TO PENALTY."(A) IN GENERAL.-Subject to subparagraph (C) and paragraph (2), an individual described in subparagraph (B) shall be fined under title 18, United States Code, or imprisoned for not more than 1 year, or both. 


\section{1}

“(B) DESCRIPTION.-An individual referred to in subparagraph (A) is an individual who-

“(i) pursuant to this section, obtained possession of, or has access to, information protected from disclosure under this section; and

"(ii) knowing that the information is protected from disclosure under this section, willfully discloses the information in any manner to any person not entitled to receive that information.

"(C) Exception.-This paragraph shall not apply to any medical professional (including an emergency medical technician or other first responder) who discloses any information obtained under paragraph (5) or (6) of subsection (d) to a patient treated by the medical professional, or to a person authorized to make medical or health care decisions on behalf of such a patient, as needed for the diagnosis or treatment of the patient.

“(2) OTher Laws.-Section 1905 of title 18, United States Code, shall not apply with respect to the publishing, divulging, disclosure, or making 
1 known of, or making available, information reported

2 to or otherwise obtained by the Administrator under

3 this Act.

4 "(i) APPLiCABILITY.-

5 “(1) IN GENERAL.-Except as otherwise pro-

6 vided in this section, section 8, or any other applica-

7 ble Federal law, the Administrator shall have no au-

8 thority-

9

10

11

12

13

14

15

16

17

18

19

20

21

22

23

24

25
"(A) to require the substantiation or resubstantiation of a claim for the protection from disclosure of information reported to or otherwise obtained by the Administrator under this Act prior to the date of enactment of the Frank R. Lautenberg Chemical Safety for the 21st Century Act; or

"(B) to impose substantiation or resubstantiation requirements, with respect to the protection of information described in subsection (a), under this Act that are more extensive than those required under this section.

“(2) ACTIONS PRIOR TO PROMULGATION OF RULES.-Nothing in this Act prevents the Administrator from reviewing, requiring substantiation or resubstantiation of, or approving, approving in part, or denying any claim for the protection from disclosure 
1 of information before the effective date of such rules

2 applicable to those claims as the Administrator may 3 promulgate after the date of enactment of the Frank

4 R. Lautenberg Chemical Safety for the 21st Century 5 Act.

6 "(j) Access By Congress.-Notwithstanding any

7 limitation contained in this section or any other provision

8 of law, all information reported to or otherwise obtained

9 by the Administrator (or any representative of the Admin-

10 istrator) under this Act shall be made available, upon writ-

11 ten request of any duly authorized committee of the Con-

12 gress, to such committee.".

13 SEC. 12. PENALTies.

14 Section 16 of the Toxic Substances Control Act (15

15 U.S.C. 2615) is amended-

16 (1) in subsection (a)(1), by striking " $\$ 25,000$ ”

17 and inserting “ $\$ 37,500 ” ;$ and

$18 \quad(2)$ in subsection (b) -

19 (A) by striking "Any person" and inserting

20 the following:

21 “(1) In GENERAL.—Any person”;

22 (B) by striking “ $\$ 25,000$ ” and inserting

$23 \quad$ "\$50,000”; and

24 (C) by adding at the end the following: 


\section{SEC. 13. STATE-FEDERAL RELATIONSHIP.}

24 Section 18 of the Toxic Substances Control Act (15 25 U.S.C. 2617) is amended- 
1 (1) by amending subsection (a) to read as fol2 lows:

3 “(a) In GeneraL.-

4 “(1) Establishment or EnForcenent.-Ex-

5 cept as otherwise provided in subsections (c), (d),

6 (e), (f), and (g), and subject to paragraph (2), no

7 State or political subdivision of a State may estab-

8 lish or continue to enforce any of the following:

9 “(A) Development of information.-A

10 statute or administrative action to require the

11 development of information about a chemical

12 substance or category of chemical substances

13 that is reasonably likely to produce the same in-

14 formation required under section 4,5 , or 6 in-

15 "(i) a rule promulgated by the Admin-

$16 \quad$ istrator;

17 “(ii) a consent agreement entered into

18 by the Administrator; or

19 "(iii) an order issued by the Adminis-

$20 \quad$ trator.

21 "(B) Chemical substances found not

22 TO PRESENT AN UNREASONABLE RISK OR RE-

23 STRICTED.—A statute, criminal penalty, or ad-

24 ministrative action to prohibit or otherwise re-

25 strict the manufacture, processing, or distribu- 
1 tion in commerce or use of a chemical sub-

"(i) for which the determination described in section 6(i)(1) is made, consistent with the scope of the risk evaluation under section (6)(b)(4)(D); or "(ii) for which a final rule is promulgated under section 6(a), after the effective date of the rule issued under section 6(a) for the chemical substance, consistent with the scope of the risk evaluation under section $(6)(b)(4)(D)$.

"(C) Significant NeW Use.-A statute or administrative action requiring the notification of a use of a chemical substance that the Administrator has specified as a significant new use and for which the Administrator has required notification pursuant to a rule promulgated under section 5 .

“(2) Effective DATE OF PREemption.Under this subsection, Federal preemption of statutes and administrative actions applicable to specific chemical substances shall not occur until the effective date of the applicable action described in paragraph (1) taken by the Administrator."; 
(2) by amending subsection (b) to read as fol-

2 lows:

3 “(b) New Statutes, Criminal Penalties, or Ad4 ministrative ACtions Creating Prohibitions or 5 Other RESTRICTIONS.-

6 "(1) In GENERAL.-Except as provided in sub7 sections (c), (d), (e), (f), and (g), beginning on the 8 date on which the Administrator defines the scope of 9 a risk evaluation for a chemical substance under sec10 tion 6(b)(4)(D) and ending on the date on which the 11 deadline established pursuant to section $6(\mathrm{~b})(4)(\mathrm{G})$ 12 for completion of the risk evaluation expires, or on 13 the date on which the Administrator publishes the 14 risk evaluation under section $6(\mathrm{~b})(4)(\mathrm{C})$, whichever 15 is earlier, no State or political subdivision of a State 16 may establish a statute, criminal penalty, or admin17 istrative action prohibiting or otherwise restricting 18 the manufacture, processing, distribution in com19 merce, or use of such chemical substance that is a 20 high-priority substance designated under $216(b)(1)(B)(i)$, such chemical substance that has been 22 identified under section $6(\mathrm{~b})(2)(\mathrm{A})$ (except for the 23 first 10 chemical substances so identified), or such 24 chemical substance that has been selected for risk 25 evaluation under section 6(b)(4)(E)(iv)(II). 
1

2

3

4

5

6

7

8

9

10 under subsections (a) and (b) of statutes, criminal pen-

11 alties, and administrative actions applicable to specific

12 chemical substances shall apply only to-

13

"(1) with respect to subsection (a)(1)(A), the

14

15

16

17

18

19

20

21

22

23

24

"(2) EFFECT OF SUBSECTION.—This subsection does not restrict the authority of a State or political subdivision of a State to continue to enforce any statute enacted, or administrative action taken, prior to the date on which the Administrator defines and publishes the scope of a risk evaluation under section 6(b)(4)(D).'”; and

(3) by adding at the end the following:

"(c) ScOPE OF PREemption.-Federal preemption ical substances or category of chemical substances subject to a rule, order, or consent agreement under section 4;

"(2) with respect to subsections (a)(1)(B) and (b), the hazards, exposures, risks, and uses or conditions of use of such chemical substances consistent with the scope of the risk evaluation under $6(\mathrm{~b})(4)(\mathrm{D})$; or

"(3) with respect to subsection (a)(1)(C), the uses of such chemical substances that the Administrator has specified as significant new uses and for 
1 which the Administrator has required notification

2 pursuant to a rule promulgated under section 5 .

3 “(d) ExcEptions.-

4 “(1) No PREemption of Statutes AND AD5 MINISTRATIVE ACTIONS.-

6 "(A) IN GENERAL.-Nothing in this Act, 7 nor any amendment made by the Frank R. 8 Lautenberg Chemical Safety for the 21st Cen9 tury Act, nor any rule, standard of perform10 ance, risk evaluation, or scientific assessment 11 implemented pursuant to this Act, shall affect 12 the right of a State or a political subdivision of 13 a State to adopt or enforce any rule, standard 14 of performance, risk evaluation, scientific as15 sessment, or any other protection for public 16 health or the environment that-

17 “(i) is adopted or authorized under 18 the authority of any other Federal law or 19 adopted to satisfy or obtain authorization 20 or approval under any other Federal law; "(ii) implements a reporting, monitoring, or other information obligation for the chemical substance not otherwise required by the Administrator under this Act or required under any other Federal law; 
1

2

3

4

5

6

7

8

9

10

11

12

13

14

15

16

17

18

19

20

21

22

23

24 "(iii) is adopted pursuant to authority under a law of the State or political subdivision of the State related to water quality, air quality, or waste treatment or disposal, except to the extent that the action-

"(I) imposes a restriction on the manufacture, processing, distribution in commerce, or use of a chemical substance; and

"(II)(aa) addresses the same hazards and exposures, with respect to the same conditions of use as are included in the scope of the risk evaluation published pursuant to section $6(b)(4)(D)$, but is inconsistent with the action of the Administrator; or "(bb) would cause a violation of the applicable action by the Administrator under section 5 or 6 ; or "(iv) subject to subparagraph (B), is identical to a requirement prescribed by the Administrator.

“(B) Identical Requirements.- 
"(i) IN GENERAL.-The penalties and other sanctions applicable under a law of a State or political subdivision of a State in the event of noncompliance with the identical requirement shall be no more stringent than the penalties and other sanctions available to the Administrator under section 16 of this Act.

"(ii) Penalties.-In the case of an identical requirement-

"(I) a State or political subdivision of a State may not assess a penalty for a specific violation for which the Administrator has assessed an adequate penalty under section 16 ; and

"(II) if a State or political subdivision of a State has assessed a penalty for a specific violation, the Administrator may not assess a penalty for that violation in an amount that would cause the total of the penalties assessed for the violation by the State or political subdivision of a State and the Administrator combined to exceed 


\section{4}

1

2 the maximum amount that may be assessed for that violation by the Administrator under section 16.

“(2) Applicability to Certain rules or ORDERS.-

"(A) Prior RUles AND ORDERs.-Nothing in this section shall be construed as modifying the preemptive effect under this section, as in effect on the day before the effective date of the Frank R. Lautenberg Chemical Safety for the 21st Century Act, of any rule or order promulgated or issued under this Act prior to that effective date.

"(B) Certain Chemical substances AND MIXTURES.-With respect to a chemical substance or mixture for which any rule or order was promulgated or issued under section 6 prior to the effective date of the Frank R. Lautenberg Chemical Safety for the 21st Century Act with respect to manufacturing, processing, distribution in commerce, use, or disposal of the chemical substance or mixture, nothing in this section shall be construed as modifying the preemptive effect of this section as in effect prior to the enactment of the Frank 


\section{1}

R. Lautenberg Chemical Safety for the 21st Century Act of any rule or order that is promulgated or issued with respect to such chemical substance or mixture under section 6 after that effective date, unless the latter rule or order is with respect to a chemical substance or mixture containing a chemical substance and follows a designation of that chemical substance as a high-priority substance under section $6(b)(1)(B)(i)$, the identification of that chemical substance under section $6(\mathrm{~b})(2)(\mathrm{A})$, or the selection of that chemical substance for risk evaluation under section 6(b)(4)(E)(iv)(II).

\section{“(e) Preservation of Certain Laws.-}

"(1) In GeneraL.-Nothing in this Act, subject to subsection $(\mathrm{g})$ of this section, shall-

"(A) be construed to preempt or otherwise affect the authority of a State or political subdivision of a State to continue to enforce any action taken or requirement imposed or requirement enacted relating to a specific chemical substance before April 22, 2016, under the authority of a law of the State or political subdivision of the State that prohibits or otherwise restricts manufacturing, processing, distribution 
1 in commerce, use, or disposal of a chemical sub-

2 stance; or

10 Federal law.

11

17 administrative action of that State or political sub-

18 division of the State that relates to the effects of ex-

19 posure to a chemical substance under the conditions 20 of use if the Administrator determines that-

"(B) be construed to preempt or otherwise affect any action taken pursuant to a State law that was in effect on August 31, 2003.

“(2) EFFECT OF SUBSECTION.-This subsection does not affect, modify, or alter the relationship between Federal law and laws of a State or po“(f) WAIVERS.—

“(1) Discretionary exemptions.-Upon application of a State or political subdivision of a State, the Administrator may, by rule, exempt from subsection (a), under such conditions as may be prescribed in the rule, a statute, criminal penalty, or

"(A) compelling conditions warrant granting the waiver to protect health or the environment;

"(B) compliance with the proposed requirement of the State or political subdivision of the 
State would not unduly burden interstate commerce in the manufacture, processing, distribution in commerce, or use of a chemical substance;

"(C) compliance with the proposed requirement of the State or political subdivision of the State would not cause a violation of any applicable Federal law, rule, or order; and

"(D) in the judgment of the Administrator, the proposed requirement of the State or political subdivision of the State is designed to address a risk of a chemical substance, under the conditions of use, that was identified-

"(i) consistent with the best available science;

"(ii) using supporting studies conducted in accordance with sound and objective scientific practices; and

"(iii) based on the weight of the scientific evidence.

“(2) REQUIRED EXEMPTIONS.-Upon application of a State or political subdivision of a State, the Administrator shall exempt from subsection (b) a statute or administrative action of a State or political subdivision of a State that relates to the effects 
1 of exposure to a chemical substance under the condi2 tions of use if the Administrator determines that-

"(A)(i) compliance with the proposed requirement of the State or political subdivision of the State would not unduly burden interstate commerce in the manufacture, processing, distribution in commerce, or use of a chemical substance;

"(ii) compliance with the proposed requirement of the State or political subdivision of the State would not cause a violation of any applicable Federal law, rule, or order; and

"(iii) the State or political subdivision of the State has a concern about the chemical substance or use of the chemical substance based in peer-reviewed science; or

"(B) no later than the date that is 18 months after the date on which the Administrator has initiated the prioritization process for a chemical substance under the rule promulgated pursuant to section $6(b)(1)(A)$, or the date on which the Administrator publishes the scope of the risk evaluation for a chemical substance under section 6(b)(4)(D), whichever is 
17 If the Administrator fails to make a determination

18 under paragraph (3)(B) during the 110-day period

19 beginning on the date on which an application under

20 paragraph (2) is submitted, the statute or adminis21 trative action of the State or political subdivision of 22 the State that was the subject of the application 23 shall not be considered to be an existing statute or 24 administrative action for purposes of subsection (b) 
1 by reason of the failure of the Administrator to

2 make a determination.

"(5) Notice And Comment.-Except in the

4 case of an application approved under paragraph

5 (9), the application of a State or political subdivision

6 of a State under this subsection shall be subject to

7 public notice and comment.

"(6) Final agency aCtion.-The decision of

9 the Administrator on the application of a State or

10 political subdivision of a State shall be-

"(A) considered to be a final agency ac-

tion; and

"(B) subject to judicial review.

“(7) Duration of WaIvers.-A waiver grant-

15 ed under paragraph (2) or approved under para-

16 graph (9) shall remain in effect until such time as

17 the Administrator publishes the risk evaluation 18 under section 6(b).

19 “(8) JUdicial REVIEW OF WAIVERS.-Not later

20 than 60 days after the date on which the Adminis-

21 trator makes a determination on an application of a

22 State or political subdivision of a State under para-

23 graph (1) or (2), any person may file a petition for

24 judicial review in the United States Court of Appeals 
1 for the District of Columbia Circuit, which shall

2 have exclusive jurisdiction over the determination.

“(9) Approval.-

"(A) Automatic approval.-If the Administrator fails to meet the deadline established under paragraph (3)(B), the application of a State or political subdivision of a State under paragraph (2) shall be automatically approved, effective on the date that is 10 days after the deadline.

“(B) REQUIREMENTS.-Notwithstanding paragraph (6), approval of a waiver application under subparagraph (A) for failure to meet the deadline under paragraph (3)(B) shall not be considered final agency action or be subject to judicial review or public notice and comment. "(g) Savings.-

“(1) No PREEMPTION OF COMMON LAW OR STATUTORY CAUSES OF ACTION FOR CIVIL RELIEF OR CRIMINAL CONDUCT.-

"(A) IN GENERAL.-Nothing in this Act, nor any amendment made by the Frank R. Lautenberg Chemical Safety for the 21st Century Act, nor any standard, rule, requirement, standard of performance, risk evaluation, or sci- 
entific assessment implemented pursuant to this Act, shall be construed to preempt, displace, or supplant any State or Federal common law rights or any State or Federal statute creating a remedy for civil relief, including those for civil damage, or a penalty for a criminal conduct.

"(B) Clarification OF NO PREempTION.-Notwithstanding any other provision of this Act, nothing in this Act, nor any amendments made by the Frank R. Lautenberg Chemical Safety for the 21st Century Act, shall preempt or preclude any cause of action for personal injury, wrongful death, property damage, or other injury based on negligence, strict liability, products liability, failure to warn, or any other legal theory of liability under any State law, maritime law, or Federal common law or statutory theory.

“(2) No EFFeCt on PRIVAte Remedies."(A) IN GENERAL.-Nothing in this Act, nor any amendments made by the Frank R. Lautenberg Chemical Safety for the 21st Century Act, nor any rules, regulations, requirements, risk evaluations, scientific assessments, or orders issued pursuant to this Act shall be 
1 interpreted as, in either the plaintiff's or de-

2 fendant's favor, dispositive in any civil action.

"(B) Authority OF COURTs.-This Act does not affect the authority of any court to make a determination in an adjudicatory proceeding under applicable State or Federal law with respect to the admission into evidence or any other use of this Act or rules, regulations, requirements, standards of performance, risk evaluations, scientific assessments, or orders issued pursuant to this Act.".

\section{SEC. 14. JUDICIAL REVIEW.}

13 Section 19(a) of the Toxic Substances Control Act

14 (15 U.S.C. 2618(a)) is amended-

(1) in paragraph (1), by adding at the end the

16 following:

17 "(C)(i) Not later than 60 days after the publi18 cation of a designation under section $6(\mathrm{~b})(1)(\mathrm{B})(\mathrm{ii})$

19 or (iii), any person may commence a civil action to 20 challenge the designation.

"(ii) The United States Court of Appeals for

22 the District of Columbia Circuit shall have exclusive

23 jurisdiction over a civil action filed under this sub24 paragraph."; and

(2) by striking paragraph (3). 
1 SEC. 15. CITIZENS' CIVIL ACTIONS.

2 Section 20(b) of the Toxic Substances Control Act

3 (15 U.S.C. $2619(\mathrm{~b})$ ) is amended-

4 (1) in paragraph (1)(B), by striking "or" at the

5 end; and

6 (2) in paragraph (2), by striking the period at

7 the end and inserting the following: ", except that

8 no prior notification shall be required in the case of

9 a civil action brought to compel a decision by the

10 Administrator pursuant to section 18(f)(3)(B); or

11 "(3) in the case of a civil action brought to

12 compel a decision by the Administrator pursuant to

13 section $18(\mathrm{f})(3)(\mathrm{B})$, after the date that is 60 days

14 after the deadline specified in section 18(f)(3)(B).".

\section{SEC. 16. STUDIES.}

16 Section 25 of the Toxic Substances Control Act (15

17 U.S.C. 2624) is repealed.

18 SEC. 17. ADMINISTRATION OF THE ACT.

19 Section 26 of the Toxic Substances Control Act (15

20 U.S.C. 2625) is amended-

(1) in subsection (b)(1)-

(A) by striking "of a reasonable fee";

(B) by striking "data under section 4 or 5 to defray the cost of administering this Act" and inserting "information under section 4 or a notice or other information to be reviewed by 
the Administrator under section 5, or who manufactures or processes a chemical substance that is the subject of a risk evaluation under section $6(\mathrm{~b})$, of a fee that is sufficient and not more than reasonably necessary to defray the cost related to such chemical substance of administering sections 4,5 , and 6 , and collecting, processing, reviewing, and providing access to and protecting from disclosure as appropriate under section 14 information on chemical substances under this title, including contractor costs incurred by the Administrator";

(C) by striking "Such rules shall not provide for any fee in excess of $\$ 2,500$ or, in the case of a small business concern, any fee in excess of $\$ 100 . " ;$ and

(D) by striking "submit the data and the cost to the Administrator of reviewing such data" and inserting "pay such fee and the cost to the Administrator of carrying out the activities described in this paragraph";

(2) in subsection (b)-

(A) in paragraph (2), by striking "paragraph (1)" and inserting "paragraph (4)"; and (B) by adding at the end the following: 
1 “(3) FUND.—

2 “(A) Establishment.-There is established in 3 the Treasury of the United States a fund, to be

4 known as the TSCA Service Fee Fund (in this para5 graph referred to as the 'Fund'), consisting of such 6 amounts as are deposited in the Fund under this 7 paragraph.

"(B) Collection AND Deposit of FeEs.-

9 Subject to the conditions of subparagraph (C), the

10 Administrator shall collect the fees described in this

11 subsection and deposit those fees in the Fund.

“(C) Use OF Funds BY ADMINISTRATOR.-

13 Fees authorized under this section shall be collected

14 and available for obligation only to the extent and in

15 the amount provided in advance in appropriations

16 Acts, and shall be available without fiscal year limi-

17 tation for use in defraying the costs of the activities

18 described in paragraph (1).

"(D) Accounting And Auditing.-

"(i) Accounting.-The Administrator shall biennially prepare and submit to the Committee on Environment and Public Works of the Senate and the Committee on Energy and Commerce of the House of Representatives a report 
1 the Administrator under this paragraph and amounts disbursed from the Fund for the period covered by the report, as reflected by financial statements provided in accordance with sections 3515 and 3521 of title 31, United States Code.

"(ii) Auditing.-

"(I) IN GENERAL.-For the purpose of section $3515(\mathrm{c})$ of title 31, United States Code, the Fund shall be considered a component of a covered executive agency.

"(II) Components of AudiT.-The annual audit required in accordance with sections 3515 and 3521 of title 31, United States Code, of the financial statements of activities carried out using amounts from the Fund shall include an analysis of-

"(aa) the fees collected and amounts disbursed under this subsection;

"(bb) the reasonableness of the fees in place as of the date of the audit to meet current and projected costs of administering the provisions 
1

2

15 FUNDS.-In setting fees under this section, the Adminis-

16 trator shall-

of this title for which the fees may be used; and

"(cc) the number of requests for a risk evaluation made by manufacturers under section $6(\mathrm{~b})(4)(\mathrm{C})$ (ii).

“(III) FEDERAL RESPONSIBILITY.The Inspector General of the Environmental Protection Agency shall conduct the annual audit described in subclause (II) and submit to the Administrator a report that describes the findings and any recommendations of the Inspector General resulting from the audit.

“(4) Amount and Adjustment of Fees; Re"(A) prescribe lower fees for small business concerns, after consultation with the Administrator of the Small Business Administration;

"(B) set the fees established under paragraph (1) at levels such that the fees will, in aggregate, provide a sustainable source of funds to annually defray-

"(i) the lower of- 
1
"(I) 25 percent of the costs to the Administrator of carrying out sections 4, 5, and 6 , and of collecting, processing, reviewing, and providing access to and protecting from disclosure as appropriate under section 14 information on chemical substances under this title, other than the costs to conduct and complete risk evaluations under section $6(\mathrm{~b})$; or

“(II) $\$ 25,000,000$ (subject to adjustment pursuant to subparagraph $(\mathrm{F})$ ); and "(ii) the costs of risk evaluations specified in subparagraph (D);

"(C) reflect an appropriate balance in the assessment of fees between manufacturers and processors, and allow the payment of fees by consortia of manufacturers or processors;

“(D) notwithstanding subparagraph (B) "(i) except as provided in clause (ii), for chemical substances for which the Administrator has granted a request from a manufacturer pursuant to section 6(b)(4)(C)(ii), establish the fee at a level sufficient to defray the full costs to the Administrator of conducting the risk evaluation under section $6(\mathrm{~b})$; 
"(ii) for chemical substances for which the Administrator has granted a request from a manufacturer pursuant to section 6(b)(4)(C)(ii), and which are included in the 2014 update of the TSCA Work Plan for Chemical Assessments, establish the fee at a level sufficient to defray 50 percent of the costs to the Administrator of conducting the risk evaluation under section $6(\mathrm{~b})$; and

“(iii) apply fees collected pursuant to clauses (i) and (ii) only to defray the costs described in those clauses;

"(E) prior to the establishment or amendment of any fees under paragraph (1), consult and meet with parties potentially subject to the fees or their representatives, subject to the condition that no obligation under the Federal Advisory Committee Act (5 U.S.C. App.) or subchapter II of chapter 5 of title 5, United States Code, is applicable with respect to such meetings;

"(F) beginning with the fiscal year that is 3 years after the date of enactment of the Frank $R$. Lautenberg Chemical Safety for the 21st Century Act, and every 3 years thereafter, after consultation with parties potentially subject to the fees and their 


\section{1}

1 representatives pursuant to subparagraph (E), in-

2 crease or decrease the fees established under para-

3 graph (1) as necessary to adjust for inflation and to

4 ensure that funds deposited in the Fund are suffi-

5 cient to defray-

6 “(i) approximately but not more than 25

7 percent of the costs to the Administrator of car-

8 rying out sections 4,5 , and 6 , and of collecting,

9 processing, reviewing, and providing access to

10 and protecting from disclosure as appropriate

11 under section 14 information on chemical sub-

12 stances under this title, other than the costs to

13 conduct and complete risk evaluations requested

$14 \quad$ under section $6(\mathrm{~b})(4)(\mathrm{C})(\mathrm{ii})$; and

15 "(ii) the costs of risk evaluations specified

16 in subparagraph (D); and

$17 \quad$ " $(\mathrm{G})$ if a notice submitted under section 5 is

18 not reviewed or such a notice is withdrawn, refund

19 the fee or a portion of the fee if no substantial work

20 was performed on the notice.

21 “(5) Minimum Amount of Appropriations.-Fees

22 may not be assessed for a fiscal year under this section

23 unless the amount of appropriations for the Chemical Risk

24 Review and Reduction program project of the Environ-

25 mental Protection Agency for the fiscal year (excluding 
1 the amount of any fees appropriated for the fiscal year)

2 are equal to or greater than the amount of appropriations

3 for that program project for fiscal year 2014.

4 “(6) Termination.-The authority provided by this

5 subsection shall terminate at the conclusion of the fiscal

6 year that is 10 years after the date of enactment of the

7 Frank R. Lautenberg Chemical Safety for the 21st Cen-

8 tury Act unless otherwise reauthorized or modified by

9 Congress."; and

10 (3) by adding at the end the following:

11 “(h) Scientific Standards.-In carrying out sec-

12 tions 4, 5, and 6, to the extent that the Administrator

13 makes a decision based on science, the Administrator shall

14 use scientific information, technical procedures, measures,

15 methods, protocols, methodologies, or models, employed in

16 a manner consistent with the best available science, and

17 shall consider as applicable-

18 "(1) the extent to which the scientific informa-

19 tion, technical procedures, measures, methods, proto-

20 cols, methodologies, or models employed to generate

21 the information are reasonable for and consistent

22 with the intended use of the information;

23 "(2) the extent to which the information is rel-

24 evant for the Administrator's use in making a deci-

25 sion about a chemical substance or mixture; 
"(3) the degree of clarity and completeness with

2 which the data, assumptions, methods, quality assur-

3 ance, and analyses employed to generate the infor-

4 mation are documented;

5 "(4) the extent to which the variability and un6 certainty in the information, or in the procedures,

7 measures, methods, protocols, methodologies, or

8 models, are evaluated and characterized; and

"(5) the extent of independent verification or

10 peer review of the information or of the procedures, 11 measures, methods, protocols, methodologies, or 12 models.

13 “(i) Weight of Scientific Evidence.-The Ad14 ministrator shall make decisions under sections 4, 5, and 156 based on the weight of the scientific evidence.

16 “(j) Availabiliti of Information.-Bubject to 17 section 14, the Administrator shall make available to the 18 public-

19 "(1) all notices, determinations, findings, rules, 20 consent agreements, and orders of the Administrator 21 under this title;

22 "(2) any information required to be provided to 23 the Administrator under section 4;

24 “(3) a nontechnical summary of each risk eval25 uation conducted under section 6(b); 
2 ministrator in carrying out each such risk evalua-

3 tion, along with the results of those studies; and

"(5) each designation of a chemical substance

5 under section $6(\mathrm{~b})$, along with an identification of

6 the information, analysis, and basis used to make

7 the designations.

8 “(k) Reasonably Available Information.-In

9 carrying out sections 4, 5, and 6, the Administrator shall

10 take into consideration information relating to a chemical

11 substance or mixture, including hazard and exposure in-

12 formation, under the conditions of use, that is reasonably

13 available to the Administrator.

14 “(l) Policies, Procedures, and Guidance.-

15 “(1) Development.-Not later than 2 years

16 after the date of enactment of the Frank R. Lauten-

17 berg Chemical Safety for the 21st Century Act, the

18 Administrator shall develop any policies, procedures,

19 and guidance the Administrator determines are nec-

20 essary to carry out the amendments to this Act

21 made by the Frank R. Lautenberg Chemical Safety

22 for the 21st Century Act.

23 “(2) REVIEW.-Not later than 5 years after the

24 date of enactment of the Frank R. Lautenberg

25 Chemical Safety for the 21st Century Act, and not 
1 less frequently than once every 5 years thereafter,

2 the Administrator shall-

"(A) review the adequacy of the policies, procedures, and guidance developed under paragraph (1), including with respect to animal, nonanimal, and epidemiological test methods and procedures for assessing and determining risk under this title; and

"(B) revise such policies, procedures, and guidance as the Administrator determines necessary to reflect new scientific developments or understandings.

“(3) Testing of Chemical substances and MIXTURES.-The policies, procedures, and guidance developed under paragraph (1) applicable to testing chemical substances and mixtures shall-

"(A) address how and when the exposure level or exposure potential of a chemical substance or mixture would factor into decisions to require new testing, subject to the condition that the Administrator shall not interpret the lack of exposure information as a lack of exposure or exposure potential; and

"(B) describe the manner in which the Administrator will determine that additional infor- 
mation is necessary to carry out this title, including information relating to potentially exposed or susceptible populations.

“(4) Chemical Substances WiTH COMPLETED RISK ASSESSMENTS.-With respect to a chemical substance listed in the 2014 update to the TSCA Work Plan for Chemical Assessments for which the Administrator has published a completed risk assessment prior to the date of enactment of the Frank R. Lautenberg Chemical Safety for the 21st Century Act, the Administrator may publish proposed and final rules under section 6(a) that are consistent with the scope of the completed risk assessment for the chemical substance and consistent with other applicable requirements of section 6 .

“(5) GuIDANCE.-Not later than 1 year after the date of enactment of the Frank R. Lautenberg Chemical Safety for the 21st Century Act, the Administrator shall develop guidance to assist interested persons in developing and submitting draft risk evaluations which shall be considered by the Administrator. The guidance shall, at a minimum, address the quality of the information submitted and the process to be followed in developing draft risk evaluations for consideration by the Administrator. 
1 “(m) Report to CONGRESS.-

2 “(1) INITIAL REPORT.-Not later than 6

3 months after the date of enactment of the Frank R.

4 Lautenberg Chemical Safety for the 21st Century

5 Act, the Administrator shall submit to the Commit-

6 tees on Energy and Commerce and Appropriations

7 of the House of Representatives and the Committees

8 on Environment and Public Works and Appropria-

9 tions of the Senate a report containing an estimation

10 of-

11 "(A) the capacity of the Environmental 12 Protection Agency to conduct and publish risk 13 evaluations under section 6(b)(4)(C)(i) and(ii), 14 and the resources necessary to conduct the min15 imum number of risk evaluations required $16 \quad$ under section $6(\mathrm{~b})(2)$;

17 "(B) the capacity of the Environmental 18 Protection Agency to conduct and publish risk 19 evaluations under section $6(\mathrm{~b})(4)(\mathrm{A})(\mathrm{ii})$, the 20 likely demand for such risk evaluations, and the 21 anticipated schedule for accommodating that 22 demand;

23 "(C) the capacity of the Environmental 24 Protection Agency to promulgate rules under 25 section $6($ a) as required based on risk evalua- 
1

2 tions conducted and published under section $6(\mathrm{~b})$; and

"(D) the actual and anticipated efforts of the Environmental Protection Agency to increase the Agency's capacity to conduct and publish risk evaluations under section $6(\mathrm{~b})$.

“(2) Subsequent REPORTs.-The Administrator shall update and resubmit the report described in paragraph (1) not less frequently than once every 5 years.

\section{"(n) Annual Plan.-}

"(1) IN GENERAL.—The Administrator shall inform the public regarding the schedule and the resources necessary for the completion of each risk evaluation as soon as practicable after initiating the risk evaluation.

"(2) Publication OF Plan. - At the beginning of each calendar year, the Administrator shall publish an annual plan that-

"(A) identifies the chemical substances for which risk evaluations are expected to be initiated or completed that year and the resources necessary for their completion; 
1

2

8 mitTee on Chemicals.pleted; and

"(B) describes the status of each risk evaluation that has been initiated but not yet com-

"(C) if the schedule for completion of a risk evaluation has changed, includes an updated schedule for that risk evaluation.

“(o) Consultation With Science Advisory Com-

“(1) Establishment.-Not later than 1 year

10 after the date of enactment of the Frank R. Lauten-

11 berg Chemical Safety for the 21st Century Act, the

12 Administrator shall establish an advisory committee,

13 to be known as the Science Advisory Committee on

14 Chemicals (referred to in this subsection as the

15 'Committee').

16 "(2) Purpose.-The purpose of the Committee

17 shall be to provide independent advice and expert 18 consultation, at the request of the Administrator, 19 with respect to the scientific and technical aspects of 20 issues relating to the implementation of this title.

“(3) Composition.-The Committee shall be 22 composed of representatives of such science, govern23 ment, labor, public health, public interest, animal 24 protection, industry, and other groups as the Admin25 istrator determines to be advisable, including rep- 
1 resentatives that have specific scientific expertise in

2 the relationship of chemical exposures to women,

3 children, and other potentially exposed or susceptible

4 subpopulations.

5 “(4) Schedule.-The Administrator shall con-

6 vene the Committee in accordance with such sched-

7 ule as the Administrator determines to be appro-

8 priate, but not less frequently than once every 2

9 years.

10 “(p) Prior Actions.-

11 “(1) Rules, ORDERs, AND EXEMPTIONS.-

12 Nothing in the Frank R. Lautenberg Chemical Safe-

13 ty for the 21st Century Act eliminates, modifies, or

14 withdraws any rule promulgated, order issued, or ex-

15 emption established pursuant to this Act before the

16 date of enactment of the Frank R. Lautenberg

17 Chemical Safety for the 21st Century Act.

18 “(2) Prior-initiated evaluations.-Nothing

19 in this Act prevents the Administrator from initi-

20 ating a risk evaluation regarding a chemical sub-

21 stance, or from continuing or completing such risk

22 evaluation, prior to the effective date of the policies,

23 procedures, and guidance required to be developed

24 by the Administrator pursuant to the amendments 
1 made by the Frank R. Lautenberg Chemical Safety

2 for the 21st Century Act.

“(3) ACtions COMPleted PRIOR tO COMPle-

4 Tion of policies, Procedures, AND Guidance.-

5 Nothing in this Act requires the Administrator to re-

6 vise or withdraw a completed risk evaluation, deter-

7 mination, or rule under this Act solely because the

8 action was completed prior to the development of a

9 policy, procedure, or guidance pursuant to the

10 amendments made by the Frank R. Lautenberg

11 Chemical Safety for the 21st Century Act.".

12 SEC. 18. STATE PROGRAMS.

13 Section 28 of the Toxic Substances Control Act (15

14 U.S.C. 2627) is amended by striking subsections (c) and 15 (d).

16 SEC. 19. CONFORMING AMENDMENTS.

17 (a) TABle of Contents.-The table of contents in 18 section 1 of the Toxic Substances Control Act is amend19 ed-

(1) by striking the item relating to section 6

21 and inserting the following:

"Sec. 6. Prioritization, risk evaluation, and regulation of chemical substances and mixtures.";

(2) by striking the item relating to section 10

23 and inserting the following:

"Sec. 10. Research, development, collection, dissemination, and utilization of information."; 
1 (3) by striking the item relating to section 14

2 and inserting the following:

"Sec. 14. Confidential information."; and

3 (4) by striking the item relating to section 25 .

4 (b) Section 2.-Section 2(b)(1) of the Toxic Sub-

5 stances Control Act (15 U.S.C. 2601(b)(1)) is amended

6 by striking "data" both places it appears and inserting 7 "information".

8 (c) Section 3.-Section 3 of the Toxic Substances

9 Control Act (15 U.S.C. 2602) is amended-

10 (1) in paragraph (8) (as redesignated by section

113 of this Act), by striking "data" and inserting "in12 formation"; and

13 (2) in paragraph (15) (as redesignated by sec14 tion 3 of this Act)-

15 (A) by striking "standards" and inserting 16 "protocols and methodologies";

17 (B) by striking "test data" both places it 18 appears and inserting "information"; and

19 (C) by striking "data" each place it ap20 pears and inserting "information".

21 (d) Section 4.-Section 4 of the Toxic Substances 22 Control Act (15 U.S.C. 2603) is amended-

(1) in subsection (b)-

(A) in paragraph (1)- 
1 (i) in the paragraph heading, by adding ", ORDER, OR CONSENT AGREEMENT" at the end; and

(ii) by striking "rule" each place it appears and inserting "rule, order, or consent agreement";

(B) in paragraph (2)(B), by striking "rules" and inserting "rules, orders, and consent agreements";

(C) in paragraph (3)(A), by striking "rule" and inserting "rule or order"; and (D) in paragraph (4) -

(i) by striking "rule under subsection (a)" each place it appears and inserting "rule, order, or consent agreement under subsection (a)";

(ii) by striking "repeals the rule" each place it appears and inserting "repeals the rule or order or modifies the consent agreement to terminate the requirement"; and

(iii) by striking "repeals the application of the rule" and inserting "repeals or modifies the application of the rule, order, or consent agreement"; 
1

2
(2) in subsection (c)-

(A) in paragraph (1), by striking "rule" and inserting "rule or order";

(B) in paragraph (2) -

(i) in subparagraph (A), by striking "a rule under subsection (a) or for which data is being developed pursuant to such a rule" and inserting "a rule, order, or consent agreement under subsection (a) or for which information is being developed pursuant to such a rule, order, or consent agreement";

(ii) in subparagraph (B), by striking "such rule or which is being developed pursuant to such rule" and inserting "such rule, order, or consent agreement or which is being developed pursuant to such rule, order, or consent agreement'; and

(iii) in the matter following subparagraph (B), by striking "the rule" and inserting "the rule or order";

(C) in paragraph (3)(B)(i), by striking "rule promulgated" and inserting "rule, order, or consent agreement'; and

(D) in paragraph (4)- 


\section{1}

2

3

4

5

6

7

8

9

10

11 serting "rule, order, or consent agreement"; and

12

13

14

15 Control Act (15 U.S.C. 2604) is amended-

16

17

18

19

20

21

22

23

(i) by striking "rule promulgated" each place it appears and inserting "rule, order, or consent agreement";

(ii) by striking "such rule" each place it appears and inserting "such rule, order, or consent agreement"; and

(iii) in subparagraph (B), by striking "the rule" and inserting "the rule or order";

(3) in subsection (d), by striking "rule" and in(4) in subsection (g), by striking "rule" and inserting "rule, order, or consent agreement".

(e) Section 5.-Section 5 of the Toxic Substances

(1) in subsection (b)-

(A) in paragraph $(1)(\mathrm{A})-$

(i) by striking "rule promulgated" and inserting "rule, order, or consent agreement"; and

(ii) by striking "such rule" and inserting "such rule, order, or consent agreement"; 
1

2

3

4

5

6

7

8

9

10 Control Act (15 U.S.C. 2606(a)) is amended-

11

12

13

14

15

16

17

18

19

20 and or consent agreement'; and and inserting "rule, order, or consent agreement". a consent agreement under section 4'; and promulgated" and inserting "rule or order";

(C) in paragraph $(2)(\mathrm{A})(\mathrm{ii})$, by striking "rule promulgated" and inserting "rule, order,

(2) in subsection $(\mathrm{d})(2)(\mathrm{C})$, by striking "rule" (f) Section 7.-Section 7(a) of the Toxic Substances

(1) in paragraph (1), in the matter following subparagraph (C), by striking "a rule under section 4, 5, 6, or title IV or an order under section 5 or title IV" and inserting "a determination under section 5 or 6 , a rule under section 4,5 , or 6 or title IV, an order under section 4, 5, or 6 or title IV, or

(2) in paragraph (2), by striking "subsection $6(\mathrm{~d})(2)(\mathrm{A})(\mathrm{i})$ " and inserting "section $6(\mathrm{~d})(3)(\mathrm{A})(\mathrm{i})$ ". (g) Section 8.- Section 8(a) of the Toxic Sub21 stances Control Act (15 U.S.C. $2607(\mathrm{a})$ ) is amended-

(1) in paragraph (2)(E), by striking "data" and 23 inserting "information"; and

(2) in paragraph $(3)(\mathrm{A})(\mathrm{ii})(\mathrm{I})$, by striking "or 25 an order in effect under section 5(e)" and inserting 
1 ", an order in effect under section 4 or $5(\mathrm{e})$, or a

2 consent agreement under section 4".

3 (h) Section 9.-Section 9 of the Toxic Substances

4 Control Act (15 U.S.C. 2608) is amended-

5 (1) in subsection (a), by striking "section 6"

6 each place it appears and inserting "section 6(a)";

$7 \quad$ and

8 (2) in subsection (d), by striking "Health, Edu-

9 cation, and Welfare" and inserting "Health and

10 Human Services".

11 (i) SECTION 10.-Section 10 of the Toxic Substances

12 Control Act (15 U.S.C. 2609) is amended-

13 (1) in the section heading, by striking "DATA"

14 and inserting "INFORMATION";

15 (2) by striking "Health, Education, and Wel-

16 fare" each place it appears and inserting "Health

17 and Human Services";

$18 \quad$ (3) in subsection (b)-

19 (A) in the subsection heading, by striking

20 "DATA" and inserting "Information";

21 (B) by striking "data" and inserting "in-

22 formation" in paragraph (1);

23 (C) by striking "data" and inserting "in-

24 formation" in paragraph $(2)(\mathrm{A})$; and 
1

2

3

4

5

6 stances Control Act (15 U.S.C. 2610(b)(2)) is amendedinformation" in paragraph $(2)(\mathrm{B})$; and

(4) in subsection (g), by striking "data" and in-

(1) by striking "data" each place it appears and inserting "information"; and

10

(2) in subparagraph (E), by striking "rule pro-

11 mulgated" and inserting "rule promulgated, order issued, or consent agreement entered into".

13 stances Control Act (15 U.S.C. 2611(b)(1)) is amended

14 by striking "data" both places it appears and inserting 15 "information".

17 stances Control Act (15 U.S.C. 2614(1)) is amended by 18 striking "(A) any rule" and all that follows through "or 19 (D)" and inserting "any requirement of this title or any 20 rule promulgated, order issued, or consent agreement en21 tered into under this title, or'".

22 (m) SECTION 19.-Section 19 of the Toxic Sub23 stances Control Act (15 U.S.C. 2618) is amended-

(1) in subsection (a)- 
(i) by striking "Not later than 60 days after the date of the promulgation of a rule under section 4(a), 5(a)(2), 5(b)(4), $6(\mathrm{a}), 6(\mathrm{e})$, or 8 , or under title II or IV" and inserting "Except as otherwise provided in this title, not later than 60 days after the date on which a rule is promulgated under this title, title II, or title IV, or the date on which an order is issued under section 4, 5(e), 5(f), or 6(i)(1),";

(ii) by striking "such rule" and inserting "such rule or order"; and

(iii) by striking "such a rule" and inserting "such a rule or order";

(B) in paragraph (1)(B)—

(i) by striking "Courts" and inserting "Except as otherwise provided in this title, courts"; and

(ii) by striking "subparagraph (A) or (B) of section 6(b)(1)" and inserting "this title, other than an order under section 4, 5(e), 5(f), or 6(i)(1),"; and

(C) in paragraph (2) -

(i) by striking "rulemaking record" and inserting "record"; and 
1 (ii) by striking "based the rule" and inserting "based the rule or order";

(2) in subsection (b)-

(A) by striking "review a rule" and inserting "review a rule, or an order under section 4, $5(\mathrm{e}), 5(\mathrm{f})$, or $6(\mathrm{i})(1), " ;$

(B) by striking "such rule" and inserting "such rule or order";

(C) by striking "the rule" and inserting "the rule or order";

(D) by striking "new rule" each place it appears and inserting "new rule or order"; and (E) by striking "modified rule" and inserting "modified rule or order"; and (3) in subsection (c)-

(A) in paragraph (1) -

(i) in subparagraph $(\mathrm{A})$ -

(I) by striking "a rule" and inserting "a rule or order"; and (II) by striking "such rule" and inserting "such rule or order"; (ii) in subparagraph (B)-

(I) in the matter preceding clause (i), by striking "a rule" and inserting "a rule or order"; 
1
(II) by amending clause (i) to read as follows:

"(i) in the case of review of-

"(I) a rule under section 4(a), 5(b)(4), 6(a) (including review of the associated determination under section $6(\mathrm{~b})(4)(\mathrm{A}))$, or $6(\mathrm{e})$, the standard for review prescribed by paragraph (2)(E) of such section 706 shall not apply and the court shall hold unlawful and set aside such rule if the court finds that the rule is not supported by substantial evidence in the rulemaking record taken as a whole; and

“(II) an order under section 4, 5(e), 5(f), or 6(i)(1), the standard for review prescribed by paragraph (2)(E) of such section 706 shall not apply and the court shall hold unlawful and set aside such order if the court finds that the order is not supported by substantial evidence in the record taken as a whole; and"; and

(III) by striking clauses (ii) and (iii) and the matter after clause (iii) and inserting the following:

"(ii) the court may not review the contents and adequacy of any statement of basis and purpose required by section 553(c) of title 5, United States 
1 Code, to be incorporated in the rule or order, except

$2 \quad$ as part of the record, taken as a whole."; and

(iii) by striking subparagraph (C);

and

(B) in paragraph (2), by striking "any rule" and inserting "any rule or order".

7 (n) SEction 20.-Section 20(a)(1) of the Toxic Sub8 stances Control Act (15 U.S.C. 2619(a)(1)) is amended

9 by striking "order issued under section 5" and inserting 10 "order issued under section 4 or 5".

11 (o) Section 21.-Section 21 of the Toxic Substances

12 Control Act (15 U.S.C. 2620) is amended-

13 (1) in subsection (a), by striking "order under 14 section 5(e) or (6)(b)(2)" and inserting "order 15 under section 4 or $5(\mathrm{e})$ or (f)"; and

16 (2) in subsection (b)-

17 (A) in paragraph (1), by striking "order 18 under section 5(e), 6(b)(1)(A), or 6(b)(1)(B)" 19 and inserting "order under section 4 or $5(\mathrm{e})$ or $20 \quad$ (f)"; and

(i) in the matter preceding clause (i), by striking "order under section $5(\mathrm{e})$ or 6(b)(2)" and inserting "order under section 4 or $5(\mathrm{e})$ or (f)"; 
1

2

15 Control Act (15 U.S.C. 2625) is amended-

16

17 cation, and Welfare" each place it appears and in18

(ii) in clause (i), by striking "order under section 5(e)" and inserting "order under section 4 or $5(\mathrm{e})$ or (f)"; and

(iii) in clause (ii), by striking "section 6 or 8 or an order under section $6(\mathrm{~b})(2)$ "' and inserting "section $6(\mathrm{a})$ or 8 or an order under section 5(f)"'.

(p) Section 24.- Section 24(b)(2)(B) of the Toxic Substances Control Act (15 U.S.C. 2623(b)(2)(B)) is amended-

(1) by inserting "and" at the end of clause (i);

(2) by striking clause (ii); and

(3) by redesignating clause (iii) as clause (ii). (q) Section 26.-Section 26 of the Toxic Substances serting "Health and Human Services"; and

(2) in subsection $(\mathrm{g})(1)$, by striking "data" and inserting "information".

(r) SECTION 27.-Section 27(a) of the Toxic Substances Control Act (15 U.S.C. 2626(a)) is amended(1) by striking "Health, Education, and Welfare" and inserting "Health and Human Services"; 
1

2

6 tocols and methodologies".

7

8 stances Control Act (15 U.S.C. 2629(2)) is amended by

9 striking "rule" and inserting "rule, order, or consent

10 agreement".

\section{SEC. 20. NO RETROACTIVITY.}

12 Nothing in sections 1 through 19, or the amendments

13 made by sections 1 through 19, shall be interpreted to

14 apply retroactively to any State, Federal, or maritime legal

15 action filed before the date of enactment of this Act.

16 SEC. 21. TREVOR'S LAW.

17 (a) Purposes._- The purposes of this section are-

18 (1) to provide the appropriate Federal agencies

19 with the authority to help conduct investigations into

20 potential cancer clusters;

21

22 authority to undertake actions to help address can-

23 cer clusters and factors that may contribute to the

24 creation of potential cancer clusters; and 
1 (3) to enable Federal agencies to coordinate

2 with other Federal, State, and local agencies, insti-

3 tutes of higher education, and the public in inves-

$4 \quad$ tigating and addressing cancer clusters.

5 (b) Designation and Investigation of Poten-

6 tial Cancer Clusters.-Part P of title III of the Pub-

7 lic Health Service Act (42 U.S.C. $280 \mathrm{~g}$ et seq.) is amended

8 by adding at the end the following:

9 "SEC. 399V-6. DESIGNATION AND INVESTIGATION OF POTENTIAL CANCER CLUSTERS.

11 “(a) Definitions.-In this section:

"(1) Cancer Cluster.-The term 'cancer

13 cluster' means the incidence of a particular cancer

14 within a population group, a geographical area, and

15 a period of time that is greater than expected for

16 such group, area, and period.

17 “(2) Particular CANCER.-The term "par-

18 ticular cancer' means one specific type of cancer or

19 a type of cancers scientifically proven to have the 20 same cause.

21 “(3) Population Group.-The term "popu22 lation group' means a group, for purposes of calcu23 lating cancer rates, defined by factors such as race, 24 ethnicity, age, or gender. 
1 “(b) Criteria for Designation of Potential

2 Cancer Clusters.-

3

4 retary shall develop criteria for the designation of

5 potential cancer clusters.

6

7

8

9

10

11

12

13

14

15

16

17

18

19

20

21

22

23

“(1) Development of Criteria.-The Sec-

“(2) REQUIREMENTS.-The criteria developed under paragraph (1) shall consider, as appropriate"(A) a standard for cancer cluster identification and reporting protocols used to determine when cancer incidence is greater than would be typically observed;

"(B) scientific screening standards that ensure that a cluster of a particular cancer involves the same type of cancer, or types of cancers;

"(C) the population in which the cluster of a particular cancer occurs by factors such as race, ethnicity, age, and gender, for purposes of calculating cancer rates;

"(D) the boundaries of a geographic area in which a cluster of a particular cancer occurs so as not to create or obscure a potential cluster by selection of a specific area; and 
"(E) the time period over which the number of cases of a particular cancer, or the calculation of an expected number of cases, occurs.

5 tial Cancer Clusters.-The Secretary, in consultation

6 with the Council of State and Territorial Epidemiologists

7 and representatives of State and local health departments,

8 shall develop, publish, and periodically update guidelines

9 for investigating potential cancer clusters. The guidelines

10 shall-

11 "(1) recommend that investigations of cancer 12 clusterssection $(\mathrm{b})$; dence; 


\section{1}

2

\section{"(1)}

"(A) in consultation with representatives of the relevant State and local health departments, shall consider whether it is appropriate to conduct an investigation of a potential cancer cluster; and

"(B) in conducting investigations shall have the discretion to prioritize certain potential cancer clusters, based on the availability of resources.

“(2) Coordination.-In investigating potential cancer clusters, the Secretary shall coordinate with agencies within the Department of Health and Human Services and other Federal agencies, such as the Environmental Protection Agency.

“(3) Biomonitoring.-In investigating potential cancer clusters, the Secretary shall rely on all appropriate biomonitoring information collected under other Federal programs, such as the National Health and Nutrition Examination Survey. The Secretary may provide technical assistance for relevant biomonitoring studies of other Federal agencies.

“(e) Duties.—The Secretary shall— 
$1 \quad$ “(1) ensure that appropriate staff of agencies 2 within the Department of Health and Human Serv3 ices are prepared to provide timely assistance, to the 4 extent practicable, upon receiving a request to inves5 tigate a potential cancer cluster from a State or $6 \quad$ local health authority;

“(2) maintain staff expertise in epidemiology, 8 toxicology, data analysis, environmental health and 9 cancer surveillance, exposure assessment, pediatric 10 health, pollution control, community outreach, health 11 education, laboratory sampling and analysis, spatial 12 mapping, and informatics;

13 "(3) consult with community members as inves14 tigations into potential cancer clusters are con15 ducted, as the Secretary determines appropriate;

16 "(4) collect, store, and disseminate reports on 17 investigations of potential cancer clusters, the pos18 sible causes of such clusters, and the actions taken 19 to address such clusters; and

20 “(5) provide technical assistance for inves21 tigating cancer clusters to State and local health de22 partments through existing programs, such as the 23 Epi-Aids program of the Centers for Disease Control 24 and Prevention and the Assessments of Chemical 
1 Exposures Program of the Agency for Toxic Sub$2 \quad$ stances and Disease Registry.'.

3 TITLE II-RURAL HEALTHCARE 4 CONNECTIVITY

5 SEC. 201. SHORT TITLE.

6 This title may be cited as the "Rural Healthcare

7 Connectivity Act of $2016 "$ ".

8 SEC. 202. TELECOMMUNICATIONS SERVICES FOR SKILLED NURSING FACILITIES.

10 (a) In GeneraL.-Section 254(h)(7)(B) of the Com11 munications Act of 1934 (47 U.S.C. $254(\mathrm{~h})(7)(\mathrm{B})$ ) is 12 amended-

13 (1) in clause (vi), by striking "and" at the end;

14 (2) by redesignating clause (vii) as clause (viii);

15 (3) by inserting after clause (vi) the following:

16 "(vii) skilled nursing facilities (as de-

17 fined in section 1819(a) of the Social Secu18 rity Act (42 U.S.C. 1395i-3(a))); and";

19 and

20 (4) in clause (viii), as redesignated, by striking 21 "clauses (i) through (vi)" and inserting "clauses (i) 22 through (vii)".

23 (b) Savings Clause.-Nothing in subsection (a) 24 shall be construed to affect the aggregate annual cap on 25 Federal universal service support for health care providers 
181

1 under section 54.675 of title 47, Code of Federal Regula-

2 tions, or any successor regulation.

3 (c) EFFECTIVE Date.-The amendments made by

4 subsection (a) shall apply beginning on the date that is

5180 days after the date of the enactment of this Act.

$\mathrm{X}$ 